This material is presented to ensure timely dissemination of scholarly and technical work. Copyright and all rights therein are retained by authors or by other copyright holders. All persons copying this information are expected to adhere to the terms and constraints invoked by each author's copyright. In most cases, these works may not be reposted without the explicit permission of the copyright holder.

This version of the referenced work is the post-print version of the article-it is NOT the final published version nor the corrected proofs. If you would like to receive the final published version please send a request to any of the authors and we will be happy to send you the latest version. Moreover, you can contact the publisher's website and order the final version there, as well.

The current unpublished reference for this work is as follows:

*Paul Benjamin Lowry, Jun Zhang, Chuang Wang, and Mikko Siponen (2016). "Why do adults engage in cyberbullying on social media? An integration of online disinhibition and deindividuation effects with the social structure and social learning (SSSL) model,” Information Systems Research (ISR) (accepted 01-Sept-2016).

* = corresponding author

If you have any questions, would like a copy of the final version of the article, or would like copies of other articles we've published, please contact any of us directly, as follows:

- *Prof. Paul Benjamin Lowry

o Email: Paul.Lowry.PhD@gmail.com

o System to request Paul's articles: https://seanacademic.qualtrics.com/SE/?SID=SV_7WCaP0V7FA0GWWx

- Dr. Jun Zhang

o Email: junzhangnju@gmail.com

- Dr. Chuang Wang

o Email: Lindsey.Wang@my.cityu.edu.hk

- Prof. Mikko Siponen

o Email: mikko.t.siponen@jyu.fi

o Website: https://www.jyu.fi/it/laitokset/cs/staff/cs_staff/siponen-mikko

* = corresponding author 


\title{
Why do adults engage in cyberbullying on social media? An integration of online disinhibition and deindividuation effects with the social structure and social learning (SSSL) model
}

\begin{abstract}
The dramatic increase in social media use has challenged traditional social structures and shifted a great deal of interpersonal communication from the physical world to cyberspace. Much of this social media communication has been positive: Anyone around the world who has access to the Internet has the potential to communicate with and attract a massive global audience. Unfortunately, such ubiquitous communication can be also used for negative purposes such as cyberbullying, which is the focus of this paper. Previous research on cyberbullying, consisting of 135 articles, has improved the understanding of why individuals — mostly adolescents—engage in cyberbullying. However, our study addresses two key gaps in this literature: (1) how the IT artifact fosters/inhibits cyberbullying and (2) why people are socialized to engage in cyberbullying. To address these gaps, we propose the social media cyberbullying model (SMCBM), which modifies Akers' (2011) social structure and social learning (SSSL) model. Because Akers developed his model for crimes in the physical world, we add a rich conceptualization of anonymity composed of five sub-constructs as a key social media structural variable in SMCBM to account for the IT artifact. We tested the SMCBM with 1,003 adults who have engaged in cyberbullying. The empirical findings support the SMCBM. Heavy social media use combined with anonymity facilitates the social learning process of cyberbullying in social media in a way that fosters cyberbullying. Our results indicate new directions for cyberbullying research and implications for anti-cyberbullying practices.
\end{abstract}

\section{KEYWORDS}

Cyberbullying, cyberstalking, cyberharassment, social media, social media cyberbullying model (SMCBM), neutralization, anonymity, disinhibition, deindividuation, differential association, differential reinforcement, definition, imitation, social structure and social learning (SSSL) model, social learning, social learning theory (SLT) 


\section{INTRODUCTION}

In 2007, worldwide media reported on the case of Megan, a 13-year-old who was cyberbullied on social media by a "cute boy” named Josh she had met online. The two had an intense online friendship that ended poorly, with Josh branding Megan a “liar and slut.” His last message to Megan was “you are a bad person and everybody hates you. Have a shitty rest of your life. The world would be a better place without you.” The next day, Megan committed suicide. The startling twist to this story was that Josh was not a teenage boy but an adult female, Lori, who was married with children, had no criminal record, and ran a successful advertising business. She told police she had intended to “mess with Megan” because Megan had fallen out with her daughter, Sarah. It was later discovered that another adult female had helped with the cyberbullying. As this case demonstrates, although cyberbullying is a growing problem with adolescents (Gannett 2013), it is also an adult phenomenon that has extended to workplace settings (Acohido 2013). For example, nearly half (46.2\%) of trainee doctors have experienced workplace cyberbullying that has negatively influenced their job satisfaction (Farley et al. 2015). In fact, it is estimated that the average online stalker/bully is 41 years old (McFarlane \& Bocij 2003).

A recent workplace cyberbullying case is an good illustration of this problem (Pershing Square Law Firm 2013): Ralph Espinoza was mildly disabled and had no fingers on his right hand. In 2006, two of his co-workers anonymously created two personal blogs to publish malicious comments about Espinoza. They referred to him as the “one handed bandit,” labelled his right hand "the claw,” and offered a reward for photos of his hand. This cyberbullying campaign quickly drew attention from numerous people, including other colleagues and strangers inside and outside the workplace, who also started to cyberbully Espinoza using fictitious (anonymous) names. The harassment continued for over a year and caused Espinoza to take medical leave. Although the cyberbullying extended beyond the workplace, the courts awarded US\$820,000 to Espinoza because his employer did not adequately supervise its employees and did not act to thwart the cyberbullying.

Accordingly, widespread concerns about cyberbullying have inspired research on cyberbullying in different disciplines. This literature has included explorations of ethical and moral factors (Tavani \& 
Grodzinsky 2002), gender and age differences (Tokunaga 2010), sociodemographics (Vandebosch \& Van Cleemput 2009), and the relationships between online delinquent behavior and psychotic and symptomatic factors (Hinduja \& Patchin 2010). Although previous research has improved the understanding of the motivations behind cyberbullying, we highlight two issues that require further study.

First, evidence consistently shows that people are more likely to bully or stalk online than offline (Marcum et al. 2014; Slonje \& Smith 2007). Recently, it was even estimated that 3.4 million people over 18 years of age were harassed online in the United States annually (Baum et al. 2009). Although researchers have acknowledge that theories and studies of traditional bullying are not applicable to cyberbullying due to differences between online and offline contexts (Dooley et al. 2009; Hinduja \& Patchin 2008; Slonje \& Smith 2007), little research has examined exactly what makes the context of cyberbullying different from that of traditional bullying. Four studies that examined this issue highlighted the role of anonymity (Barlett et al. 2014; Udris 2014; Varjas et al. 2010; Wright 2014). Although this is an insightful start, these studies did not present anonymity as it is understood in the theoretical information systems (IS) literature and thus did not explain how and why it encourages cyberbullying or what creates anonymity itself. These studies offered only a binary representation of anonymity that focuses on lack of identification (yes/no), even though in an online social context, anonymity is highly perceptual and—aside from lack of identification—includes diffused responsibility, lack of proximity, knowledge of others, and confidence in the system's functionality (Lowry et al. 2013; Pinsonneault \& Heppel 1998).

Second, it has been recognized that cyberbullying in social media can cause more psychosocial and emotional damage than traditional offline physical bullying because of the increased volume, scale, scope, and number of witnesses (Gillespie 2006). Worse still, through social media, cyberbullying can spread with a rapid, broad scale that it is almost unstoppable (Huang \& Chou 2010; Li 2008). For example, in the Ralph Espinoza case, the wide exposure to the cyberbullying activities and the extensive interaction with peers exhibiting cyberbullying behaviors on social media demonstrate the potential of social learning and influence to run amok very quickly online. However, we are not exactly sure why this 
social learning and influence occurs. Therefore, a related unexplored issue is to what extent leading social learning and criminology research, such as that involved with social learning theory (SLT) (Akers 2011), can be used to explain cyberbullying, to what degree such theory must be modified.

Motivated by these issues in cyberbullying research, and by the fact that most studies focus on adolescents [adult cyberbullying is overlooked in research (Nycyk 2015) and is generally ignored in management practice, even though much occurs at work or amongst coworkers (Baum et al. 2009)], we propose a new model to explain adult cyberbullying that accounts for the social media artifact of perceived anonymity in a social learning context. Our model, the social media cyberbullying model (SMCBM), builds upon Akers’ (2011) seminal work on criminology and deviance. Our study aims to explain the pervasiveness and high transmissibility of adult cyberbullying by adopting the perspective of SLT, which posits that criminal behaviors are learned through association with deviant others (Akers 2011). We thus also examine the extent to which the social learning components (including differential association, reinforcement, and definition) that are relevant to traditional (non-cyber) deviance and crime are also relevant to cyberbullying (e.g., Akers 2011), and if so, how any of these are influenced by perceived anonymity and the use of social media. We tested the SMCBM with 1,003 adult social media users who had a range of experiences with different types of cyberbullying. The results support the SMCBM and lay a foundation for compelling future cyberbullying research.

\section{BACKGROUND ON CYBERBULLYING}

\subsection{Defining Cyberbullying}

The literature does not clearly distinguish between cyberbullying, cyberstalking, and cyberharassment. Cyberbullying generally refers to deliberate and hostile behavior intended to harm people using the Internet by leveraging the imbalance of power between bullies and victims (Limber 2012; Smith et al. 2008). Notably, cyberbullying can involve stalking behaviors—such as sending threatening and harassing e-mails or messages and passing on rumors_as well as harassment, flaming, and denigration (Li 2006). Cyberharassment can be defined as repeated or one-off malicious Internet behaviors that are unsolicited but noticed by victims, which are intended to upset, disturb, or threaten other people (Piotrowski 2012; 
Workman 2010). Cyberstalking generally refers to a series of repeated intrusive behaviors performed via the Internet, such as gathering private information or direct communication, that are intended to convey implicit and explicit threats and thus induce fear in online victims (Bocij 2004; Meloy 2001; Robert \& Doyle 2003). Cyberstalking is also known by other names such as online harassment, online abuse or cyberharassment.” (Philips \& Morrissey 2004, p. 67). However, unlike cyberbullying and cyberharassment, cyberstalking might involve following a former lover online but not involve harassing behaviors (i.e., victims do not always know they are victims).

In reviewing these definitions, we consider cyberstalking and cyberharassment to be specialized forms of cyberbullying. Moreover, we argue that cyberbullying is a more appropriate term for the current study because cyberstalking generally involves repeated behaviors (Meloy 2001), whereas our scope includes one-off harassing behaviors. Moreover, cyberbullying typically involves aggressive behavior and an imbalance of power (Sourander et al. 2010). Such deliberation and power-imbalance causes more psychosocial and emotional damage than traditional offline physical bullying (Gillespie 2006). Thus, given our context, when we refer to cyberbullying, we refer to social harassment on social media, whether it takes the form of stalking, bullying, or harassment. Our definition necessarily excludes other online deviant behaviors with a weaker social media and interpersonal orientation, such as Internet addiction, pornography addiction, computer abuse, and online scams.

\subsection{Gaps in the Cyberbullying Literature}

Studying adult cyberbullying is challenging because most of the research involves juveniles, and the nascent literature has not yet developed a cohesive approach to studying cyberbullying. However, this broader cyberbullying literature is arguably the best starting point for building a theoretical model to better understand adult cyberbullying. We thus performed a review of the related literature (135 articles), as detailed in Online Appendix A. In this section, we summarize how this review informed our theorybuilding. Of the 135 articles, fewer than half provided empirical evidence, and most of those that did were atheoretical and focused on juvenile offenders. A large portion of these studies have nonetheless appeared in high-quality and high-impact-factor journals, as noted in Online Appendix A. 
In the cyberbullying articles that were theory-driven and supported by empirical evidence, the most frequently used theories were from psychology and criminology, including general strain theory, SLT, social cognitive theory, social norms theory, social dominance theory, and social ecological theory. However, these theories are either macro-level (environment level) theories that explain how cyberbullying can be directly influenced by the general environment or micro-level (individual level) theories that investigate the cognitive processes of individuals when they are involved in cyberbullying. Thus far, the cyberbullying literature has not established a theoretical integration of the macro- and microperspectives, which has been achieved elsewhere in the deviance literature of Akers (2011). Thus, cyberbullying research currently lacks a cohesive theoretical approach to unifying inconsistent results.

Moreover, simply adopting models that were derived from offline/physical contexts is unlikely to result in accurate explanations of the unique social media context of cyberbullying. Although the cyberbullying literature is replete with claims that the nature of cyberbullying is different from that of offline bullying, most of these studies have glossed over the central issue: the role of the IT or social media artifacts themselves in promoting cyberbullying. Most of the reviewed studies have inferred or acknowledged in passing that such artifacts are factors but have rarely explained these factors theoretically. For example, Raskauskas \& Stoltz (2007) made two brief mentions of the "anonymity of electronics” (p. 566), with no further explanation, measurement, or modeling. Interestingly, although they cited Ybarra (2004) as support for electronic anonymity, Ybarra’s study did not mention anonymity. Even the most recent cyberbullying study, which is forthcoming in a top journal, only mentioned anonymity in passing (Barlett et al. 2016). This literature is replete with this kind of insubstantial treatment of and vague assumptions regarding anonymity. However, this point is not meant to condemn the current research, because it has been conducted primarily by psychologists and sociologists, whose focus is not on social media artifacts and how they might foster anonymity. This is where IS research can contribute.

To date, only four studies have dealt with IT artifact issues (doing so as a secondary consideration), and three of these offered only a binary representation of anonymity, which focused on lack of identification (yes/no) (Barlett et al. 2014; Varjas et al. 2010; Wright 2014). Another study 
inferred anonymity but focused more on the role of the disinhibition/disassociation created by online interactions (Udris 2014). Thus, Varjas et al.'s (2010) qualitative account of 20 high schoolers stands out as particularly insightful because it addresses both anonymity and disinhibition.

The initial work on the cyberbullying IT artifact is a good start, but it is not a complete picture of anonymity or disinhibition in cyberbullying, and it omits explanations of causal mechanisms, which are crucial to theory-building. Again, IS researchers have discovered that in an online social context, anonymity is highly perceptual and involves not just a lack of identification but also diffused responsibility, lack of proximity, knowledge of others, and confidence in the system's functionality (Lowry et al. 2013; Pinsonneault \& Heppel 1998). Outside of cyberbullying, these two studies and others have pinpointed the important underlying mechanisms of disinhibition (e.g., Suler 2004) and deindividuation (e.g., Silke 2003) in changing people’s online behaviors.

\section{THEORY: THE SSSL MODEL IN CYBERBULLYING CONTEXTS}

Given the opportunities revealed from the literature, we first propose a theoretical model that includes both macro- and micro-components related to social learning. We do so by adopting, for the first time in cyberbullying research, a criminology theory that was designed for macro- and micro-components. Our model is a contextualized version of Akers' (2011) social structure and social learning (SSSL) model of crime and deviance. The SSSL model builds on the core social learning (i.e., micro) components of SLT, which Akers himself developed. For the macro-components, the SSSL model adds environmental social structure and sociodemographic factors that drive the model.

Accordingly, before formally proposing our model, we present its theoretical foundation. We first explain the micro-factors derived from SLT. We then explain the macro-factors derived from the SSSL model. Next, we propose our model, which is a unique contextualization of the SSSL model that accounts for social media artifacts that foster anonymity and related disinhibition and deindividuation. We posit that these factors change the nature of social learning such that cyberbullying is fostered.

\subsection{An Overview of SLT and Its Response to Sutherland's Theory of Differential Association}

Akers' early education and career took place during an era when Sutherland's theory of differential 
association was widely used to explain crime (Akers 2011) but was beginning to be criticized. Sutherland (1947) suggested that deviant behavior is not genetically inherited or predetermined, nor is it learned through media, news, or movies (a point we later challenge with social media, which allows people unprecedented association opportunities). Sutherland maintained that in American society, individuals associate personally with both law-abiding people and criminals. Whether a person becomes a deviant or a law-abiding citizen depends on the extent to which the individual has been exposed to criminal values (associated differently) versus law-abiding values. Ultimately, criminal behavior is socially learned in the same way as law-abiding behavior (Sutherland 1947). A key critique of Sutherland's differential association is that he did not specify the "precise underlying learning mechanisms," except for noting that learning is more than simple imitation (Akers 2011, p. 41) and that it can include gestures and verbal communication (Sellers \& Winfree 1990, p. 23). Besides lacking accurate specification of the learning process, Sutherland also did not address the order in which the learning process takes place (Cressey 1960, p. 54).

Burgess \& Akers (1966) addressed these criticisms by positing that Skinner’s (1953) psychological behaviorism could supply relevant information by specifying the underlying learning mechanisms that Sutherland's theory lacked. This was not the only modification that Akers proposed (2011). Besides modifying Sutherland's (1947) definitions, Akers modified the underlying learning mechanism using Bandura’s (1977) cognitive SLT and introduced the concepts of imitation and reinforcement into his theory of social learning (Akers 1973; Sellers \& Winfree 1990). The resulting theory was called the SLT of crime (Akers et al. 1979), which included "differential association, differential reinforcement, imitation, and definitions” (Akers 2011, p. 48). Although each element can be expressed in the form of an individual hypothesis, an underlying assumption of SLT is that these elements are considered as a whole (Akers 2011). This means that when all the elements lean more toward deviant behaviors, the probability of deviant behaviors increases (Akers 2011, p. 48). 


\subsection{The Core Components of SLT}

\subsubsection{Differential association}

In contrast with earlier literature (for example, Cohen (1955) proposed the subculture theory of crime, according to which crime and criminal attitudes are formed within gangs and criminal subcultures), associations in SLT do not refer to particular gang or criminal subcultures, although these can also be differential associations. For Sutherland (1947), and even more so for SLT, associations refer to any social interactions. Consequently, differential association is the process by which individuals directly and indirectly interact and identify with others to learn deviant or acceptable behaviors (Akers et al. 1979). For SLT, the relevant social groups can change during an individual's development (Akers 2011). In relation to cyberbullying, differential association means that cyberbullies-in-the-making associate with different social groups (i.e., ones with cyberbullies in them) than conforming people (i.e., noncyberbullies).

SLT emphasizes that differential association results in interactional peer influence but not peer pressure, which plays only a marginal role in deviant behavior (Akers 2011, p. 63). When individuals are associated with people who perform certain behaviors, they are provided with a social environment "in which exposure to definitions, imitation of models, and social reinforcement for use of or abstinence from any particular substance take place” (Akers et al. 1979, p. 638). Thus, deviant acts are partially learned from deviants. Likewise, non-deviant acts are learned from non-deviants (Akers 2011). Recent research has suggested that in an social media context, differential associations can include online friends, influential online personalities (e.g., bloggers and celebrities), and even anonymous virtual group members, in addition to offline intimate personal groups (Hawdon 2012; Pauwels \& Schils 2016). We leverage these social media-related insights in our theoretical model.

\subsubsection{Differential reinforcement}

Differential reinforcement refers to the positive and negative outcomes that are anticipated to result from an act based on observation of the consequences of similar behaviors performed by others. Akers (1998) 
points out that differential reinforcement is considered “the core behavior-shaping mechanism” (Tittle et al. 2012, p. 864) of SLT, because all the cognitive and non-cognitive elements of social learning (i.e., definitions, imitation) are first shaped largely by the reinforcement process. In general, if rewards and positive consequences are observed, the behavior will be reinforced over time; conversely, if punishments and negative outcomes are observed, the behavior will be thwarted over time.

There are four reinforcement mechanisms that can either strengthen or weaken a behavior (Akers 2011): (1) positive reinforcement (providing rewards), (2) negative reinforcement (removal of punishments), (3) positive punishment (providing punishment), and (4) negative punishment (removal of rewards). Although there are similarities between these concepts and their counterparts in deterrence theory and rational choice theory (RCT), they should not be conflated.

Differential reinforcements may seem similar to deterrence and rational choice theories of crime. For example, deterrence theory includes punishment, and the RCT of crime entails sanctions and rewards (Akers 1990). Deterrence theory also features specific deterrence, which is self-learned consequences, and general deterrence, which is the observed experience of others being punished (Gibbs 1975). Thus, deterrence theory implicitly entails learning, but unlike SLT, deterrence theory does not outline specific learning mechanisms beyond specific and general deterrence (Gibbs 1975). Also, deterrence theory does not highlight the roles of associations, definitions, or balance probability (e.g., rewards and costs) (Gibbs 1975). The RCT of crime, especially Becker's early version (1968), involves rational calculations intended to maximize benefits, and it is therefore the “economist's analysis to crime,” as Becker called it (p. 2). SLT does not explain crimes in terms of rational cost-benefit calculations aimed at maximizing benefits but rather as actions learned through associations with criminals.

\subsubsection{Imitation}

The imitation construct was later added to SLT by Akers et al. (1979), following Bandura’s (1977) theorizing. ${ }^{\mathrm{i}}$ Imitation takes place when one observes behaviors and behavioral consequences and then decides to do the same (Akers 2011). Pondering the consequences of a behavior links imitation to reinforcement. It is crucial to SLT that when people are exposed more to deviant role models than to non- 
deviant role models, they are more likely to imitate the deviant role models (Sellers \& Winfree 1990). The learning mechanisms, which for SLT include imitation and observational learning, explain not only how people become deviants but also the maintenance and desistance of deviant behavior (Akers 2011). However, SLT posits that imitation is "more important in the initial acquisition and performance of novel behavior than in the maintenance or cessation of behavioral patterns once established” (Akers \& Sellers 2004, p. 89). Akers et al. (1979) suggest that “after the initial use, imitation becomes less important” (Akers et al. 1979, p. 638) in predicting sustained behavior. They found that imitation variables explain "almost none of the variance" (for about only $0.1 \%$ of various kinds of abuse behavior) in predicting longitudinal deviant behaviors (Akers et al. 1979, p. 651). Thus, we do not model or measure it and instead assume it to be a causal mechanism of the SL process.

\subsubsection{Definitions}

In SLT, definitions "are orientations, rationalizations, definitions of the situation, and other evaluative and moral attitudes that define the commission of an act as right or wrong, good or bad, desirable or undesirable, justified or unjustified” (Akers \& Sellers 2004, p. 86). Notably, definitions arise from the vicarious experience of differential reinforcement and the direct experience of imitating others. For SLT, because definitions can strengthen deviant behavior, they play a key role in explaining deviant behavior. Akers (2011) distinguished among three types of definitions: positive, negative, and neutralizing. Positive definitions result in the approval or acceptance of deviant behavior, negative ones result in the disapproval of such behavior, and neutralizations result in behavioral justification, which at a minimum is a form of positive, temporary approval. In this way, Akers links neutralizations, originally put forward by Sykes \& Matza (1957), to definitions. Akers views neutralization as an extension of differential association theory in the sense that neutralizations are learned from deviant peers. Using neutralization techniques, deviants accept deviant acts as “all right under certain conditions” that are seen as “exceptional” (Akers 2011, p. 36). Thus, deviants use neutralization techniques to characterize a given set of conditions as exceptional, which in turn makes an act that in other circumstances would be morally unjustifiable feel acceptable. 


\subsection{The SSSL Model: Integrating Social Structures with SLT}

The SSSL model is an extension of SLT that adds macro-factors to the micro-factors of SLT. ${ }^{\text {ii }}$ As a framework for cross-level theory integration, the SSSL model makes it possible to combine macro-level social structure theories with micro-level social learning variables to explain deviant behaviors. The motivation for considering the influence of social structure variables in SLT is that social structure determines the "general culture and structure of society and the particular communities, groups, and other contexts of social interaction” (Lee et al. 2004, p. 17) that influence social learning mechanisms, including the people with whom one is associated, reinforcement stimuli in the learning environment, and group norms regarding what is approved and disapproved. Online Appendix B summarizes our literature review of the SSSL model-based studies on which we build. Only two of these (Holt et al. 2010; Morris \& Higgins 2010) have investigated a form of cyberdeviance using the SSSL model. Neither Holt et al. (2010) nor Morris \& Higgins (2010) studied how social media artifacts influence social learning.

In the SSSL model, social structure "can be conceptualized as an arrangement of sets and schedules of reinforcement contingencies and other social behavioral variables” (Lee et al. 2004, p. 17) that create a deviance-producing or deviance-preventing environment that shapes an individual's behavior through the social learning process (Verrill 2005). In the SSSL model, Akers (2011) distinguishes four categories of social structural variables that can be used to predict social learning, as shown in Figure 1.

Figure 1. An Overview of Aker's (2011) SSSL Model, which Extends SLT

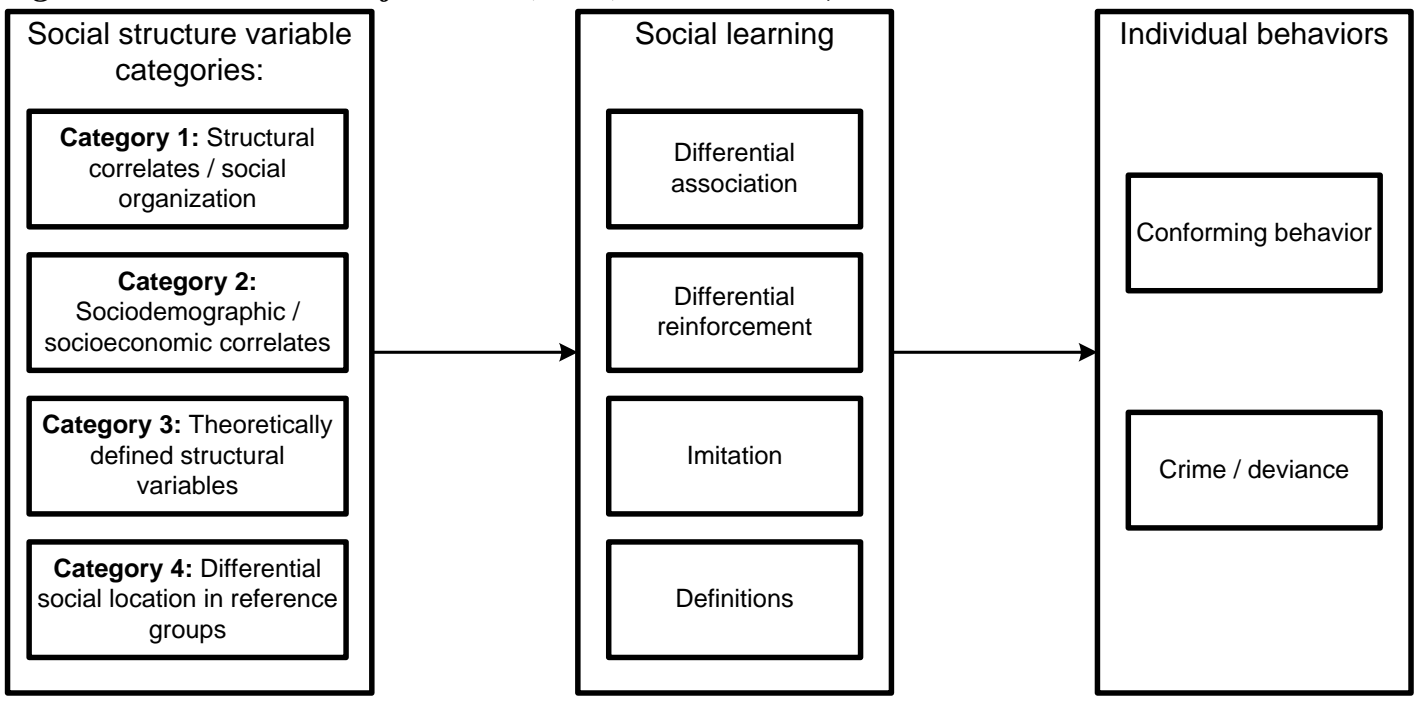


The four categories are: (1) structural crime correlates, which include geographical, societal, cultural, social, and community differences; (2) sociodemographic and socioeconomic crime correlates, which deal with one's location in the social structure (e.g., age, gender, income, employment, class, and religion); (3) theoretically defined structural causes, such as those involving social disorganization (e.g., class conflict, oppression, and racism); and (4) different social locations of primary and secondary reference groups (e.g., family, peers, church, school, and work). The effects of structural variables on crime mean that a person's race or place of residence do not directly cause crime. Rather, structural variables explain why people of certain ages or races may associate with certain reference groups, from whom they learn definitions, crime techniques, and differential reinforcements of criminal behavior.

\subsection{Proposing the SMCBM based on the SSSL Model and SLT}

Here, we present an overview of how we contextualize the SSSL model for cyberbullying, which results in the SMCBM. Figure 2 outlines this proposed theoretical model. Table 1 summarizes how we map the key social learning constructs to constructs that are more closely contextualized to cyberbullying. As follows, we explain how cyberbullying maps to the SSSL model and SLT. In the hypothesis section, we then return to the Ralph Espinoza case and discuss it using these principles.

First, although there is no strict order in which the social structure elements must be applied, we posit that moving from offline social interactions to interacting through social media can result in a meaningful shift in a person's social environment. First, the social group one affiliates with offline is replaced by the group of people one observes or interacts with on social media (i.e., structural correlates/social organization [the first SSSL model category] and differential social location in reference groups [the fourth SSSL model category]). Thus, whether lurking and observing a heated Discuss ${ }^{\mathrm{TM}}$ debate on rival sports teams or actively engaging in discussions about politics on Facebook ${ }^{\mathrm{TM}}$, a person takes up a virtual affiliation with a sub-community and starts to internalize its rules of engagement and norms regarding cyberbullying. Characteristics of these social media sub-societies—such as culture, social cohesion, social stability, surveillance, and informal control—can also differ across different forms of social media. For example, some Reddit ${ }^{\mathrm{TM}}$ communities might have strict moderators (moderators are a 
Figure 2. The Proposed Theoretical Model: The Social Media Cyberbullying Model (SMCBM)

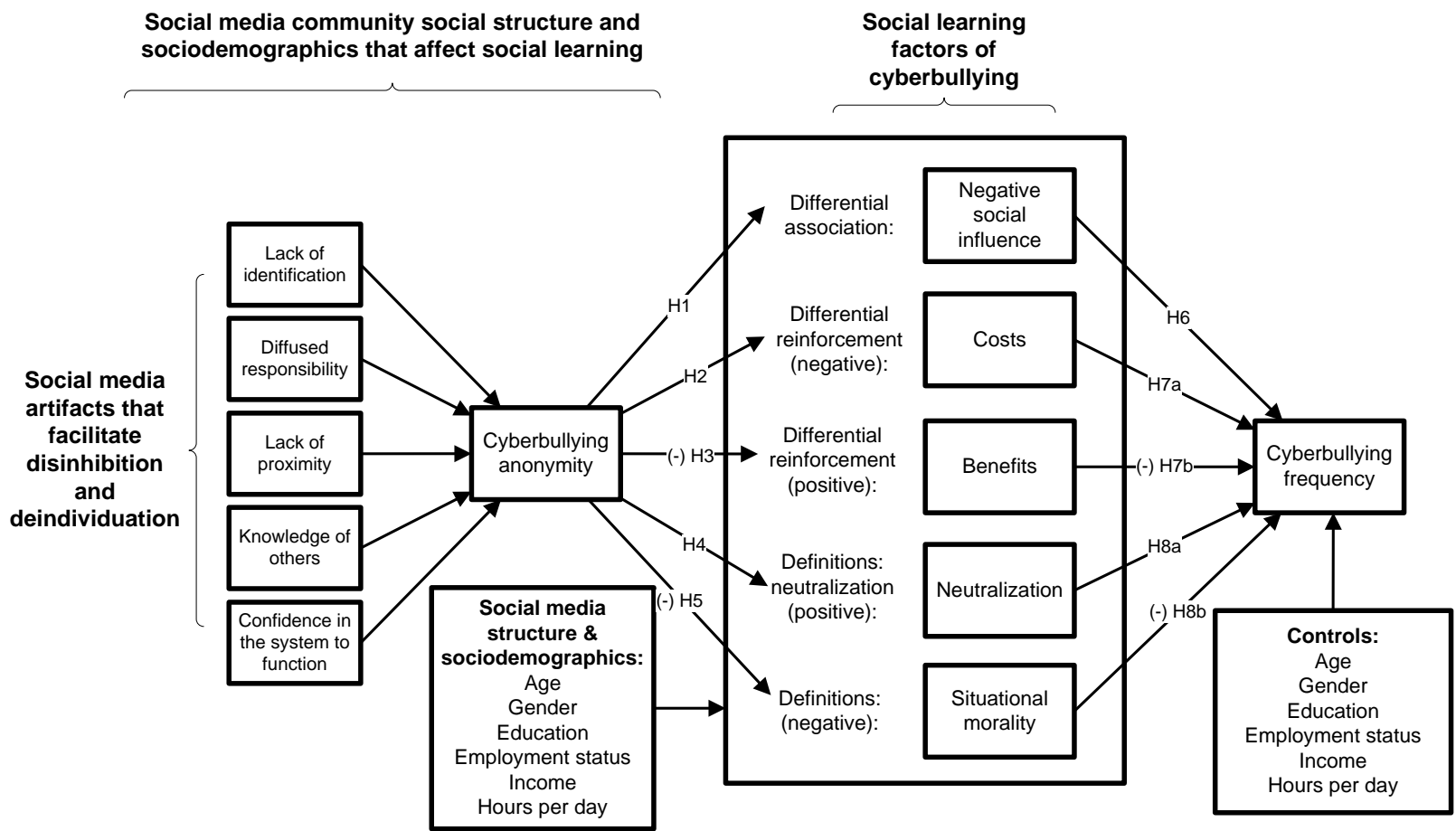

Table 1. Mapping of Key Social Learning Factors to this Research

\section{Social Definition of Construct from SLT Constructs Used in Our Research Model \\ Learning}

Concept

Differential

association

Differential
reinforcement
(including
imitation)

Formation of definitions
The process by which individuals directly and indirectly interact and identify with others who already engage in deviance to learn deviance, through the norms and frequency of these behaviors.

The frequency, amount, and probability of rewards (i.e., negative reinforcement, encouraging deviance) and costs/punishment (i.e., positive reinforcement, blunting deviance) associated with deviant behaviors (both through one's own experiences and through vicarious experiences of observing others through differential association). This subsumes the potential imitation process of social learning. ${ }^{\text {iii }}$ Whether a deviant behavior is perceived as good or bad based on learned attitudes, beliefs, morality, and neutralization. The neutralizing definition is whether the deviant behavior can be justified as good.
We use cyberbullying negative social influence (norms and frequency) to reflect the extent to which individuals are exposed to the norms and cyberbullying of people who are socially important references (e.g., friends, family, colleagues, and people they follow online).

To represent negative differential reinforcement, we use cyberbullying costs, which represents a person's perceptions of any potential intrinsic or extrinsic losses that could occur from a cyberbullying act.

To represent positive differential reinforcement, we use cyberbullying benefits, which represents a person's perception of the potential intrinsic or extrinsic gains that could occur from a cyberbullying act.

We use cyberbullying situational morality as a positive definition to reflect the extent to which a person believes a given form of cyberbullying to be unethical. We use cyberbullying neutralization as a negative definition to represent the degree to which a person suspends their offline moral judgment and instead rationalizes a given form of cyberbullying as acceptable. 
common feature in this tool) who block people for cyberbullying, whereas others might be known for unmoderated bullying behavior.

Second, the scale and scope of cyberbullying allows people, through social media, to affiliate and interact with more communities than is possible through other means. We describe this as increased “social media reach.” Today, unlike in any other time in history, a person in Des Moines, Iowa can communicate with and befriend someone-whom they have never met in person—in Tanzania, and have similar relationships with hundreds of others. Unfortunately, the same is true for bullying. Social media allows different kinds of people (e.g., with different sociodemographic/socioeconomic backgrounds) to affiliate with the same social communities (i.e., social structure category two and category three). For cyberbullying, the greater social media reach provided means that people can observe a greater variety of bullying, differing norms regarding cyberbullying, and a greater variety of bullies (e.g., children, working adults, parolees, celebrities, politicians, felons, sex offenders, cult members, retirees, veterans, lesbian, gay, bisexual, and transgender [LGBT] advocates, terrorists, and “shut ins”). We use standard elements of social structure category two (i.e., structural crime correlates), using basic demographics that are typically used as social learning correlates (e.g., gender, age, education, income, employment), but we also add a crucial factor for social media that should drive one's exposure to negative social influence: hours of social media use per day.

Third, we posit that the social media artifact itself changes the social structure. That is, social media strengthens the perception of anonymity, which fosters the underlying causal mechanisms of online disinhibition and deindividuation that change social learning and encourage cyberbullying. When people feel anonymous online and are considering cyberbullying, their increased disinhibition and deindividuation will change their differential reinforcement to downplay perception of risk and exaggerate perception of reward. Likewise, their definitions will be skewed such that negative definitions (e.g., neutralization) will increase and positive definitions (e.g., situational morality) will increase. These will then foster cyberbullying. Importantly, all of these social learning factors are reciprocal and selfreinforcing over time, as emphasized in the literature, even though they are rarely measured as such 
(Akers 2011). Next, we explain the causal mechanisms of perceived anonymity on social media.

\subsection{How Social Media Fosters Perceived Anonymity}

We argue that perceived anonymity plays a role in traditional crimes, even though criminological theories (e.g., SLT, deterrence theory, and RCT) may not specifically or directly theorize this role. (For example, a robber may use a mask in an attempt to avoid identification.) Although anonymity is not formally identified by criminological theories, several studies of criminology and deviance highlight the role of perceived anonymity in fostering deviant outcomes. For example, urban settings with higher population density and population mobility help to foster a sense of anonymity that enables crime and deviance (Clear et al. 2003; Crutchfield 1989; Crutchfield et al. 1982). Never mind that in urban environments, perpetrators are more likely to be caught on camera than in nonurban environments-perceptions are what matter. For instance, Clear et al. (2003) and Warner \& Pierce (1993) suggest that environments perceived as anonymous as a result of residential mobility reduce people’s sense of commitment, surveillance, and informal social control, which further weakens social stability (Crutchfield et al. 1982). Similarly, according to Trumbull (1989), a more anonymous environment created by overcrowding (high population density) increases criminal opportunities. Danzinger (1976, p. 292) also points out that “anonymity makes identification of criminal suspects more difficult;” thus, crime rates in large cities tend to be higher because of the reduced apprehension of perpetrators. Jackson (1991, p. 384) argues that anonymity decreases social cohesion and restrains law enforcement, which influences "the ease of crime commission.” Thus, anonymity serves as a macro-level predictor of general deviance in the physical world, and its role is stronger online.

However, perceived anonymity is much more complex than mere lack of identification. The five related sub-constructs of perceived anonymity established by Pinsonneault \& Heppel (1998) are foundational to our explanation of how social media artifacts change the social structure that influences social learning: lack of identification, diffused responsibility, lack of proximity, lack of knowledge of others, and confidence in the system's functionality. Building on Pinsonneault \& Heppel (1998) and Lowry et al. (2013), we define these sub-constructs as follows: lack of identification is the degree to 
which potential cyberbullies believe their personal identities will not be revealed by the social media system; diffused responsibility is the degree to which potential cyberbullies believe they will not be held accountable for their cyberbullying on social media; lack of proximity is the extent to which potential cyberbullies believe others are not physically close enough to their computer to observe their cyberbullying; lack of knowledge of others is the degree to which potential cyberbullies believe others in the social media system do not know them well enough to recognize them; and confidence in the system to function is the degree to which potential cyberbullies have confidence that the social media system will not malfunction, involve secret monitoring, or have "back doors” that will reveal their identity against their wishes. Given these definitions, it is clear that the meaning of anonymity is richer in a social context (Lowry et al. 2013) in which "anonymity can only significantly affect disinhibition, and other behaviors in general, when social evaluation is an important source of inhibition” (Pinsonneault \& Heppel 1998, p. 97). We argue that perceived anonymity’s role in cyberbullying is multidimensional and subjective.

Several key factors explain why the five factors of perceived anonymity are altered in social media social structures and why they are highly subjective. First, several technical features of social media allow for increased anonymity, such as using pseudonyms, throwaway accounts, and false identities (i.e., lack of identification). Second, many sophisticated tools can be used outside of social media (e.g., browser extensions) that can further hide identity from social media providers (i.e., lack of identification and confidence in the system). Third, people are more likely to harass or bully people they do not know (Ybarra \& Mitchell 2004) (i.e., knowledge of others and lack of proximity). Fourth, social media introduces dramatic shifts in scope and scale. Users can target thousands of people, engage in more frequent and more intense interactions, and reach people who are unreachable offline (Mangolda \& Faulds 2009) (i.e., diffused responsibility and knowledge of others). Fifth, prosecuting cyberbullies requires law enforcement authorities to obtain Internet protocol (IP) addresses and other information from Internet service providers, which often are located in different countries or jurisdictions only governable by national law enforcement (i.e., diffused responsibility and confidence in the system). This means that cyberbullying is difficult to prosecute even when it involves a crime (e.g., a direct threat) and that people 
are less likely to witness the arrests and prosecution of cyberbullies.

\subsection{How Cyberbullying Anonymity Fosters Disinhibition and Deindividuation and Changes Social Structure and Social Learning}

We now explain that perceived anonymity facilitates the underlying causal mechanisms of disinhibition and deindividuation, and it is these factors that desensitize people such that their social learning is altered to increase their willingness to engage in cyberbullying. Just as alcohol may disinhibit some people and consequently give them the courage (or stupidity) to pick a fight with a member of a biker gang at a bar, anonymity’s disinhibition and deindividuation mechanisms foster acts of online deviance in which people would not normally engage.

The relationship between criminal behavior and the anonymity of cyberspace has been found to be significant in two empirical studies (Baggili \& Rogers 2009; Barlett \& Gentile 2012), but it has not been clearly explained. The theory of online disinhibition—which posits that several macro-level online characteristics are related to the high rate of online crime/deviance (Suler 2004)_offers an explanation for the prevalence of online deviance. Li (2007, p. 4) likewise argues that anonymous computer-mediated communication "not only fosters playful disinhibition but reduces social accountability,” leading to more engagement in aggressive acts. Consistent with this claim, Delmonico \& Griffin (2008) suggest that online disinhibition explains “why the Internet is an ideal venue for problematic sexual behavior” (p. 461). Lapidot-Lefler \& Barak (2012) have also used online disinhibition to explain flaming behavior and suggest that the disproportionately high occurrence of deviant behaviors such as "violence, incitement, flaming, and verbal attacks” on social media should be attributed to online disinhibition (p. 434). Thus, we argue that due to the distinct nature of social media, disinhibition effects will influence the social psychological process of individuals committing cyberbullying. Specifically, online disinhibition occurs when individuals feel free to perform behaviors in cyberspace that they feel inhibited from performing offline (Lowry et al. 2013; Suler 2004).

Importantly, in describing the disinhibition effect, Suler (2004) regards anonymity as the principal factor of increased disinhibition online, which in turn leads to cyberdeviance. For concision, we 
too focus primarily on anonymity; it allows more straightforward conceptualization and measurement. According to Suler (2004), the disinhibition effect occurs because a high degree of anonymity enables people to easily separate their online actions from their offline identities and "avert responsibility for those behaviors, almost as if superego restrictions and moral cognitive processes have been temporarily suspended from the online psyche” (Suler 2004, p. 322). Such disinhibition has been predicted to exert significant influence over cyberbullying (Hinduja \& Patchin 2008) and cyberstalking (Bocij \& McFarlane 2003), but our study is the first to explain and test this relationship.

The second causal mechanism fostered by anonymity is deindividuation, which is "the loss of one’s sense of individuality and personal responsibility” (Valkenburg \& Peter 2011, p. 122). It has been shown that anonymity (either in online or offline settings) is one of the major causes of deindividuation (Silke 2003). Anonymous conditions facilitate deindividuation by causing a loss of self-awareness (Silke 2003). The social identity model of deindividuation (Reicher et al. 1995) also proposes that "anonymity promotes a shift in the kind of self-awareness from the personal to the group” (in this model, the process is also called depersonalization) (Lea et al. 2001, p. 527). The "sense of responsibility for actions online" will be inhibited (Brink 2014, p. 4), and individuals may convince themselves that they are not responsible for their online deviant behaviors (Freestone \& Mitchell 2004; Harris \& Dumas 2009). In addition, depersonalization caused by anonymity magnifies the influence of group norms and thereby makes it easier for individuals to learn negative definitions from deviant peers (DeHue et al. 2008).

\section{OPERATIONAL MODEL AND HYPOTHESES}

The hypotheses, depicted in Figure 2, closely follow our theoretical review that created SMCBM, which is a modification of SSSL to fit the cyberbullying context. Here, we start with predictions of how the IT artifact of cyberbullying anonymity changes the influence of the social learning constructs. We then explain how these influence cyberbullying frequency. We refer back to the Ralph Espinoza case as an illustration of these relationships and of how social learning influences cyberbullying. 


\subsection{How the IT Artifact of Perceived Anonymity Can Change Social Learning Outcomes}

\subsubsection{How Cyberbullying Anonymity Influences Differential Association}

Again, differential association is the process by which individuals directly and indirectly interact and identify with others who engage in deviant behaviors to learn such behaviors. Consequently, our surrogate for this construct is negative social influence. We argue that perceived anonymity online encourages more association with those who engage in deviant behaviors. In the Ralph Espinoza case, anonymity allowed more co-workers to join. Worse, it allowed unknown people outside of work to observe and join the negative social spectacle.

We posit that anonymity fosters this problem for a couple of reasons: Most importantly, online anonymity allows one to associate with people who engage in deviant behaviors with whom one would not normally associate offline because of socials restraint and potential embarrassment, as well as lack of access/reach. According to Neal (2010), people with relatively good social status are less willing to be associated with aggressive peers in a non-anonymous setting, because association with deviant peers can damage their social position. However, such restraint does not exist if aggressive behaviors are conducted anonymously. In the Ralph Espinoza case, people from outside work anonymously joined the fray in large numbers; this would be highly unrealistic in the physical world. Recall that a key causal mechanism of anonymity is behavioral disinhibition (Lowry et al. 2013; Suler 2004). Such inhibition should also extend to association. That is, it should be much easier and less risky to associate with social deviants anonymously online (e.g., associating with highly profane, angry, criminal, or racist people) than to do so offline. For example, it is much less socially risky for most people to visit a neo-Nazi Subreddit anonymously than to attend a neo-Nazi recruitment meeting. Notably, the more one affiliates with deviant groups or people, the more negative social influence (NSI) will be experienced, which we explain next.

Both the SSSL model and the SLT posit that deviant behaviors are learned from behavioral models that emerge during social interaction. Differential association attempts to capture the extent to which individuals are exposed to deviant behavior through their associations with others. In the physical world, SSSL indicates that the association would be a physical association with criminals. In our context, 
we posit that instead the association is virtual and involves observing cyberbully on social media. This negative exposure is called NSI. Such negative social influence is associated with traditional crimes (Kahan 1997). In our context, NSI can be expressed from the SLT literature (Akers et al. 1989) as a subjective norm [the degree to which one perceives important referent others approve/disapprove of specific behaviors (Ajzen 1991)] and frequency (how often behavior is observed) as the perception that comes into play when individuals learn to perform cyberbullying from others online by virtue of SLT phenomena, such as differential reinforcement and definitions. This is shown in the Ralph Espinoza case: the more people got involved, the less people spoke out, and the longer it went on, the worse the cyberbullying became.

Moreover, such anonymity allows for "lurking” behaviors in which one can observe offensive behaviors online committed by others without any public or social responsibility to speak out against them. In the Ralph Espinoza case no one-including management—spoke out against what was happening. Through social media, one can witness offensive cyberbullying, but no one has to know that one was a witness. We argue that this can foster an online version of the bystander effect. This effect has been documented to occur in physical environments in which bystanders do not offer any help to a victim, and it tends to increase the more people are present because of a sense of diffused responsibility, ambiguity, and cohesiveness (Darley \& Latané 1968). Preliminary research indicates that such effects could occur online in chat rooms as people see more users being added to a room (Markey 2000). Similarly, anonymity should make such effects stronger for cyberbullying on large social media platforms, especially because of the previous literature we noted showing a connection between anonymity and deindividuation, which helps foster a loss of one's sense of individual responsibility (Freestone \& Mitchell 2004; Harris \& Dumas 2009; Valkenburg \& Peter 2011), fostering NSI. Thus, H1. An increase in anonymity is associated with increased cyberbullying NSI.

\subsubsection{How Cyberbullying Anonymity Influences Differential Reinforcement}

Again, differential reinforcement deals with the frequency, amount, and probability of rewards and punishments associated with a behavior (Akers 1990). Thus the more an outcome is perceived on the 
basis of social learning as negative (e.g., as a cost), the more likely it discourages those behaviors (Akers 1990). We contend that perceptions of anonymity disrupt normal social structures such that a large volume of bullying is witnessed without negative consequences, and normal calculations of cost-benefit are skewed such that benefits are artificially inflated and costs are not fully manifested or perceived. The Ralph Espinoza case went on for 1.5 years without any punishments or chastisement from management; meanwhile, those who participated had the rewards of increased social bonding, power, and entertainment from otherwise dull work. Hence, their differential reinforcement was skewed by the anonymity provided by social media. In the context of non-anonymous abuse, such behavior likely never would have carried on for so long, and it could not have involved as many people.

Because of a lack of anonymity in the physical world, people have a higher chance of witnessing bullies getting caught and receiving sanctions, which may include anything from negative peer reactions, to work suspensions, to legal consequences. Conversely, social media that is perceived as anonymous is often loaded with rude expressions, name-calling, and insulting language. Because of anonymity, the resulting punishments and social disapproval tend to be weaker and harder to enforce. According to SSSL, via differential reinforcement over time, this explains why users can perceive the costs of cyberbullying as low. ${ }^{\text {iv }}$ The online disinhibition effect can further explain calculations of reduced costs because anonymity enables people to “avert responsibility for those behaviors” (Suler 2004). Moreover, the criminology literature shows that anonymity weakens informal social controls (Clear et al. 2003), which suggests that informal costs are reduced online as well. ${ }^{\mathrm{v}}$ This shift in the social environment through increased anonymity skews the cyberbullying social learning reinforcement process toward diminishing costs. Thus,

\section{H2. An increase in anonymity is associated with decreased cyberbullying costs.}

Moving from costs to benefits, per differential reinforcement, the more an outcome is perceived on the basis of social learning as positive (e.g., as a benefit), the more likely it tends to encourage the modeled behaviors (Akers 1990). The extant cyberbullying literature also argues that offenders not only examine costs but calculate benefits before they decide to commit such acts (e.g., Hemphill \& Heerde 2014; 
Hinduja \& Patchin 2013). Anonymity can also influence the perception of benefits, although this is often less tangible than costs. The basic idea is that anonymity allows offenders to experience benefits they would not experience non-anonymously. The direct benefits of cyberbullying vary from case to case; however, according to existing literature, these benefits generally include revenge, seeking social approval, having fun, attracting attention, asserting power/influence, and so forth (Miller 2013; Varjas et al. 2010; Xiao \& Wong 2013). In the Ralph Espinoza case, the likely rewards were social bonding, power, and entertainment.

Regardless of the benefits imagined by bullies, we argue that anonymity increases imagined and/or real benefits. Likewise, anonymity can also give bullies more power and control, as has also been theorized in the early cyberbullying literature (Dooley et al. 2009). Later it was similarly theorized that cyberbullies benefit themselves through “a systematic abuse of power” on their victims (Slonje et al. 2013, p. 26), and these external/internal benefits are magnified by increased power imbalance between the cyberbullies and the victims. Anonymity amplifies this imbalance. For example, in the online world, a number of different fake accounts can be created, which can be used for bullying the same or different victims (Galán-GarcÍa et al. 2016). Social media via anonymity also provides many different ways to bully someone and thus achieve stronger benefits than is possible non-anonymously (e.g., anonymous versions of: messaging, photos, fake people, memes, down voting, attachments, comments to a victim's friends, movies, and so on). In such an anonymous environment, with numerous ways to commit powerimbalanced attacks, victims are virtually powerless to protect themselves, which makes the cyberbullies' abuse of power more effective (Moore et al. 2012), and thus the more likely perceived benefits will result. Hence,

H3. An increase in anonymity is associated with increased cyberbullying benefits.

\subsubsection{How Cyberbullying Anonymity Influences Definitions}

Again, definitions refer to whether an action is good or bad (i.e., favorable or unfavorable) based on the learned attitudes, beliefs, and justifications for certain behaviors (Akers 1990). Moreover, the neutralizing definition is whether the deviant behavior can be justified as good. Here, definitions emphasize the inner 
values formed from past cyberbullying experiences that may further influence the justifications for performing such behaviors in the future. We continue to argue that cyberbullying anonymity shifts the social structure such that definitions are different than in the physical world, and this includes increased neutralizing definitions. One who has chosen to cyberbully is more likely to have defined and justified cyberbullying as generally favorable and acceptable, at least in a particular instance. In the Ralph Espinoza case, the bullies thought they were just having a "good time," and they were not aware of the severe psychosocial damage they were doing to him. (This is more likely with anonymity because there is a lack of two-way communication through which the victim's pain can be conveyed.) Worse, the longer it went on, the more normal and acceptable this routine was.

Previous research has argued that the high degree of anonymity in such environments increases the likelihood that cyberdeviant behaviors harmful to others “do not cause so many negative feelings (e.g., guilt, shame, self-condemnation)” for perpetrators (Pornari \& Wood 2010, p. 89) and reduce “the chance of empathizing with the victim” (Robson \& Witenberg 2013, p. 214). According to SSSL, by using neutralization techniques, criminals may accept deviant acts as "all right under certain conditions” (Akers 2011, p. 36).

SSSL applied to neutralization theory readily explains why such justifications are increased by anonymity. We posit that the structure of the online environment makes such "acceptable conditions” more readily available. For example, because of key anonymity sub-constructs on social mediaparticularly, diffused responsibility, lack of proximity, and lack of knowledge of others—-the perpetrator can hide, and the consequences of a cyberbullying act are difficult to see or measure. These factors allow cyberbullies to invoke neutralization techniques that involve denial of responsibility (Siegal 2011; Sykes \& Matza 1957). Likewise, unlike physical bullying, it is hard to see the actual consequences of cyberbullying, especially if anonymity is involved and the victim thus cannot express his or her injury to the bully. This fosters the neutralization technique of denial of injury (Siegal 2011; Sykes \& Matza 1957), among other likely neutralization techniques. We thus propose,

H4. An increase in anonymity is associated with increased cyberbullying neutralization. 
Likewise, we argue that perceived anonymity on social media further modifies the social structure of the online environment by fostering moral disengagement, which in turn facilitates the learning of definitions that support cyberbullying. This increase in moral disengagement then results in increased neutralization and decreased situational morality, which is the mechanism that otherwise ethical people use to justify immoral behavior. Moral disengagement comprises "the mechanisms individuals activate to override the influence of their internal self-sanctions and to distance themselves from perceived reprehensible consequences of their behavior” (Garbharran \& Thatcher 2011, p. 302). In the Ralph Espinoza case, even though the cyberbullying behaviors were abhorrent to others, the people involved were generally well-behaved, moral, and professional in their day-to-day work. Once online, it was as if their dark alter-egos took over their normal morality and skewed their behavior as normal, acceptable, and moral — even fun. Anonymity helped create this conundrum due to the lack of rich media and communication to understand the pain they were causing Espinoza.

We posit that moral disengagement is a natural consequence of disinhibition and deindividuation. Per Suler (2004), when individuals commit deviance in an online anonymous environment, their moral cognitive processes are often temporarily suspended. We argue that it is this that fosters positive moral definitions of deviate behavior. Pornari \& Wood (2010, p. 89) argue that the high degree of anonymity in such environments increases the likelihood that cyberdeviant behaviors harmful to others "do not cause so many negative feelings (e.g., guilt, shame, self-condemnation)” for perpetrators and reduce "the chance of empathizing with the victim” (Robson \& Witenberg 2013, p. 214). Thus, people find it easier to justify their deviant behaviors in response to criticism from others in anonymous online environments (Davenport 2002). Anonymity suspends normal forms of social interaction and social mores; thus, “problem behaviors may be recognized, rationalized, and mutually encouraged by others” (Ko et al. 2008, p. 575). According to Bauman \& Pero (2011) and Gini et al. (2014), moral disengagement caused by online disinhibition results in disregard for social mores and morals. Thus,

H5. An increase in anonymity is associated with decreased cyberbullying situational morality. 


\subsection{How Social Learning Outcomes Influence Cyberbullying Frequency}

NSI is especially apt in our context because in SLT, a criminal or delinquent actor models and imitates the deviant behavior (i.e., NSI) of fellow group members (Akers et al. 1979). Thus, a strong connection exists between NSI and crime (Kahan 1997). Related research has shown that if people belong to a group that promotes violence (i.e., NSI), they are more likely to assimilate such negative norms as less costly and more beneficial and engage in similar behavior (Bocij \& McFarlane 2003). The cyberbullying literature has also begun to identify this link, primarily in connection with various forms of negative social norms and exposure (Hinduja \& Patchin 2013). Imagine in the Ralph Espinoza case if employees or management had intervened early on and tried to socially shame the bullies. Instead, no one stood against the NSI. As a consequence, unchallenged NSI in cyberbullying groups strengthens the belief that cyberbullying is “cool,” beneficial, or acceptable (DeHue et al. 2008), and thus encourage cyberbullying. In summary, if the SSSL model holds true in our context, then

H6. An increase in cyberbullying NSI is associated with increased cyberbullying.

Next, we deal with the effects of perceived cyberbullying benefits and costs on cyberbullying frequency. These hypotheses should hold prima facie, based on the SSSL model, the SLT, and the previous hypotheses related to benefits and costs. SSSL and SLT posit that the observed benefits from a crime are linked with increased rates of a crime, and observed costs are associated with decreased rates of a crime. These are argued to hold also for the social media context and cyber bullying. Thus, when people experience differential reinforcement that artificially increases perceived cyberbullying benefits and decreases perceived costs, they are more likely to commit cyberbullying. This was certainly the situation in the Ralph Espinoza case, but the converse could also have been true- -had there been any management oversight, positive peer pressure, or workplace punishments.

H7a. An increase in cyberbullying benefits is associated with increased cyberbullying. $H 7 b$. An increase in cyberbullying costs is associated with decreased cyberbullying.

Neutralization theory (Sykes \& Matza 1957) argues that neutralizations are linked to criminal behavior. A basic assumption of neutralization theory is that people who engage in delinquent behavior 
“believe in the norms and values of the community in general” but are temporarily suspending them by using neutralization techniques in order to avoid guilt (Siponen \& Vance 2010, p. 489). In the Ralph Espinoza case, the people involved in cyberbullying saw it as harmless fun and a way to "blow off steam.” They did not recognize the immorality of their behavior or the psychosocial damage to Espinoza. Worse, the more people who joined in on the abuse, the more acceptable it became because "everyone was doing it.”

Moreover, early neutralization theory studies have proposed a distinction between "acts that are wrong in themselves” and “acts that are illegal but not immoral” (Sykes \& Matza 1957, p. 667); the former causes more guilt than the latter. Thus, non-sociopathic people feel guilty and ashamed when they realize their behaviors do not comply with ethical standards, which in turn prevents them from performing deviant behaviors, unless they morally disengage and neutralize such behaviors. Before engaging in delinquent behavior, people often justify it subjectively with neutralizing definitions, and certain neutralization techniques ${ }^{\mathrm{vi}}$ help them to justify their delinquent behaviors as acceptable under the circumstances, thereby removing moral restrictions (Mitchell \& Dodder 1980). Finally, a few studies have proposed that juveniles use neutralization when they choose to cyberbully (e.g., Bauman 2010; Renati et al. 2012), and given the above, this link likely extends to adults. Thus, we hypothesize:

H8a. An increase in cyberbullying neutralization is associated with increased cyberbullying.

Finally, because perceived anonymity leads to moral disengagement—which decreases situational morality — we continue this chain of logic to explain how increased situational morality decreases cyberbullying, Importantly, the evaluation of an act as morally wrong leads to avoidance of the action, especially when the person has the freedom to do so (Hare 1981). The converse is also true: When an action is regarded as morally acceptable, it is likely to be done, especially when the person has motivations to do so. We argue that the same reasoning holds for cyber bullying. Thus,

H8b. An increase in situational morality is associated with decreased cyberbullying.

\section{METHODOLOGY}

This study is the result of engaged scholarship (Van de Ven 2007) pursued over several years to build a 
model and gather empirical data to enhance the understanding of cyberbullying. We started with four preliminary studies, which were followed by two separate data collections that were part of the peerreview process for this manuscript. The present study represents the third data collection. Details of the other studies are available upon request.

\subsection{Data Collection and Advanced Sample Filtering to Improve Data Quality}

The most challenging aspect of our research is that despite its pervasiveness, cyberbullying involves behaviors that are considered socially unacceptable in most cultures. We needed to study such behaviors in a manner that would elicit honest responses while maintaining anonymity. We chose to use an anonymous self-reported cross-sectional survey, which is strongly supported in the literature: Previous studies of deviant behaviors have effectively used cross-sectional studies in a variety of settings (e.g., Bennett \& Robinson 2000; Higgins et al. 2008; Hinduja 2007; Lowry \& Moody 2015; Lowry et al. 2015; Posey et al. 2015). SLT has also been examined by self-report studies conducted by its developers (Akers et al. 1979) and others (e.g., Higgins 2006; Higgins \& Makin 2004; Skinner \& Fream 1997; Winfree et al. 1994). Moreover, substantial IS research has used cross-sectional studies involving self-reported behaviors, in a greater variety of contexts (Karahanna et al. 1999; Lankton et al. 2010; Moody \& Siponen 2013; Vance et al. 2012; Venkatesh et al. 2012).

The use of self-reports may involve social desirability bias, which we took the following measures to reduce: First, we provided the respondents with a certain level of anonymity. To ensure anonymity between the respondents and researchers, we used a third-party online panel. Consequently, the respondents never interacted with the researcher, and the researcher never had access to the respondent's contact information, which is a leading practice to thwart social desirability bias (Awad \& Ragowsky 2008; Lowry et al. 2013; Posey et al. 2013). Using the specific panel of Mechanical Turk ${ }^{\mathrm{TM}}$ (MTurk) also allowed us to gather respondents from a wide range of sociodemographic backgrounds, people who would have been virtually impossible to reach otherwise. MTurk is a particularly useful platform for such studies because millions of people are registered to respond, and the platform allows for advance-screening measures, which are helpful in recruiting people with preferred characteristics. 
We followed the latest methodological literature on MTurk (e.g., Goodman et al. 2013; Landers \& Behrend 2015; Lowry et al. 2016; Steelman et al. 2014) and used it in combination with advanced survey features and filtering through Qualtrics ${ }^{\mathrm{TM}}$ online surveys, which greatly improved the data quality (e.g., Goodman et al. 2013; Landers \& Behrend 2015; Lowry et al. 2016). This literature indicates that our data collection context was an especially good fit for MTurk; it is a topic of general interest for which no special expertise was needed, the data could be collected with reasonable assurances of anonymity, and it is an ideal way to reach a large number of people with specific traits (e.g., having committed cyberbullying). First, we employed multiple screeners (including IP address and geolocation information) to ensure that only English-speaking adult respondents who lived in the United States could take the survey (the same country and language were required for consistency in the laws and norms regarding social media). The respondents were also required to have had committed at least one act of cyberbullying on social media in the last year and to have been willing to provide their opinions about cyberbullying in general. To eliminate (semi) professional survey-takers, we used the MTurk's screening capabilities to make the survey known and available only to people who had taken a maximum of three previous surveys. However, we also paid a reasonable amount of compensation such that participants had the reasonable opportunity to earn around United States (US) minimum wage per hour. We also used Qualtrics ${ }^{\mathrm{TM}}$ ' technical option to prevent more than one response from the same IP address.

In view of the length and sensitive nature of the survey, to decrease mono-method bias and increase both honesty and attention, we implemented the following procedural remedies taken from the literature (e.g., Goodman et al. 2013; Landers \& Behrend 2015; Lowry et al. 2016; Lowry et al. 2013; Rouse 2015; Steelman et al. 2014) that have been shown to address these issues: (1) We randomized the order of the survey questions; (2) we reversed the scaling and anchors of half of the survey questions; (3) we used questions with different anchors; (4) we combined questions that were each other's opposite or were unrelated; (5) we implemented randomly presented attention-trap questions to ensure that the respondents were reading and understanding the questions; (6) we asked the respondents to verify their honesty and completeness in answering; (7) we explained the importance of paying attention and the 
scientific importance of the study; (8) we tracked the time spent in completing the surveys and eliminated any that were taken unusually fast compared to our pilot tests; (9) we provided data validation, look-ups, and other survey screeners to improve data accuracy; and (10) aside from these efforts—-which help to prevent common-method bias a priori-we gathered a marker variable per Richardson et al. (2009), which in our case was based on organizational commitment and provides additional evidence for the absence of common method bias.

\subsection{Data Filtering and Sociodemographic Data}

Following the leading practices for MTurk studies that involve lengthy surveys, we employed a high degree of filtering to ensure a high degree of data quality; this is because such studies are prone to high drop-out rates and attempts to rush through the survey. ${ }^{\text {vii }}$ The sociodemographic data of the 1,003 respondents were as follows: age ( $\bar{x} 31.02$ years; SD 8.36), first year on the Internet ( $\bar{x}$ 1999; SD 4.00 years; $\min 1993$, max 2012), and work years ( $\bar{x} 12.00$ years; SD 8.27). The gender distribution was 514 males (51.2\%), 483 females (48.2\%), and six other genders (0.6\%). The respondents’ employment distribution was as follows: 185 full-time students (18.4\%), 92 unemployed and non-students (9.2\%), 162 employed part-time (16.2\%), and 564 employed full-time (56.2\%). Full details of all demographics and individual cyberbullying behaviors are presented at the end of Online Appendix D.

\subsection{Measures and Controls}

All measures were based on established measures and were modified to fit our cyberbullying context where necessary. Here, we supply details on how some of our key constructs were measured to illustrate important aspects of our measurement strategy. Full details on measurement, with source, controls, prompts, and survey logic are in Online Appendix C.

To measure cyberbullying anonymity, we asked respondents to answer questions with respect to the social media platform they had most used for cyberbullying, the idea being that the level of anonymity can varying across platforms and even within a particular platform depending on a person's use patterns (see Table 2 for details). To measure cyberbullying frequency, we again asked them to answer with 
respect to the platform they had most used for cyberbullying, and to disclose the frequency (i.e., Never,

One Time, Monthly, Weekly, Daily) with which they had engaged in each of four behaviors: (1) post something hurtful, rude, inappropriate, or mean that targets someone; (2) publicly embarrass or prank someone with true information or photos that are potentially harmful; (3) spread a rumor or untrue information about someone; (4) send threatening or harassing messages, or send messages after someone told you to stop. To measure the SLT variables we again asked respondents to answer with respect to the platform they had most used for cyberbullying. We also had them answer these questions separately for each of the four cyberbullying behaviors, the rationale being that a respondent's perceptions could vary across the different cyberbullying behaviors. For example, the perceived costs and benefits of "posting something hurtful" could be different from those for "sending threatening or harassing messages." The neutralizations used to justify "publicly embarrassing or pranking someone" could be different from those for "spreading a rumor or untrue information."

\section{Table 2. Prompt, Scaling, and Measurement Items for Cyberbullying Anonymity}

Prompt: You indicated that you have used [social media] in the past year for cyberbullying. We would like to know your beliefs about using [social media] for cyberbullying. When cyberbullying other people using [social media] which of the following best describes your opinions about [the social media itself] in bullying others? "I believe that...”

Scaling: 7-point Likert-type scale anchored on 1=very strongly disagree...7=very strongly agree.

A-LI1....my personal identity won't be provided.

A-LI2....my cyberbullying is entirely secret.

A-CS1. ...the system(s) will not identify me without my permission.

A-CS2.... no names will be attached to the systems' internal records unless that is what I want.

A-DR1.... it is impossible to make me more accountable than others for cyberbullying.

A-DR2. ... it is impossible to blame me personally for any cyberbullying.

A-PX1. ...others can't physically see what I am doing on my computer screen (e.g., walk by and see what I'm writing).

A-PX2. ... I feel assured that no one can physically observe me in the act of cyberbullying (e.g., look over my shoulder when I'm typing).

A-KO1. ...my behavior(s) do NOT have enough distinguishing characteristics that would allow other people to identify me as the originator of the cyberbullying.

A-KO2. ... it is impossible to identify me as the origin of the cyberbullying based on my personal characteristics.

Note: The cyberbullying anonymity measures were modified from social anonymity measures by Lowry et al.

(2009). Social anonymity is second-order factor composed of the following reflective constructs: lack of identity (A-

LI); confidence in the system (A-CS); diffused responsibility (A-DR); proximity (A-PX); and knowledge of others

(A-KO) 


\section{ANALYSIS AND RESULTS}

For model analysis, we used partial least squares (PLS) regression using SmartPLS version 2.0 (Ringle et al. 2005); because PLS is especially adept at the validation of mixed models of formative and reflective indicators, is more appropriate than covariance-based structural equation modeling for preliminary model building, and it is ideal for large models (Chin et al. 2003; Gefen et al. 2011; Lowry \& Gaskin 2014).

We first conducted pre-analysis and data validation for four purposes: (1) to establish the factorial validity of the measures through convergent and discriminant validity, (2) to establish that multicollinearity was not a problem for any of the measures, (3) to check for common-method bias, and (4) to establish strong reliabilities. Details are given in Online Appendix D. Figure 3 shows the final results of all paths and controls. The full details are available in Table D.5.

Figure 3. Model Results with Controls and Exploratory Relationships $(n=1003)$

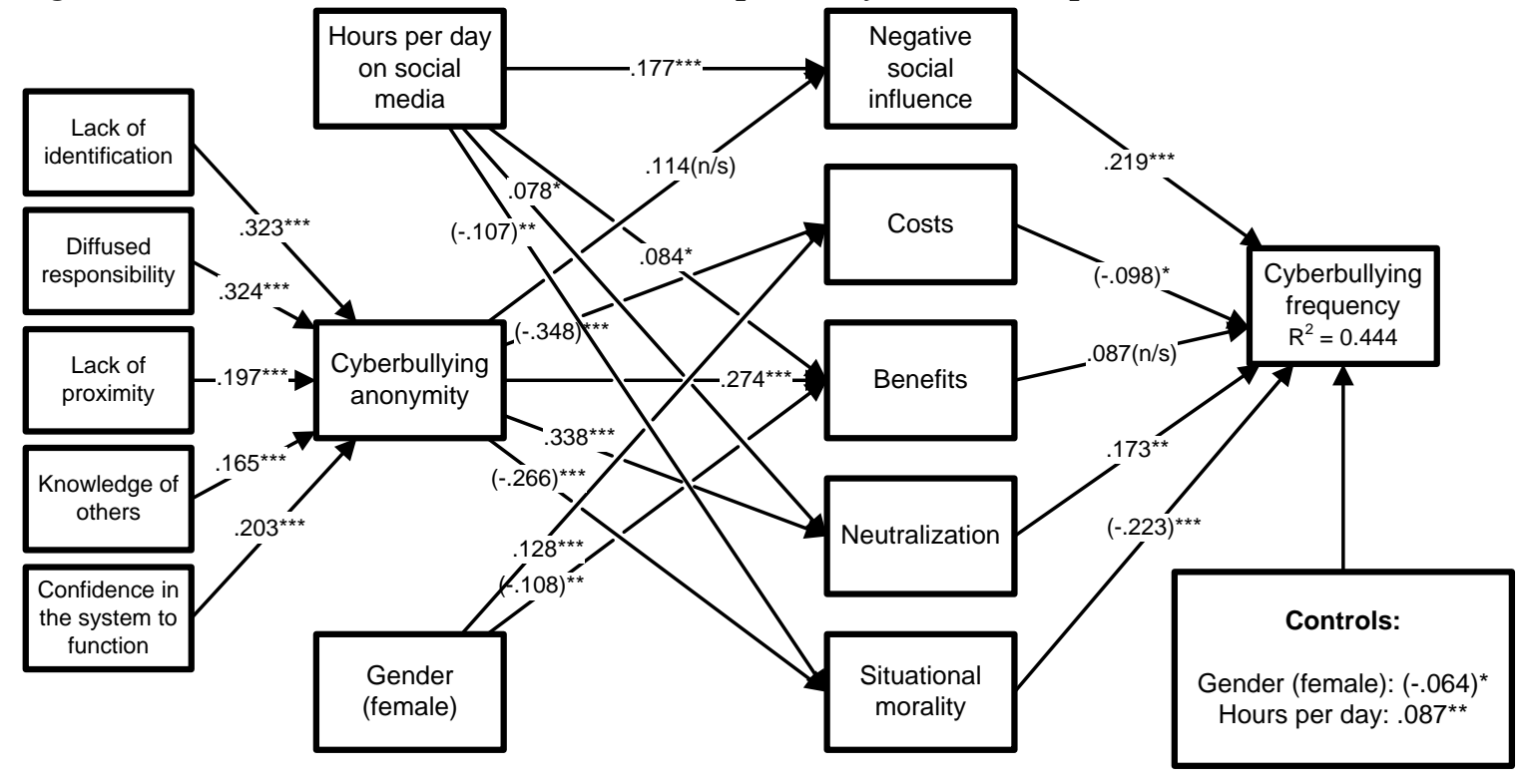

Note: this figure includes all hypothesized paths, but only significant control paths.

We also used bootstrapping techniques to test for mediation in our model (see Online Appendix D). We confirmed that our model follows the core SSSL model prediction, in which all social learning constructs act as full mediators. We are the first to show the rich second-order construct of cyberbullying anonymity as a direct driver of cyberbullying that is fully mediated by social learning constructs. 


\section{DISCUSSION}

\subsection{Summary of Results}

Most of our hypotheses were supported. The association between anonymity and NSI was significant in the initial model but became insignificant when hours per day on social media was added (H1 rejected). Anonymity was associated with decreased costs (H2 supported), increased benefits (H3 supported), increased neutralization (H4 supported), and decreased situational morality (H5 supported). NSI was associated with increased cyberbullying (H6 supported). Costs was associated with decreased cyberbullying (H7a supported), but benefits was not associated with increased cyberbullying (H7b rejected). Neutralization was associated with increased cyberbullying (H8a supported), and situational morality was associated with decreased cyberbullying (H8b supported).

We also explored several traditional sociodemographic factors that have influenced social learning constructs in more traditional criminal and deviance research (Akers 2011). We also ran the same factors as control variables against cyberbullying frequency, including age, gender, education, employment status, income, and hours per day on social media. We were surprised by how few of these influenced any of the social learning constructs or cyberbullying frequency, although this is another indicator that the social media community context is indeed unique: Social structural correlates of the physical world cannot represent the social structure of one’s network characteristics in social media. In terms of significant structural correlates, being female was associated with decreased cyberbullying benefits and increased costs; hours per day on social media was associated with increased cyberbullying NSI, increased benefits, increased cyberbullying neutralization, and decreased situational morality. There were no effects associated with age, education, employment, or income. In terms of the control variables, hours on social media was associated with increased cyberbullying frequency. Being female was associated with decreased cyberbullying frequency, whereas age, education, income, and employment status had no influence on cyberbullying frequency. Again, this is interesting in an SLT context, where such sociodemographics often matter. 


\subsection{Interpretation of Results and Contributions}

Our study provides several key contributions to the understanding of adult cyberbullying. First, we examined to what extent the SSSL model can account for cyberbullying, and we also revised the SSSL model to account for the unique social media community environment that is fostered by perceived anonymity and its associated causal mechanisms of disinhibition and deindividuation. We show that few of the traditional environmental criminological factors apply online and that the social learning mechanisms are instead largely driven by three factors: the richly conceptualized factor of perceived anonymity (i.e., lack of identification, diffused responsibility, lack of proximity, knowledge of others, and confidence in the system's functionality), hours per day spent on social media, and gender. Hence, the SMCBM is a compelling model to use to study cyberbullying, especially when social learning and environmental influences are of utmost concern.

We are also among the first to examine more than one specific cyberbullying behavior in either an SSSL model or an SLT study, and we are the first to provide a social learning micro- and macroperspective on cyberbullying. Examining four major sets of cyberbullying behavior allowed for a more robust and generalizable test of the SMCBM. We employed a novel survey-only design in which each unique cyberbullying behavior was randomly ordered (to cancel out any ordering effects), and the respondents provided social learning responses to one specific form of cyberbullying at a given time. Although it made sense in traditional SLT/SSSL studies to examine one behavior because other behaviors are unrelated (e.g., larceny, alcoholism, elder abuse, and shoplifting), we argue this is not the case with cyberbullying because it involves a lot of related but distinct behaviors. Thus, we believe that providing a set of four commonly committed types of cyberbullying provides a stronger, more realistic, and more generalizable test of our SMCBM than if we had chosen one form of cyberbullying (e.g., sending a malicious message, saying something hurtful, passing on a malicious rumor, or intentionally embarrassing someone).

Moreover, to robustly test SMCBM, we tested for mediation using advanced bootstrapping techniques. These results are detailed in Online Appendix D. We thus are able to demonstrate that the 
influence of cyberbullying anonymity on cyberbullying frequency is fully mediated by the social learning constructs. This further shows that SMCBM model fits the underlying theoretical assumptions of the SSSL model. That is, the social learning constructs are mediators, and the causal ordering matters. This hopefully sets the foundation for additional research that involves more direct testing of causality and longitudinal effects.

Notably, unlike traditional SSSL models involving criminology, there were no social learning effects associated with age, education, employment, or income, which are often associated with traditional crimes (Akers 2011). We explain this difference by the contextual differences between the physical world and the unique context of social media. For example, in the physical world, lack of employment and low income may motivate some people to commit crimes to earn money (Sutherland 1947). Moreover, the type of social media platforms our respondents engaged in were generally sociallybased and not associated with financial opportunities. Education might be able to prevent crimes in the physical world by inculcating values that favor social norms against crimes. Indeed, research has argued that many of our moral values are established through upbringing and education and evolve over time (Hare 1981; Kohlberg 1981). Thus, it may be that the inculcation of values against cyberbullying through educational institutions has either not taken hold of today's adults or they have never received this education.

However, we do find a strong social learning effect with hours per day on social media—so much so that when it was added to the baseline model, it predicted NSI and anonymity dropped out. Our interpretation is that from a social structure standpoint, the amount of time spent on social media much more greatly influences whom one associates with who is committing deviant behaviors than does anonymity. Time matters, in matters, because it shift's one's social structure increasingly from offline to online. Moreover, much abusive, socially modelled behavior can be easily witnessed without anonymity. However, further research on this is needed because hours per day on social media was a one-item measure. There also could be measurement issues in differential association because our formative measure mixed two different kinds of scaling (norms and frequency). 
We also found a strong gender effect that we did not expect or predict. Females in our sample were significantly less likely to commit cyberbullying than males. Moreover, females perceived fewer benefits and more costs of cyberbullying than did males. Hence, there may be strong social learning differences in cyberbullying behavior based on gender, including how costs and benefits are interpreted. Some of this could likely have to do with a key motivating factor of cyberbullying: that of control and power imbalance between the bully and the victim (e.g., Moore et al. 2012; Slonje et al. 2013). These results may also relate to differences in genders based on aggression. Although the stereotype is that men are aggressive than women, the reality is more complex. Older meta-analysis shows that men tend to be more aggressive in terms of physical harm, but not in terms of social or psychological harm (Eagly \& Steffen 1986). Interestingly, the same research does show that women are more likely to perceive harm to the victim, guilt, anxiety, and danger to oneself when envisioning performing an aggressive behavior. These factors need further research in respect to cyberbullying.

As noted earlier, although cyberbullying is acknowledged as a serious issue with juveniles, it is also a serious issue with adults (Nycyk 2015). However, prior to this study, little was known about how to predict and discourage this behavior in adults or about their actual cyberbullying patterns and social media choices. As a new generation of social media users - who grew up as digital natives and have routinely practiced cyberbullying as a rite of passage_enters the workforce, many are bringing these pernicious, socially- learned behaviors with them. Of concern is our finding that our adult respondents use neutralization to suspend normal, rational judgment when choosing to engage in cyberbullying, because they likewise decrease perceived costs, increase perceived benefits, and suspend their offline moral inclinations. Worse, it is the characteristics of social media itself (e.g., perceived anonymity) combined with hours per day on social media that create this toxic condition. The behaviors we report involve not only minor harassment and rudeness but also harmful actions that can lead to reduced work productivity, social strain, psychological trauma, criminal behavior, job loss, and lawsuits—as in the Ralph Espinoza case.

Moreover, the role of social media providers as enablers of cyberbullying requires further 
attention, and our work in laying out the rich construct of perceived anonymity is only a starting point. Certainly, Facebook stands out as the chief adult cyberbullying platform, but our results show that adults use several other channels (e.g., Reddit, YouTube, Twitter, Instagram, and Disqus). We show that certain social media artifacts make cyberbullying easier, which helps explain why corresponding physical behaviors (e.g., bullying and stalking) in adults are not as prevalent. Social media artifacts can inspire disinhibition and deindividuation, which make adults feel more comfortable performing deviant behaviors online than offline, and social media providers are largely responsible for the design of the IT artifacts and system conditions that create disinhibition and deindividuation. We assume that these conditions are especially worsened by social media artifacts intentionally designed for anonymity, such as allowing selfdestructing messages, non-identified users, multiple accounts at the same IP address, easy access to “friends of friends,” not monitoring access from known IP-masking services, not requiring human moderators, and not having bots that monitor behavior.

\subsection{Limitations and Future Research Directions}

Our study focuses on the "dark side” of social media and thus lacks an emphasis on positive aspects that prevent people from being involved in cyberbullying. It is thus particularly important to better understand what prevents Ralph Espinoza cases from happening in the first place, such as positive conforming behavior in the workplace. First, SLT suggests that association with non-deviant peers can also lead people to perform conforming behaviors against cyberbullying (Akers 2011). In some real-world cases, role models against workplace cyberbullying play an important role in allowing colleagues to learn conforming rather than deviant behavior (XpertHR 2012). Second, companies can cultivate employees’ positive conforming behavior and adopt measures to thwart and punish cyberbullying. In some cases, employees must be fired to protect the work environment. For example, a call-center employee made offensive Facebook comments about a colleague, and the employee was fairly dismissed even after appealing the case (XpertHR 2012). In addition, the US government has developed a one-stop shop of tools at Stopbullying.gov that emphasizes use of social networking features to prevent cyberbullying behaviors (Uknowkids 2013). Thus, future research should consider positive aspects of social media that 
can help people leverage a positive social learning process of anti-bullying behaviors and examine how IT artifacts themselves can help prevent cyberbullying behaviors.

The SMCBM is intended to maximize prediction of adult cyberbullying frequency, as modified from the SSSL model. Nonetheless, the SMCBM contains more inferred causality than can be tested with cross-sectional data, because it has been explained by factors such as the causal mechanisms of disinhibition and deindividuation. As with a typical variance model, causation can be inferred primarily from the theoretical explanation, but little such causation can be demonstrated on the basis of our form of testing, other than through the mediation testing we conducted. Likewise, the nature of our measurement design does not allow for a distinction between initial and ongoing deviance. Our model implicitly assumes that most of the participants' deviance is ongoing, such that they are not new to cyberbullying. It would be particularly interesting to study people who had just committed their first and only act of cyberbullying to better understand the imitation process, but this is especially challenging because of sampling constraints. Akers et al. (1979) found that imitation was important in explaining one's very first act of deviance; after that, it had virtually no predictive effect on ongoing deviance. For these reasons, we did not include imitation in our model.

Consequently, other methodologies should be employed to further build this area of research; however, this is easier said than done in social learning and SSSL model research. For example, experimentation is probably the most problematic solution and has yet to find much success in such studies. Researchers have previously found it difficult to obtain results by using short-term experimentation in this context (Pratt et al. 2010). We believe the reason for this is straightforward: Social learning is a process that takes time, and it is thus unrealistic to expect that an artificial manipulation will cause immediate changes. That is, social learning is not one event (unlike a fear appeal or other classic “interventions”); it requires continuous observation/imitation during a longer time period (Akers 2011). This is why cross-sectional studies are preferred over experimentation in this literature: Cross-sectional studies can at least take snapshots of where a given person is at a given point in time in the social learning process. Moreover, our context is inherently social, involving interactions with large numbers of people 
over time. How to emulate this in a realistic manner in a short-term experiment has yet to be determined.

Because social learning is a process, longitudinal studies of cyberbullying are more promising than one-time experiments. In SLT/SSSL research, some longitudinal studies have been conducted, but these are especially challenging in deviance studies because it is difficult to find participants willing to disclose potentially criminal behavior over time (causing a stronger self-selection bias), and such studies are prone to high dropout rates. Moreover, longitudinal studies are difficult to execute without full identification of the participants because the researchers must ensure that the right data is mapped to the right person. Such identification undermines anonymity, which then foster responses that are prone to social desirability bias. Another challenge of these studies is that the social learning processes for cyberbullying may require years of exposure. Nevertheless, this is an important future direction for cyberbullying research.

Although we had a large number of respondents from a diverse sociodemographic range, our study cannot be assumed to be widely generalizable. First, we allowed only US respondents to ensure similarity with respect to assumed laws and national cultural mores. We expect that cyberbullying in countries with heavy social and governmental monitoring and different cultural norms would take on nuanced forms and might have different foci in the social learning constructs. Cross-cultural IS research in other contexts has been informative (e.g., Lowry et al. 2011; Posey et al. 2010); thus, testing the SMCBM in places such as China, India, Indonesia, Russia, Egypt, Brazil, South Africa, Nigeria, and Mexico would likely be informative,

It is also important to note that our study had a self-selection bias, which is difficult to estimate. In our case, the respondents were those who willingly and anonymously disclosed their cyberbullying behavior. Thus, it is theoretically possible that those who remain silent about their cyberbullying may experience other, more influential factors of which we are not aware (e.g., a greater sense of shame or more self-control). Furthermore, we cannot infer that these results transfer to juveniles because of differences in moral development, but we still believe that applying the SMCBM to them would be a useful starting place because much of the model will likely hold. 
Again, we tested common sociodemographic factors that have been used in SLT/SSSL deviance studies, and most of these were insignificant. Going forward, other explanations for cyberbullying should be explored and added to the SMCBM. For example, a potential explanation is one's lack of self-control or propensity to anger and under which conditions such predispositions lead to cyberbullying. Power is another example of a promising area for further theorizing and research. The physical power differential between victim and offender has recently been reported to be important in traditional bullying but not in cyberbullying (Barlett et al. 2016). However, there may still be kinds of power or status effects that matter in cyberbullying.

Despite its social and technological importance, adult cyberbullying is overlooked in research (Nycyk 2015) and is generally ignored in management practice, even though much cyberbullying occurs at work or amongst coworkers (Baum et al. 2009). In fact, we found no previous studies involving participants over an average age of 25 . As a result, adult cyberbullying remains unstudied, even though it is a pressing social problem and a dark side of the Internet (Nycyk 2015). We showed that SMCBM works well to explain adult behavior, and that it appears that key factors such as situational morality, neutralization, negative social influence, and costs/benefits must be accounted for. However, given this useful baseline, more research must be conducted to see just how adolescents and adults differ, which will require future SMCBM data collections and modifications for adolescents. For example, research has shown that moral decision-making develops over time and can thus differ between juveniles and adults (Kohlberg 1981). Research has also shown that juveniles are more prone to engage in risky behaviors and more likely to be pressured into such behaviors than adults because adults can better estimate long-term consequences than juveniles (Gardner \& Steinberg 2005). Thus, it may be that adults will have stronger situational morality considerations, and juveniles may be more affected by low self-control.

Another limitation is that for simplicity of modeling and measurement, we aggregated the four main types of cyberbullying in our main model. That is, we used an average of perceptions related to four related but different behaviors to predict the average level of those behaviors. To further address this concern, we conducted a sensitivity analysis of running four separate models for the four different 
behaviors (summarized in Table D.8). The results across all four models were highly similar to our overall model, showing that SMCBM holds well across different behaviors. However, there are many other specific forms of cyberbullying that require further investigation for which we cannot claim our model to hold and may create more varied results, such as sexting, breaking into another person's computer for revenge, sending unwanted porn to someone, defacing a person's social media site, and so on. Other more advanced methodologies—such as multi-level modeling and hierarchical linear modeling — may also be useful when dealing with such highly disparate cyberbullying behaviors.

Moreover, although benefits was supported in our baseline model, it dropped out when the control variables and social media and structure factors were added. Hence, we cannot conclude benefits should not be included in SMCBM; it just appears to be a weaker factor than is costs. We suspect this may have to do with the nature of self-report in that costs of cyberbullying are likely easier to envision than benefits. For example, it is likely easier to envision getting caught than visualizing the benefits of power imbalance. Notably, we measured costs and benefits more generally, as is often the case in RCT applications to deviant behaviors (e.g., Bulgurcu et al. 2010; Hu et al. 2011), so that our adult respondents could best define what they considered to be costs and benefits for themselves. This assumption is particularly useful for social learning, because costs and benefits are learned and not necessarily entirely rational or predictable across all forms of cyberbullying. Consequently, when people experience positive consequences of cyberbullying, such experiences reinforce their intention to cyberbully. Future research could benefit from the examination of specific costs and benefits of adult cyberbullying, and how these come about.

Finally, for concision, we focus on the five sub-constructs of perceived anonymity that are the most likely drivers of the causal mechanisms of disinhibition and deindividuation in cyberbullying contexts. However, it is worthwhile to investigate other social media design considerations that may further drive or work in parallel with anonymity and to establish how they are different. This could include factors such as degree of synchronicity, media richness, and perceptions of monitoring. Moreover, future research should consider actual social media artifacts that could blunt cyberbullying, such as 
interfaces that are designed to increase accountability, social presence, and personal identity. Research should also account for the fact that people are increasingly using technologies external to social media (e.g., IP masking, VPNs, and bit bleachers) to increase the anonymity of their social media interactions. In Table 3, we map many of the various social media design choices and technical factors that could have positive (+) and negative (-) influences on the five major factors of anonymity. At this point, these ideas are mostly speculative and need more theoretical development because little literature exists to support these relationships. Vance et al. (2015) showed a novel way that high volumes of IT artifact designs can be tested in a behavior security setting. We believe such an approach could be extended to study social media IT artifacts involved with cyberbullying. This alone provides an agenda for future cyberbullying artifact research and further illustrates the uniqueness of the social media context.

\section{CONCLUSION}

Whereas most cyberbullying research focuses on exploratory studies of juveniles or college students, ours is the first to focus on adult cyberbullies. Using engaged scholarship, we propose the SMCBM to integrate the inconsistent knowledge of drivers of cyberbullying with a re-contextualization of the SSSL model that includes the social media artifact of perceived anonymity as a key social structure driver of cyberbullying. The SMCBM was largely supported, implying that the social media artifact of anonymity, along with hours of social media use per day, helps to drive the social learning process and that this process is largely responsible for adult cyberbullying. We thus offer the SMCBM as a comprehensive model — the first to include micro- and macro-components of social learning — for further research on adult cyberbullying and as a potential theoretical starting point for research on juvenile cyberbullying. 
Table 3. Social Media Artifacts and Contextual Factors that Can Change Cyberbullying Anonymity

Social Media Artifact and Contextual Factors

The Five Sub-constructs of

Perceived Cyberbullying

Anonymity:

\begin{tabular}{l|l|l|l|l|}
\hline LI & DR & LP & KO & CS \\
\hline
\end{tabular}

Social media anonymity influencers that can be chosen in most social media systems

Interacting only with strangers

Interacting with real-world associations

Using a small social community with largely known people

Using a large social community with largely unknown people

Communicating untrue details or using inauthentic personas

Using one's true identity

Using pseudonyms

Using asynchronous features to "buy time" to plot responses

Using different accounts and identities for different activities and goals

\begin{tabular}{|l|l|l|l|l|}
+ & + & + & + & \\
\hline- & - & - & - & \\
\hline- & - & & - & \\
+ & + & & + & \\
\hline+ & & + & + & \\
\hline- & - & & - & - \\
\hline+ & + & & & \\
\hline+ & + & & + & + \\
\hline+ & + & & + & + \\
\hline
\end{tabular}

Social media anonymity influencers that exist only in some social media systems

Using throwaway accounts

Using avatars

Disallowing the creation of more than one account from the same IP address

Interacting with real-time video conferencing

Interacting with real-time instant messaging

Allowing users to easily report bad behavior or malicious comments

Requiring background checks and authentication of identity before joining

Using a social media system that is designed to conceal true identities ${ }^{\dagger}$

Sending self-destructing messages

Allowing access to friends of friends

Using a social media system that has automatic behavior-monitoring bots

Using a social media system that has human moderators or censors

\begin{tabular}{|l|l|l|l|l|}
\hline+ & + & & & + \\
\hline+ & + & & + & \\
\hline- & - & - & & - \\
\hline- & - & - & - & - \\
\hline- & - & & - & - \\
\hline- & - & & & - \\
\hline- & - & - & - & - \\
\hline+ & + & + & + & + \\
\hline & + & & + & + \\
\hline & + & + & + & \\
\hline- & - & & - & - \\
\hline- & - & & - & - \\
\hline
\end{tabular}

Technical techniques that can be used with browsers or apps to increase cyberbullying anonymity

Using IP-masking software or VPN

Blocking third-party cookies

Blocking location data

Using anonymous browser or do-not-track functions

Blocking plugins and JavaScript

Using encrypted connections

Using prepaid "burner" cell phones bought with cash

Bit-scrubbing and history-scrubbing software

\begin{tabular}{|l|l|l|l|l|}
\hline & + & + & & + \\
\hline+ & + & & & + \\
\hline+ & + & + & & + \\
\hline+ & + & + & & + \\
\hline+ & & & & + \\
\hline+ & + & + & & + \\
\hline+ & + & + & & + \\
\hline+ & & + & & + \\
\hline
\end{tabular}

${ }^{\dagger}$ Examples of social media systems designed to conceal identifies include Whisper ${ }^{\mathrm{TM}}$, Yik Yak ${ }^{\mathrm{TM}}$, and After School $^{\mathrm{TM}}$. LI = lack of identification, DR = diffused responsibility, $\mathrm{LP}=$ lack of proximity, $\mathrm{KO}=$ lack of knowledge of others, and CS = confidence in the system.

\section{ACKNOWLEDGMENTS}

We are especially grateful and indebted to Rob Fichman, the SE of this manuscript, who

thoughtfully and patiently oversaw the development of this manuscript. We are also grateful to Rob

Fichman, Ram Gopal, Alok Gupta, and Sam Ransbotham for organizing the special issue workshop at

Boston College, which also benefited our work. We also thank Tailai Wu for earlier work he contributed 
to this project. Finally, we acknowledge partial financial support for this project from City University of

Hong Kong and the University of Jyväskylä.

\section{REFERENCES}

Acohido B (2013) Cyberbullying extends to workplace, bedroom. USA Today.

Ajzen I (1991) The theory of planned behavior. Organizational Behavior and Human Decision Processes 50(2):179-211.

Akers RL (1973) Deviant Behavior: A Social Learning Approach, (Wadsworth, Belmont, CA).

Akers RL (1990) Rational choice, deterrence, and social learning theory in criminology: The path not taken. J. Criminal Law \& Criminology 81(3):653-676.

Akers RL (1998) Social Learning and Social Structure: A General Theory of Crime and Deviance, (Northeastern University Press, Boston, MA).

Akers RL (2011) Social Learning and Social Structure: A General Theory of Crime and Deviance, (Northeastern University Press, Boston, MA).

Akers RL, Krohn MD, Lanza-Kaduce L, Radosevich M (1979) Social learning and deviant behavior: A specific test of a general theory. American Sociological Review 44(4):636-655.

Akers RL, La Greca AJ, Cochran J, Sellers C (1989) Social learning theory and alcohol behavior among the elderly. Sociological Quarterly 30(4):625-638.

Akers RL, Sellers CS (2004) Criminological Theories: Introduction, Evaluation, and Application, 4th ed.(Roxbury Publishing, Los Angeles, CA).

Awad NF, Ragowsky A (2008) Establishing trust in electronic commerce through online word of mouth: An examination across genders. Journal of Management Information Systems 24(4):101-121.

Baggili I, Rogers M (2009) Self-reported cyber crime: An analysis on the effects of anonymity and preemployment integrity. International Journal of Cyber Criminology 3(2):550-565.

Bandura A (1977) Social Learning Theory, (Prentice-Hall, Englewood Cliffs, NJ).

Barlett CP, Gentile DA (2012) Attacking others online: The formation of cyberbullying in late adolescence. Psychology of Popular Media Culture 1(2):123-135.

Barlett CP, Gentile DA, Chew C (2014) Predicting cyberbullying from anonymity. Psych. Popular Media Culture 5(2):171-180.

Barlett CP, Prot S, Anderson CA, Gentile DA (2016) An empirical examination of the strength differential hypothesis in cyberbullying behavior. Psychology of Violence forthcoming(

Baum K, Catalano S, Rand M, Rose K (2009) Stalking Victimization in the United States, (National Institute of Justice, Washington, DC).

Bauman S (2010) Cyberbullying in a rural intermediate school: An exploratory study. J. Early Adolescence 30(6):803-833.

Bauman S, Pero H (2011) Bullying and cyberbullying among deaf students and their hearing peers: An exploratory study. J. Deaf Studies and Deaf Education 16(2):236-253.

Becker G (1968) Crime and punishment: An economic approach. Journal of Political Economy 76(169217.

Bennett RJ, Robinson SL (2000) Development of a measure of workplace deviance. Journal of Applied Psychology 85(3):349-360.

Bocij P (2004) Cyberstalking: Harassment in the Internet Age and How to Protect Your Family, (Praeger Publishers, Westport, CT).

Bocij P, McFarlane L (2003) Cyberstalking: The technology of hate. Police Journal 76(3):204-221.

Brink A (2014) Affective experiences with sex and sexual satisfaction among Dutch adolescents: The consequences of online and offline communication about sexuality with friends. In: Faculty of Social and Behavioural Sciences, Utrecht University.

Bulgurcu B, Cavusoglu H, Benbasat I (2010) Information security policy compliance: An empirical study of rationality-based beliefs and information security awareness. MIS Quarterly 34(3):523-548. 
Burgess RL, Akers RL (1966) A differential association-reinforcement theory of criminal behavior. Social Problems 14(2):128-147.

Calvete E, Orue I, Estévez A, Villardón L, Padilla P (2010) Cyberbullying in adolescents: Modalities and aggressors’ profile. Computers in Human Behavior 26(5):1128-1135.

Chin WW, Marcolin BL, Newsted PR (2003) A partial least squares latent variable modeling approach for measuring interaction effects: Results from a Monte Carlo simulation study and an electronicmail emotion/adoption study. Information Systems Research 14(2):189-217.

Clear TR, Rose DR, Waring E, Scully K (2003) Coercive mobility and crime: A preliminary examination of concentrated incarceration and social disorganization. Justice Quarterly 20(1):33-64.

Cohen AK (1955) Delinquent Boys: The Culture of the Gang, (Free Press, Glencoe. IL).

Cressey DR (1960) Epidemiology and individual conduct: A case from criminology. Pacific Sociological Review 3(2):47-58.

Crutchfield RD (1989) Labor stratification and violent crime. Social Forces 68(2):489-512.

Crutchfield RD, Geerken MR, Gove WR (1982) Crime rate and social integration: The impact of metropolitan mobility. Criminology 20(3-4):467-478.

D'Arcy J, Herath T (2011) A review and analysis of deterrence theory in the IS security literature: making sense of the disparate findings. European Journal of Information Systems 20(6):643-658.

Danzinger S (1976) Explaining urban crime rates. Criminology 14(291.

Darley JM, Latané B (1968) Bystander intervention in emergencies: Diffusion of responsibility. 8(377383.

Davenport D (2002) Anonymity on the Internet: Why the price may be too high. Communications of the ACM 45(4):33-35.

DeHue F, Bolman C, Völlink T (2008) Cyberbullying: Youngsters' experiences and parental perception. CyberPsychology \& Behavior 11(2):217-223.

Delmonico DL, Griffin EJ (2008) Online sex offending: Assesment and treatment. DR Laws, WT O'Donohue, eds. Sexual Deviance: Theory, Assessment, and Treatment (The Guilford Press, New York, NY) 459-485.

Dooley JJ, Pyżalski J, Cross D (2009) Cyberbullying versus face-to-face bullying. Journal of Psychology 217(4):182-188.

Eagly AH, Steffen VJ (1986) Gender and aggressive behavior: A meta-analytic review of the social psychological literature. Psychological Bulletin 100(3):309-330.

Farley S, Coyne I, Sprigg C, Axtell C, Subramanian G (2015) Exploring the impact of workplace cyberbullying on trainee doctors. Medical Education 49(4):436-443.

Freestone O, Mitchell VW (2004) Generation Y attitudes towards e-ethics and Internet-related misbehaviours. Journal of Business Ethics 54(2):121-128.

Galán-GarcÍa P, Puerta JGdl, Gómez CL, Santos I, Bringas PG (2016) Supervised machine learning for the detection of troll profiles in Twitter social network: Application to a real case of cyberbullying. Logic Journal of IGPL 24(1):42-53.

Gannett AK (2013) At Work: Cyberbullies graduate to workplace. USA Today.

Garbharran A, Thatcher A (2011) Modelling social cognitive theory to explain software piracy intention. M Smith, G Salvendy, eds. Human Interface and the Management of Information. Interacting with Information (Springer Berlin Heidelberg, Berlin, Germany) 301-310.

Gardner M, Steinberg L (2005) Peer influence on risk taking, risk preference, and risky decision making in adolescence and adulthood: An experimental study. Developmental Psychology 41(4):625-635.

Gefen D, Rigdon EE, Straub D (2011) An update and extension to SEM guidelines for administrative and social science research. MIS Quarterly 35(2):iii-A7.

Gibbs JP (1975) Crime, Punishment, and Deterrence, (Elsevier, New York, NY).

Gillespie AA (2006) Cyber-bullying and harassment of teenagers: The legal response. Journal of Social Welfare \& Family Law 28(2):123-136.

Gini G, Pozzoli T, Hymel S (2014) Moral disengagement among children and youth: A meta-analytic review of links to aggressive behavior. Aggressive Behavior 40(1):56-68. 
Goodman JK, Cryder CE, Cheema A (2013) Data collection in a flat world: The strengths and weaknesses of Mechanical Turk samples. Journal of Behavioral Decision Making 26(3):213-224.

Hare RM (1981) Moral Thinking: Its Method, Levels, and Point, (Oxford University Press, Oxford).

Harris LC, Dumas A (2009) Online consumer misbehaviour: An application of neutralization theory. Marketing Theory 9(4):379-402.

Hawdon J (2012) Applying differential association theory to online hate groups: A theoretical statement. Research on Finnish Society 5(39-47.

Hemphill SA, Heerde JA (2014) Adolescent predictors of young adult cyberbullying perpetration and victimization among Australian youth. J. Adolescent Health 55(4):580-587.

Higgins GE (2006) Gender differences in software piracy: The mediating roles of self-control theory and social learning theory. Journal of Economic Crime Management 4(1):1-30.

Higgins GE, Makin DA (2004) Does social learning theory condition the effects of low self-control on college students’ software piracy. Journal of Economic Crime Management 2(2):1-22.

Higgins GE, Wolfe SE, Marcum CD (2008) Music piracy and neutralization: A preliminary trajectory analysis from short-term longitudinal data. Intl. J. Cyber Criminology 2(2):324-336.

Hinduja S (2007) Neutralization theory and online software piracy: An empirical analysis. Ethics and Information Technology 9(3):187-204.

Hinduja S, Patchin JW (2008) Cyberbullying: An exploratory analysis of factors related to offending and victimization. Deviant Behavior 29(2):129-156.

Hinduja S, Patchin JW (2010) Bullying, cyberbullying, and suicide. Arch. of Suicide R. 14(3):206-221.

Hinduja S, Patchin JW (2013) Social influences on cyberbullying behaviors among middle and high school students. J. Youth and Adolescence 42(5):711-722.

Holt TJ, Burruss GW, Bossler AM (2010) Social learning and cyber-deviance: Examining the importance of a full social learning model in the virtual world. J. Crime and Justice 33(2):31-61.

Hu Q, Xu Z, Dinev T, Ling H (2011) Does deterrence work in reducing information security policy abuse by employees? Communications of the ACM 54(6):54-60.

Huang Y-y, Chou C (2010) An analysis of multiple factors of cyberbullying among junior high school students in Taiwan. Computers in Human Behavior 26(6):1581-1590.

Jackson PI (1991) Crime, youth gangs, and urban transition: The social dislocations of postindustrial economic development. Justice Quarterly 8(3):379-397.

Jarvis CB, MacKenzie SB, Podsakoff PM (2003) A critical review of construct indicators and measurement model misspecification in marketing and consumer research. Journal of Consumer Research 30(2):199-218.

Kahan DM (1997) Social influence, social meaning, and deterrence. Virginia Law Review 83(2):349-395.

Karahanna E, Straub DW, Chervany NL (1999) Information technology adoption across time: A crosssectional comparison of pre-adoption and post-adoption beliefs. MIS Quarterly 23(2):183-213.

King AV (2010) Constitutionality of cyberbullying laws: Keeping the online playground safe for both teens and free speech. Vanderbilt Law Review 63(3):845-884.

Klockars CB (1974) The Professional Fence, (Free Press, New York, NY).

Ko C-H, Yen J-Y, Yen C-F, Chen C-S, Weng C-C, Chen C-C (2008) The association between Internet addiction and problematic alcohol use in adolescents: The problem behavior model. CyberPsychology \& Behavior 11(5):571-576.

Kohlberg L (1981) The Philosophy of Moral Development Moral Stages and the Idea of Justice, (Harper \& Row).

Landers RN, Behrend TS (2015) An inconvenient truth: Arbitrary distinctions between organizational, Mechanical Turk, and other convenience samples. Industrial and Organizational Psychology 8(2):142-164.

Lankton NK, Wilson EV, Mao E (2010) Antecedents and determinants of information technology habit. Information \& Management 47(5):300-307.

Lapidot-Lefler N, Barak A (2012) Effects of anonymity, invisibility, and lack of eye-contact on toxic online disinhibition. Computers in Human Behavior 28(2):434-443. 
Lea M, Spears R, de Groot D (2001) Knowing me, knowing you: Anonymity effects on social identity processes within groups. Personality and Social Psychology Bulletin 27(5):526-537.

Lee G, Akers RL, Borg MJ (2004) Social learning and structural factors in adolescent substance use. W. Criminology Rev. 5(1):17-34.

Li Q (2006) Cyberbullying in schools: A research of gender differences. School Psych. Intl. 27(2):157170.

Li Q (2007) New bottle but old wine: A research of cyberbullying in schools. Computers in Human Behavior 23(4):1777-1791.

Li Q (2008) A cross-cultural comparison of adolescents' experience related to cyberbullying. Educational Research 50(3):223-234.

Limber SP (2012) Cyberbullying: Bullying in the Digital Age, (Wiley-Blackwell, Malden, MA).

Lowry PB, Cao J, Everard A (2011) Privacy concerns versus desire for interpersonal awareness in driving the use of self-disclosure technologies: The case of instant messaging in two cultures. Journal of Management Information Systems 27(4):163-200.

Lowry PB, D’Arcy J, Hammer B, Moody GD (2016) Cargo Cult' science in traditional organization and information systems survey research: A case for using nontraditional methods of data collection, including Mechanical Turk and online panels. Journal of Strategic Information Systems 2016(September):in press.

Lowry PB, Gaskin J (2014) Partial least squares (PLS) structural equation modeling (SEM) for building and testing behavioral causal theory: When to choose it and how to use it. IEEE Transactions on Professional Communication 57(2):123-146.

Lowry PB, Moody GD (2015) Proposing the control-reactance compliance model (CRCM) to explain opposing motivations to comply with organizational information security policies. Information Systems Journal 25(5):433-463.

Lowry PB, Moody GD, Galletta DF, Vance A (2013) The drivers in the use of online whistle-blowing reporting systems. Journal of Management Information Systems 30(1):153-189.

Lowry PB, Posey C, Bennett RJ, Roberts TL (2015) Leveraging fairness and reactance theories to deter reactive computer abuse following enhanced organisational information security policies: An empirical study of the influence of counterfactual reasoning and organisational trust. Information Systems Journal 25(3):193-230.

Lowry PB, Romano NC, Jenkins JL, Guthrie RW (2009) The CMC interactivity model: How interactivity enhances communication quality and process satisfaction in lean-media groups. Journal of Management Information Systems 26(1):155-196.

Mangolda WG, Faulds DJ (2009) Social media: The new hybrid element of the promotion mix. Business Horizons 54(2):357-365.

Marcum CD, Higgins GE, Ricketts ML (2014) Juveniles and cyber stalking in the United States: an analysis of theoretical predictors of patterns of online perpetration. International Journal of Cyber Criminology 8(1):47-56.

Markey PM (2000) Bystander intervention in computer-mediated communication. Computers in Human Behavior 16(2):183-188.

McFarlane L, Bocij P (2003) An exploration of predatory behaviour in cyberspace: Towards a typology of cyberstalkers First Monday (accessed March 10, 2014).

Meloy JR (2001) The Psychology of Stalking: Clinical and Forensic Perspectives, (Academic Press, San Diego, CA).

Miller ME (2013) Miami student Holly Jacobs fights revenge porn. Miami NewsTimes.

Minor WW (1981) Techniques of neutralization: A reconceptualization and empirical examination. $J$. Research in Crime and Delinquency 18(2):295-318.

Mitchell J, Dodder RA (1980) An examination of types of delinquency through path analysis. J. Youth and Adolescence 9(3):239-248.

Moody GD, Siponen M (2013) Using the theory of interpersonal behavior to explain non-work-related personal use of the Internet at work. Information \& Management 50(6):322-335. 
Moore MJ, Nakano T, Enomoto A, Suda T (2012) Anonymity and roles associated with aggressive posts in an online forum. Computers in Human Behavior 28(3):861-867.

Morris RG, Higgins GE (2010) Criminological theory in the digital age: The case of social learning theory and digital piracy. Journal of Criminal Justice 38(4):470-480.

Neal JW (2010) Social aggression and social position in middle childhood and early adolescence: Burning bridges or building them? Journal of Early Adolescence 30(1):122-137.

Nycyk M (2015) Adult-to-Adult Cyberbullying: An Exploration of a Dark Side of the Internet, (Michael Nycyk, Brisbane, Australia).

Pauwels L, Schils N (2016) Differential online exposure to extremist content and political violence: Testing the relative strength of social learning and competing perspectives. Terrorism and Political Violence 28(1):1-29.

Pershing Square Law Firm (2013) Employers must watch out for workplace cyber-bullying. Pershing Square Law Firm.

Philips F, Morrissey G (2004) Cyberstalking and cyberpredators: A threat to safe sexuality on the Internet. Convergence: The International Journal of Research into New Media Technologies 10(1):66-79.

Pinsonneault A, Heppel N (1998) Anonymity in group support systems research: A new conceptualization, measure, and contingency framework. Journal of Management Information Systems 14(3):89-108.

Piotrowski C (2012) From workplace bullying to cyberbullying: The enigma of e-harassment in modern organizations. Org. Development J. 30(4):44-53.

Pornari CD, Wood J (2010) Peer and cyber aggression in secondary school students: The role of moral disengagement, hostile attribution bias, and outcome expectancies. Aggressive Behavior 36(2):8194.

Posey C, Lowry PB, Roberts TL, Ellis S (2010) Proposing the online community self-disclosure model: The case of working professionals in France and the UK who use online communities. European Journal of Information Systems 19(2):181-195.

Posey C, Roberts TL, Lowry PB (2015) The impact of organizational commitment on insiders' motivation to protect organizational information assets. Journal of Management Information Systems 32(4):179-214.

Posey C, Roberts TL, Lowry PB, Bennett RJ, Courtney J (2013) Insiders’ protection of organizational information assets: Development of a systematics-based taxonomy and theory of diversity for protection-motivated behaviors. MIS Quarterly 37(4):1189-1210.

Pratt TC, Cullen FT, Sellers CS, Thomas Winfree Jr L, Madensen TD, Daigle LE, Fearn NE, Gau JM (2010) The empirical status of social learning theory: A meta-analysis. Justice Quarterly 27(6):765-802.

Raskauskas J, Stoltz AD (2007) Involvement in traditional and electronic bullying among adolescents. Developmental Psychology 43(3):564-575.

Reicher SD, Spears R, Postmes T (1995) A social identity model of deindividuation phenomena. European Review of Social Psychology 6(1):161-198.

Renati R, Berrone C, Zanetti MA (2012) Morally disengaged and unempathic: Do cyberbullies fit these definitions? An exploratory study. CyberPsychology, Behavior \& Social Networking 15(8):391398.

Richardson HA, Simmering MJ, Sturman MC (2009) A tale of three perspectives: Examining post hoc statistical techniques for detection and correction of common method variance. Organizational Research Methods 12(4):762-800.

Ringle CM, Wende S, Will S (2005) SmartPLS 2.0 (M3) Beta. Hamburg (accessed September 17, 2010).

Robert D, Doyle J (2003) Study on cyberstalking: Understanding investigative hurdles. FBI Law Enforcement Bulletin 72(3):10-17.

Robson C, Witenberg RT (2013) The influence of moral disengagement, morally based self-esteem, age, and gender on traditional bullying and cyberbullying. Journal of School Violence 12(2):211-231.

Rouse SV (2015) A reliability analysis of Mechanical Turk data. Computers in Human Behavior 
43(2015):304-307.

Sellers CS, Winfree LT (1990) Differential associations and definitions: A panel study of youthful drinking behavior. International Journal of the Addictions 25(7):755-771.

Siegal LJ (2011) Criminology: The Core, 4th Edition ed.(Wadsworth, Cengage Learning, Belmont, CA).

Silke A (2003) Deindividuation, anonymity, and violence: Findings from Northern Ireland. Journal of Social Psychology 143(4):493-499.

Siponen M, Vance A (2010) Neutralization: New insights into the problem of employee information systems security policy violations. MIS Quarterly 34(3):487-502.

Skinner BF (1953) Science and Human Behavior, (Macmillan, New York, NY).

Skinner WF, Fream AM (1997) A social learning theory analysis of computer crime among college students. Journal of Research in Crime and Delinquency 34(4):495-518.

Slonje R, Smith PK (2007) Cyberbullying: Another main type of bullying? Scand. J. Psych. 49(2):147154.

Slonje R, Smith PK, Frisén A (2013) The nature of cyberbullying, and strategies for prevention. Computers in Human Behavior 29(1):26-32.

Smith PK, Mahdavi J, Carvalho M, Fisher S, Russell S, Tippett N (2008) Cyberbullying: Its nature and impact in secondary school pupils. J. Child Psychology and Psychiatry 49(4):376-385.

Sourander A, Klomek AB, Ikonen M, Lindroos J, Luntamo T, Koskelainen M, Ristkari T, Helenius H (2010) Psychosocial risk factors associated with cyberbullying among adolescents: A populationbased study. Archives of General Psychiatry 67(7):720-728.

Steelman ZR, Hammer BI, Limayem M (2014) Data collection in the digital age: Innovative alterantives to student samples. MIS Quarterly 38(2):355-378.

Suler J (2004) The online disinhibition effect. CyberPsychology \& Behavior 7(3):321-326.

Sutherland EH (1947) Principles of Criminology, $4^{\text {th }}$ ed.(Lippincott, Philadelphia, PA).

Sykes GM, Matza D (1957) Techniques of neutralization: A theory of delinquency. American Sociological Review 22(6):664-670.

Tavani HT, Grodzinsky FS (2002) Cyberstalking, personal privacy, and moral responsibility. Ethics and Information Technology 4(2):123-132.

Tittle CR, Antonaccio O, Botchkovar E (2012) Social learning, reinforcement and crime: Evidence from three European cities. Social Forces 90(3):863-890.

Tokunaga RS (2010) Following you home from school: A critical review and synthesis of research on cyberbullying victimization. Computers in Human Behavior 26(3):277-287.

Topcu Ç, Yıldırım A, Erdur-Baker Ö (2013) Cyber bullying @ schools: What do Turkish adolescents think? International Journal for the Advancement of Counselling 35(2):139-151.

Trumbull WN (1989) Estimations of the economic model of crime using aggregate and individual level data. Southern Economic Journal 56(2):423-439.

Udris R (2014) Cyberbullying among high school students in Japan: Development and validation of the online disinhibition scale. Computers in Human Behavior 41(December):253-261.

Uknowkids (2013) Current anti-bullying and cyberbullying movements around the country Uknowkids (accessed August 12, 2016).

Valkenburg PM, Peter J (2011) Online communication among adolescents: An integrated model of its attraction, opportunities, and risks. Journal of Adolescent Health 48(2):121-127.

Van de Ven AH (2007) Engaged Scholarship: A Guide for Organizational and Social Research, (Oxford University Press, New York, NY).

Vance A, Lowry PB, Eggett DL (2015) A new approach to the problem of access policy violations: Increasing perceptions of accountability through the user interface. MIS Quarterly 39(2):345366.

Vance A, Siponen M, Pahnila S (2012) Motivating IS security compliance: Insights from habit and protection motivation theory. Information \& Management 49(3-4):190-198.

Vandebosch H, Van Cleemput K (2009) Cyberbullying among youngsters: Profiles of bullies and victims. New Media \& Society 11(8):1349-1371. 
Varjas K, Talley J, Meyers J, Parris L, Cutts H (2010) High school students' perceptions of motivations for cyberbullying: An exploratory study. Western J. Emergency Medicine 11(3):269-273.

Venkatesh V, Thong JY, Xu X (2012) Consumer acceptance and use of information technology: Extending the unified theory of acceptance and use of technology. MIS Quarterly 36(1):157-178.

Verrill SW (2005) Social structure and social learning in delinquency: A test of Akers' social structuresocial learning model. In: Criminology, University of South Florida.

Warner BD, Pierce GL (1993) Reexamining social disorganization theory using calls to the police as a measure of crime*. Criminology 31(4):493-517.

Winfree LT, Bäckström TV, Mays GL (1994) Social learning theory, self-reported delinquency, and youth gangs: A new twist on a general theory of crime and delinquency. Youth \& Society 26(2):147-177.

Workman M (2010) A behaviorist perspective on corporate harassment online: Validation of a theoretical model of psychological motives. Computers \& Security 29(8):831-839.

Wright MF (2014) Predictors of anonymous cyber aggression: The role of adolescents' beliefs about anonymity, aggression, and the permanency of digital content. Cyberpsychology, Behavior, and Social Networking 17(7):431-438.

Xiao BS, Wong YM (2013) Cyber-bullying among university students: An empirical investigation from the social cognitive perspective. International Journal of Business and Information 8(1):34-69.

XpertHR (2012) Call-centre worker fairly dismissed for offensive Facebook comments about colleague. XpertHR (accessed August 12, 2016).

Ybarra ML (2004) Linkages between depressive symptomatology and Internet harassment among young regular Internet users. CyberPsychology \& Behavior 7(2):247-257.

Ybarra ML, Mitchell KJ (2004) Youth engaging in online harassment: Associations with caregiver-child relationships, Internet use, and personal characteristics. J. Adolescence 27(3):319-336. 
${ }^{\mathrm{i}}$ Adding imitation and downplaying Skinnerian operant conditioning also moved the SLT from the "Skinnerian behaviorism” version of Burgess \& Akers (1966) toward cognitive learning theories (Akers 2011).

ii The SSSL model encompasses SLT because it uses social structure variables as predictors, the SLT constructs as mediators, and deviance as the dependent variable (Akers 2011). The influence for this integration came, once again, from Sutherland, who had already described that social structures "determine” social associations (Sutherland 1947, p. 8). Cressey (1960) had also asserted that crimes in the US vary according to social structural indicators such as class, gender, and race. Akers (2011, p. 320) built on this notion with the SSSL model to suggest that social structures do not have a direct effect on deviant behavior but that these structures affect social learning elements, which then drive deviance. This also explains the correlation between social structure and crime rate (Akers 2011).

iii Definitions and imitation were added to SLT by Akers et al. (1979) as extensions of differential reinforcement. In this process of reinforcement through vicarious experience, if individuals perceive in others' experiences high benefits and low costs, they are more likely to imitate the behavior. Although imitation plays an important role in initiating deviant behavior and is thus a potential fourth key SLT factor, we removed it because it is not useful in predicting sustained behavior Akers et al. (1979).

iv Other studies have also reported that perceived anonymity can make cyberbullies believe that potential sanctions are low: “Anonymity and confidentiality on the Internet provides [sic] a degree of protection for cyber bullies” (Topcu et al. 2013, p. 149); moreover, "anonymity also implies the absence of consequences, because the aggressors frequently cannot be identified," (Calvete et al. 2010, p. 1130). Consequently, King (2010, p. 850) concludes that “cyberbullies feel protected by anonymity.”

v According to Davenport (2002), anonymity weakens the behavioral constraints imposed by the criminal justice system, an effect that facilitates deviance because it minimizes the threat of being punished. As a result of the sense of anonymity, people often perceive cyberdeviance as having few repercussions (D'Arcy \& Herath 2011).

vi Examples of neutralization techniques to justify behaviors include denial of responsibility, denial of injury, denial of the victim (i.e., denying the existence of a real victim), condemnation of the condemners, appeal to higher loyalties (Sykes \& Matza 1957), the metaphor of the ledger (Klockars 1974), and the defense of necessity (Minor 1981). These techniques have been thoroughly studied, and several others are likely applicable to cyberbullies. We thus conducted a full review of these techniques and summarized 14 relevant neutralization techniques from the literature (available upon request). However, which techniques are chosen in various scenarios is not as theoretically important for the SMCBM as the general proposition that if the SLT/SSSL model holds in this context and is driven by NSI, the definitions factor of SLT is likely to be strongly represented by neutralization by those who choose to cyberbully, often against their better moral judgment. For this reason, as well as for theoretical concision, we depict neutralization as a second-order construct, which is consistent with the theoretical models developed by Jarvis et al. (2003) and Siponen \& Vance (2010).

vii A total of 1,972 people on MTurk saw our HIT and examined the disclosure page of our survey. 50 people indicated they had never committed cyberbullying and thus were disqualified. 167 people decided to not continue with the study or refused to provide consent-leaving 1,755 people who went to the first page of the survey, the demographics section. When asked for their country, five people indicated they did not live in the US, even though their IP address indicated a US-based computer, and thus were eliminated. Another 156 people did not continue at this point, leaving 1,594 people who went to the next page of demographics. Another 27 people dropped out at this point, leaving 1,567 people. Because of the length of the survey, we then randomly provided five attention-trap questions throughout the remainder of the survey to ensure the respondents were being honest, were paying attention, and were not rushing through the survey. The first trap caught 205 people off guard, who were removed, after which 20 people decided to not complete the IT artifact section, leaving 1,342 people in the study. After this, they were given instructions about the cyberbullying section and reminded of the requirement to disclose their cyberbullying behaviors. 142 people did not continue, leaving 1,200 people. In the final sections of the survey on cyberbullying behaviors, four more attention traps were executed. Trap 2 was provided in this section of the survey, causing 61 people to be removed, leaving 1,139 people. 34 people did not pass Trap 3, leaving 1,105 people. 19 people did not pass Trap 4, leaving 1,086 people. 13 people did not pass Trap 5, leaving 1,073 respondents. Another 70 people passed all of the attention traps but did not fully respond to all cyberbullying behavior questions, and thus they were dropped, leaving 1,003 respondents for the final data analysis. Finally, the attention trap questions that were used were the following:

1. $\quad$...it is true that Donald Trump has unusual hair.

2. If adding two to the number three equals five then only select "somewhat agree" and nothing else.

3. If adding two to the number six equals eight then only select "neutral" and nothing else.

4. If you have been answering honestly thus far, please only select "agree" and nothing else.

5. It is true that Hillary Clinton used to be the president of the United States. 


\section{Why do adults engage in cyberbullying on social media? An integration of online disinhibition and deindividuation effects with the social structure and social learning (SSSL) model}

\section{ONLINE APPENDIX A. LITERATURE REVIEW ON CYBERBULLYING RESEARCH}

\section{Methodology for Conducting Literature Review}

First, to ensure completeness of our review and to best understand the construct of cyberbullying, we engaged in a rigorous literature search and review process, involving a team of five researchers. All five researchers used Google Scholar ${ }^{\mathrm{TM}}$ and the EBSCO journal articles index to perform an exhaustive search on articles that had the following keywords in their abstracts or keyword index: Cyberbullying, cyber bullying, cyberstalking, cyber stalking, cyber-harassment, cyber harassment, online deviance, revenge porn, social media attacks, online mobs, harassment by computer, cyber defamation, Internet stalking, Internet bullying. As the researchers found articles in and out-of-scope, online collaborative software was used to coordinate these articles to avoid unnecessary duplication of work. We found 135 articles that dealt with our topic.

Articles were determined to be in the scope of our review if they involved any kind of peer-reviewed article (or edited book or book chapter) that specifically demonstrated related factors that lead to a form of cyberbullying (e.g., cyberbullying, cyberstalking, revenge porn). They did not have to use an underlying theory to be included. Articles were deemed out-of-scope if they dealt with the general topic area but no findings could be used in any way to explain and predict factors that lead to cyberbullying. Most cyberbullying articles were out-of-scope, and included foci such as explaining the prevalence of cyberbullying (e.g., how many people victimize or are victims), predicting what causes people to overlook cyberbullying, predicting how cyberbullying harms self-esteem, providing guidance to teachers and parents, dealing with related regulations, research essays, and the like. For every in-scope article, we also checked its reference list, the publisher's website for related articles and articles that cite it, and Google Scholar for articles that cite it. In the end, we found 62 articles to be in scope out of 135 cyberbullying articles that we found. Table A.1 summarizes these articles.

We carefully double coded (two researchers coding and checking results) for articles that were in scope. We read these articles and recorded the following key information: (1) the type of evidence presented (e.g., empirical, qualitative, or both); (2) whether it appeared in an ISI-rated journal; (3) the theorie(s) used, if any, to explain and predict cyberbullying; (4) all of the predictors used to explain cyberbullying; (5) what form of cyberbullying they were predicting (e.g., revenge porn, cyberbullying, cyberstalking, defacing Facebook, etc.); (6) how many different kinds of specific cyberbullying behaviors they were actually predicting; (7) which relationships in their model were supported or rejected; (8) the kinds of research participants that were used (e.g., adolescents, college-age adults, adults 25 years or older); (9) and the kinds of IT artifacts that were studied and purported to increase cyberbullying (if any). To ensure $100 \%$ interrater reliability, any coding disagreements were resolved by the research team through FtF discussion.

In summary, our review identified 135 manuscripts that dealt with topics related to cyberbullying, most dealing with cyberbullying and cyberstalking in adolescents. Of these articles, only 64 provided empirical or qualitative evidence on causes related to cyberbullying. The other 71 articles offered no evidence for predicting cyberbullying - they were literature reviews or commentaries, featured descriptive data, focused on legal aspects, or predicted other primary outcomes (e.g., effect on victims' self-esteem). Of the 64 in-scope articles, one involved non-college adult offenders: six involved children (under 13 years); 10 involved a mix of children and teenagers; 35 involved only teenagers; and 11 involved university students (ages 18-24). Of these 64 studies, all but one used selfreported data (the exception used scenarios).

Notably only 17 of these studies attempted to apply an underlying theory; the remaining studies were exploratory. Moreover, 12 different theories were used and thus, the findings from these studies were inconsistent. Some inferred that a cost-benefit (C-B) analysis is crucial to the decision to cyber-harass; others infer that non-C-B factors such as low self-control, habit, negative social influence, and neutralization (or moral disengagement) are more important; still others support both viewpoints. Many ignored theoretical issues and simply explored demographic factors such as age, gender, and income. 
Table A.1 Summary of 64 cyberbullying Articles in the Literature that Provide Evidence for the Predictors of cyberbullying

\begin{tabular}{|c|c|c|c|c|c|c|}
\hline Citation & $\begin{array}{l}\text { ISI rated } \\
\text { journal? } \\
\text { (impact } \\
\text { factor) }\end{array}$ & Used theory? & Specific DV & $\begin{array}{l}\text { Examines } \\
\text { effects of the IT } \\
\text { artifact? }\end{array}$ & $\begin{array}{l}\text { Type of } \\
\text { participants } \\
\text { (mean years of } \\
\text { age) }\end{array}$ & Context of study \\
\hline $\begin{array}{l}\text { Alexy et al. } \\
(2005)\end{array}$ & no & no & $\begin{array}{l}\text { self-report responses to a } \\
\text { cyberstalking scenario }\end{array}$ & no & university & 756 students in two universities \\
\hline $\begin{array}{l}\text { Ang and Goh } \\
(2010)\end{array}$ & Yes (2.032) & no & self-report cyberbullying & no & $\begin{array}{l}\text { teenagers (mean } \\
\text { 14.9) }\end{array}$ & $\begin{array}{l}396 \text { adolescents from Singapore on } \\
\text { cyberbullying }\end{array}$ \\
\hline $\begin{array}{l}\text { Ang et al. } \\
(2010)\end{array}$ & yes (1.210) & no & self-report cyberbullying & no & $\begin{array}{l}\text { teenagers (mean } \\
14 \text { ) }\end{array}$ & $\begin{array}{l}336 \text { adolescents from Singapore and } 374 \\
\text { adolescents from Malaysia }\end{array}$ \\
\hline $\begin{array}{l}\text { Ang et al. } \\
\text { (2013) }\end{array}$ & Yes (1.210) & no & self-report cyberbullying & no & $\begin{array}{l}\text { teenagers (range } \\
11-17)\end{array}$ & $\begin{array}{l}757 \text { teenagers sample from USA and } \\
\text { Singapore on cyberbullying }\end{array}$ \\
\hline $\begin{array}{l}\text { Aricak et al. } \\
(2008)\end{array}$ & yes $(2.71)$ & no & $\begin{array}{l}\text { self-report cyber- } \\
\text { harassment }\end{array}$ & no & $\begin{array}{l}\text { teenagers (mean } \\
15.1 \text { ) }\end{array}$ & Turkish students age from 12 to 19 \\
\hline $\begin{array}{l}\text { Barlett et al. } \\
(2014)\end{array}$ & no & $\begin{array}{l}\text { general learning } \\
\text { model }\end{array}$ & self-report cyberbullying & anonymity & $\begin{array}{l}\text { university (mean } \\
19.2 \text { ) }\end{array}$ & 146 undergraduate students \\
\hline $\begin{array}{l}\text { (Barlett et al. } \\
\text { 2016) }\end{array}$ & & $\begin{array}{l}\text { strength } \\
\text { differential } \\
\text { hypothesis }\end{array}$ & $\begin{array}{l}\text { self-report bullying and } \\
\text { cyberbullying }\end{array}$ & no & $\begin{array}{l}\text { study one adults } \\
\text { (mean 26.1); } \\
\text { study two college } \\
\text { students (19.2) }\end{array}$ & $\begin{array}{l}\text { Two studies: one cross-sectional and one } \\
\text { short-term longitudinal. Designed to see if } \\
\text { physical strength / power made a difference } \\
\text { between traditional bullying and } \\
\text { cyberbullying. }\end{array}$ \\
\hline $\begin{array}{l}\text { Baroncelli and } \\
\text { Ciucci (2014) }\end{array}$ & yes (1.975) & no & self-report cyberbullying & no & $\begin{array}{l}\text { children (mean } \\
\text { 12.6) }\end{array}$ & $\begin{array}{l}669 \text { preadolescents from a middle school in } \\
\text { Tuscany (Central Italy) }\end{array}$ \\
\hline Bauman (2010) & yes (1.309) & SCT & self-report cyberbullying & no & $\begin{array}{l}\text { children (grades } \\
\text { 5-8) }\end{array}$ & 221 students in a rural intermediate school \\
\hline $\begin{array}{l}\text { Bauman and } \\
\text { Pero (2011) } \\
\end{array}$ & yes (1.625) & SCT & $\begin{array}{l}\text { self-report bullying and } \\
\text { cyberbullying }\end{array}$ & no & $\begin{array}{l}\text { teenagers (grades } \\
7-12 \text { ) }\end{array}$ & 30 deaf students and 22 hearing students \\
\hline $\begin{array}{l}\text { Bayraktar et al. } \\
(2015)\end{array}$ & yes $(1.210)$ & no & $\begin{array}{l}\text { self-report cyberbullying } \\
\text { and cyber victims }\end{array}$ & no & $\begin{array}{l}\text { teenagers (mean } \\
15.1 \text { ) }\end{array}$ & $\begin{array}{l}\text { Random sample survey of } 2092 \text { Czech } \\
\text { adolescents }\end{array}$ \\
\hline $\begin{array}{l}\text { Beran and } \mathrm{Li} \\
(2005)\end{array}$ & yes $(0.670)$ & $\begin{array}{l}\text { social } \\
\text { dominance } \\
\text { theory }\end{array}$ & $\begin{array}{l}\text { self-report cyber- } \\
\text { harassment }\end{array}$ & no & $\begin{array}{l}\text { teenagers (grades } \\
7-9 \text { ) }\end{array}$ & $\begin{array}{l}432 \text { students from grades 7-9 in Canadian } \\
\text { schools }\end{array}$ \\
\hline $\begin{array}{l}\text { Beran and Li } \\
(2008)\end{array}$ & no & $\begin{array}{l}\text { social ranking } \\
\text { theory }\end{array}$ & self-report cyberbullying & no & $\begin{array}{l}\text { teenagers (grades } \\
7-9 \text { ) }\end{array}$ & $\begin{array}{l}432 \text { students from grades 7-9 in Canadian } \\
\text { schools }\end{array}$ \\
\hline Bilić (2014) & no & no & self-report cyberbullying & no & $\begin{array}{l}\text { teenagers (grades } \\
7-8 \text { ) }\end{array}$ & 481 students in elementary schools in Croatia \\
\hline $\begin{array}{l}\text { Boulton et al. } \\
\text { (2012) }\end{array}$ & yes $(2.182)$ & no & self-report cyberbullying & no & $\begin{array}{l}\text { university (mean } \\
21.3 \text { ) }\end{array}$ & 405 postgraduate students \\
\hline $\begin{array}{l}\text { Calvete et al. } \\
(2010)\end{array}$ & yes $(2.694)$ & SCT & $\begin{array}{l}\text { self-report cyber- } \\
\text { harassment }\end{array}$ & no & $\begin{array}{l}\text { teenagers (mean } \\
14.1 \text { ) }\end{array}$ & 1431 adolescents, aged between $12-17$ \\
\hline
\end{tabular}




\begin{tabular}{|c|c|c|c|c|c|c|}
\hline Citation & $\begin{array}{l}\text { ISI rated } \\
\text { journal? } \\
\text { (impact } \\
\text { factor) }\end{array}$ & Used theory? & Specific DV & $\begin{array}{l}\text { Examines } \\
\text { effects of the IT } \\
\text { artifact? }\end{array}$ & $\begin{array}{l}\text { Type of } \\
\text { participants } \\
\text { (mean years of } \\
\text { age) }\end{array}$ & Context of study \\
\hline $\begin{array}{l}\text { DeHue et al. } \\
\text { (2008) }\end{array}$ & yes $(2.71)$ & no & $\begin{array}{l}\text { self-report cyberbullying } \\
\text { via } 6 \text { different media }\end{array}$ & no & $\begin{array}{l}\text { children (mean } \\
\text { 12.7) }\end{array}$ & $\begin{array}{l}1211 \text { final-year pupils of primary schools and } \\
\text { first-year pupils of all levels of secondary } \\
\text { schools }\end{array}$ \\
\hline Dilmac (2009) & yes(0.29) & no & self-report cyberbullying & no & $\begin{array}{l}\text { university (mean } \\
\text { 19.3) }\end{array}$ & 693 socioeconomic status university students \\
\hline $\begin{array}{l}\text { Doane et al. } \\
\text { (2014) }\end{array}$ & yes $(2.694)$ & TRA & self-report cyberbullying & no & $\begin{array}{l}\text { university (mean } \\
\text { age 19.1) }\end{array}$ & $\begin{array}{l}\text { Random sample survey of } 375 \text { university } \\
\text { students in a university }\end{array}$ \\
\hline $\begin{array}{l}\text { Dooley et al. } \\
\text { (2009) (q) }\end{array}$ & yes $(0.81)$ & no & $\begin{array}{l}\text { self-report cyberbullying in } \\
\text { qualitative interview }\end{array}$ & no & $\begin{array}{l}\text { university (range } \\
\text { 12-25) }\end{array}$ & $\begin{array}{l}\text { Polish university students aged 12-25; sample } \\
\text { size unreported (qualitative) }\end{array}$ \\
\hline $\begin{array}{l}\text { Erdur-Baker } \\
(2010)\end{array}$ & yes $(2.007)$ & no & self-report cyberbullying & no & $\begin{array}{l}\text { teenagers (range } \\
\text { 14-18) }\end{array}$ & $\begin{array}{l}276 \text { adolescents (123 females, } 151 \text { males and } \\
2 \text { unknown) ranging in age from } 14 \text { to } 18 .\end{array}$ \\
\hline $\begin{array}{l}\text { Gibb and } \\
\text { Devereux } \\
(2014)\end{array}$ & yes $(2.694)$ & no & self-report cyberbullying & no & $\begin{array}{l}\text { university (mean } \\
22.7 \text { ) }\end{array}$ & $\begin{array}{l}\text { Random sample survey of } 297 \text { undergraduate } \\
\text { and graduate students on their cyberbullying } \\
\text { activities }\end{array}$ \\
\hline $\begin{array}{l}\text { Görzig and } \\
\text { Frumkin } \\
\text { (2013) }\end{array}$ & no & no & $\begin{array}{l}\text { self-report on } \\
\text { cyberbullying }\end{array}$ & no & $\begin{array}{l}\text { children / } \\
\text { teenagers (range } \\
9-16)\end{array}$ & $\begin{array}{l}\text { Random stratified sample of 25,142 Internet- } \\
\text { using children }\end{array}$ \\
\hline $\begin{array}{l}\text { Gradinger et al. } \\
(2009)\end{array}$ & yes (1.036) & no & self-report cyberbullying & no & $\begin{array}{l}\text { teenagers (mean } \\
15.6 \text { ) }\end{array}$ & 761 adolescents aged $14-19$ \\
\hline $\begin{array}{l}\text { Heirman and } \\
\text { Walrave } \\
\text { (2012) }\end{array}$ & yes $(1.210)$ & TPB & self-report cyberbullying & no & $\begin{array}{l}\text { teenagers (mean } \\
15.47 \text { ) }\end{array}$ & $\begin{array}{l}\text { Random stratified cluster sample in six } \\
\text { Belgium schools }\end{array}$ \\
\hline $\begin{array}{l}\text { Hemphill and } \\
\text { Heerde (2014) }\end{array}$ & yes (3.612) & no & self-report cyberbullying & no & $\begin{array}{l}\text { teenagers (9th } \\
\text { grade) }\end{array}$ & $\begin{array}{l}927 \text { Victorian students on their traditional and } \\
\text { cyberbullying perpetration and victimization; } \\
\text { longitudinal study from } 2006 \text { (grade 9) to } \\
2010 \text { (young adulthood) }\end{array}$ \\
\hline $\begin{array}{l}\text { Hinduja and } \\
\text { Patchin (2008) }\end{array}$ & yes(0.942) & no & $\begin{array}{l}\text { self-report cyberbullying } \\
\text { and victimization }\end{array}$ & no & teenagers & 1378 youth students \\
\hline $\begin{array}{l}\text { Hinduja and } \\
\text { Patchin (2013) }\end{array}$ & yes $(2.777)$ & no & self-report cyberbullying & no & $\begin{array}{l}\text { teenagers (12th } \\
\text { grade) }\end{array}$ & $\begin{array}{l}\text { Random sample survey of } 440012 \text { th grade } \\
\text { students on their thoughts on cyberbullying }\end{array}$ \\
\hline $\begin{array}{l}\text { Hoff and } \\
\text { Mitchell } \\
(2009)(q)\end{array}$ & no & no & cyberbullying incidents & no & $\begin{array}{l}\text { university (range } \\
\text { 18-24) }\end{array}$ & $\begin{array}{l}351 \text { students in a public research University in } \\
\text { New England about cyberbullying }\end{array}$ \\
\hline $\begin{array}{l}\text { Jang et al. } \\
\text { (2014) }\end{array}$ & yes $(2.694)$ & $\begin{array}{l}\text { general strain } \\
\text { theory }\end{array}$ & self-report cyberbullying & no & $\begin{array}{l}\text { teenagers (grade } \\
\text { 8) }\end{array}$ & $\begin{array}{l}\text { 5-year longitudinal study with } 3449 \text { Korean } \\
\text { students, start from grade } 8 \text { to grade to one } \\
\text { year after their graduation from high school }\end{array}$ \\
\hline $\begin{array}{l}\text { Juvonen and } \\
\text { Gross (2008) }\end{array}$ & yes (1.434) & no & self-report cyberbullying & no & $\begin{array}{l}\text { children / } \\
\text { teenagers (range } \\
\text { 12-17) } \\
\end{array}$ & 1454 children age between $12-17$ \\
\hline
\end{tabular}




\begin{tabular}{|c|c|c|c|c|c|c|}
\hline Citation & $\begin{array}{l}\text { ISI rated } \\
\text { journal? } \\
\text { (impact } \\
\text { factor) }\end{array}$ & Used theory? & Specific DV & $\begin{array}{l}\text { Examines } \\
\text { effects of the IT } \\
\text { artifact? }\end{array}$ & $\begin{array}{l}\text { Type of } \\
\text { participants } \\
\text { (mean years of } \\
\text { age) }\end{array}$ & Context of study \\
\hline $\begin{array}{l}\text { Kokkinos et al. } \\
\text { (2013) }\end{array}$ & no & no & $\begin{array}{l}\text { self-report cyberbullying / } \\
\text { victimization experiences }\end{array}$ & no & children & $\begin{array}{l}\text { Random sample survey of } 300 \text { Greek pre-- } \\
\text { teenage students }\end{array}$ \\
\hline $\begin{array}{l}\text { Kowalski and } \\
\text { Limber (2007) }\end{array}$ & yes (3.612) & no & self-report cyberbullying & no & $\begin{array}{l}\text { children / } \\
\text { teenagers (grades } \\
6,7,8 \text { ) }\end{array}$ & $\begin{array}{l}3767 \text { middle school students in grades } 6,7 \text {, } \\
\text { and } 8\end{array}$ \\
\hline $\begin{array}{l}\text { Kowalski et al. } \\
\text { (2012) }\end{array}$ & yes(1.447) & no & self-report cyberbullying & no & $\begin{array}{l}\text { teenagers (mean } \\
15.2 \text { ) }\end{array}$ & $\begin{array}{l}4510 \text { students in from eight schools in } \\
\text { different regions of the United States about } \\
\text { their experience of traditional and cyber } \\
\text { bullying }\end{array}$ \\
\hline Li (2007) & yes(1.52 ) & no & $\begin{array}{l}\text { self-report whether have } \\
\text { cyberbullying or not }\end{array}$ & no & $\begin{array}{l}\text { teenagers (grade } \\
\text { 7) }\end{array}$ & $\begin{array}{l}197 \text { grade seven students from China and } 264 \\
\text { grade seven students from Canada }\end{array}$ \\
\hline $\begin{array}{l}\text { Li and Fung } \\
(2012)\end{array}$ & book & no & self-report cyberbullying & no & $\begin{array}{l}\text { teenagers (under } \\
\text { 18) }\end{array}$ & $\begin{array}{l}\text { Book that focuses on frequency of } \\
\text { victimization. }\end{array}$ \\
\hline $\begin{array}{l}\text { Low and } \\
\text { Espelage } \\
\text { (2013) }\end{array}$ & yes $(2.368)$ & $\begin{array}{l}\text { social learning } \\
\text { theory }\end{array}$ & $\begin{array}{l}\text { self-report cyberbullying } \\
\text { and offline bullying }\end{array}$ & no & $\begin{array}{l}\text { teenagers (mean } \\
\text { 13.9) }\end{array}$ & $\begin{array}{l}1023 \text { students in grades 5-7 from four } \\
\text { Midwestern middle schools in US }\end{array}$ \\
\hline $\begin{array}{l}\text { Lyndon et al. } \\
\text { (2011) }\end{array}$ & yes $(2.182)$ & $\begin{array}{l}\text { attachment } \\
\text { theory \& routine } \\
\text { activities theory }\end{array}$ & self-report cyberbullying & no & $\begin{array}{l}\text { university (mean } \\
\text { 19) }\end{array}$ & $\begin{array}{l}411 \text { university student; DVs are two kinds of } \\
\text { specific stalking related with Ex-partners: } \\
\text { engage in cyber obsessional pursuit (COP) and } \\
\text { obsessive relational pursuit (ORI) }\end{array}$ \\
\hline $\begin{array}{l}\text { Menesini et al. } \\
\text { (2013) }\end{array}$ & yes $(2.841)$ & no & self-report cyberbullying & no & $\begin{array}{l}\text { teenagers (mean } \\
15.6)\end{array}$ & 390 adolescents aged $14-18$ \\
\hline $\begin{array}{l}\text { Mishna et al. } \\
\text { (2012) }\end{array}$ & yes (1.105) & no & self-report cyberbullying & no & $\begin{array}{l}\text { children / } \\
\text { teenagers (grades } \\
6,7,10,11 \text { ) }\end{array}$ & $\begin{array}{l}2186 \text { students in grade 6, 7, 10, } 11 \text { from } 33 \\
\text { schools }\end{array}$ \\
\hline $\begin{array}{l}\text { Müller et al. } \\
\text { (2014) }\end{array}$ & yes(2.182) & no & self-report cyberbullying & no & $\begin{array}{l}\text { teenagers (mean } \\
13.3 \text { ) }\end{array}$ & $\begin{array}{l}934 \text { students in } 12 \text { Berlin primary and } \\
\text { secondary schools }\end{array}$ \\
\hline $\begin{array}{l}\text { Navarro and } \\
\text { Jasinski (2012) }\end{array}$ & yes $(0.31)$ & $\begin{array}{l}\text { routine activities } \\
\text { theory }\end{array}$ & self-report cyberbullying & no & teenagers & National sample of 935 teenagers \\
\hline $\begin{array}{l}\text { Nicol and } \\
\text { Fleming (2010) }\end{array}$ & no & $\begin{array}{l}\text { theories of } \\
\text { aggression }\end{array}$ & $\begin{array}{l}\text { self-report mobile-phone } \\
\text { cyberbullying }\end{array}$ & no & $\begin{array}{l}\text { teenagers (mean } \\
\text { 14.5) }\end{array}$ & 348 student from 5 high schools \\
\hline $\begin{array}{l}\text { Patchin and } \\
\text { Hinduja (2010) }\end{array}$ & yes $(1.722)$ & $\begin{array}{l}\text { general strain } \\
\text { theory }\end{array}$ & self-report cyberbullying & no & $\begin{array}{l}\text { children / } \\
\text { teenagers (grades } \\
6-8 \text { ) }\end{array}$ & $\begin{array}{l}1963 \text { students in } 30 \text { middle schools in US for } \\
\text { their traditional bullying and cyberbullying } \\
\text { experience }\end{array}$ \\
\hline $\begin{array}{l}\text { Pornari and } \\
\text { Wood (2010) }\end{array}$ & yes $(2.275)$ & $\begin{array}{l}\text { SCT, } \\
\text { neutralization }\end{array}$ & self-report cyberbullying & no & $\begin{array}{l}\text { teenagers (mean } \\
13.3 \text { ) }\end{array}$ & $\begin{array}{l}339 \text { students in years } 7 \text { to } 9 \text { (mainly studied } \\
\text { offline aggression but has a small portion of } \\
\text { survey for cyber aggression) }\end{array}$ \\
\hline
\end{tabular}




\begin{tabular}{|c|c|c|c|c|c|c|}
\hline Citation & $\begin{array}{l}\text { ISI rated } \\
\text { journal? } \\
\text { (impact } \\
\text { factor) }\end{array}$ & Used theory? & Specific DV & $\begin{array}{l}\text { Examines } \\
\text { effects of the IT } \\
\text { artifact? }\end{array}$ & $\begin{array}{l}\text { Type of } \\
\text { participants } \\
\text { (mean years of } \\
\text { age) }\end{array}$ & Context of study \\
\hline $\begin{array}{l}\text { (Raskauskas } \\
\text { and Stoltz } \\
\text { 2007) }\end{array}$ & yes (4.141) & no & $\begin{array}{l}\text { self-report traditional } \\
\text { bullying and cyberbullying }\end{array}$ & no & $\begin{array}{l}\text { teenagers (mean } \\
15.4 \text { ) }\end{array}$ & 83 adolescents from ages 13 to 18 \\
\hline $\begin{array}{l}\text { Renati et al. } \\
(2012)\end{array}$ & yes (2.182) & no & self-report cyberbullying & no & $\begin{array}{l}\text { teenagers (mean } \\
16.1 \text { ) }\end{array}$ & $\begin{array}{l}819 \text { adolescents randomly selected from } \\
\text { multiple cities in Italian }\end{array}$ \\
\hline $\begin{array}{l}\text { Riebel et al. } \\
\text { (2009) }\end{array}$ & No & no & self-report cyberbullying & no & $\begin{array}{l}\text { children / } \\
\text { teenagers (mean } \\
\text { 13) }\end{array}$ & 1987 pupils from 6 to 19 years of age \\
\hline $\begin{array}{l}\text { Schultze- } \\
\text { Krumbholz and } \\
\text { Scheithauer } \\
\text { (2009) }\end{array}$ & yes $(1.036)$ & no & self-report cyberbullying & no & children & Student sample (unknown sample size) \\
\hline $\begin{array}{l}\text { Smith et al. } \\
\text { (2008) }\end{array}$ & yes $(6.459)$ & no & self-report cyberbullying & no & $\begin{array}{l}\text { children / } \\
\text { teenagers (range } \\
11-16) \\
\end{array}$ & $\begin{array}{l}92 \text { pupils from } 14 \text { schools }+ \text { another } 533 \\
\text { pupils from } 5 \text { schools }\end{array}$ \\
\hline $\begin{array}{l}\text { Sontag et al. } \\
(2011)\end{array}$ & yes $(2.777)$ & no & self-report cyberbullying & no & $\begin{array}{l}\text { children (mean } \\
12.89 \text { ) }\end{array}$ & 300 children \\
\hline $\begin{array}{l}\text { Steffgen et al. } \\
\text { (2011) }\end{array}$ & yes(2.182) & no & self-report cyberbullying & no & $\begin{array}{l}\text { teenagers (mean } \\
15.9)\end{array}$ & $\begin{array}{l}2070 \text { students on their experience of } \\
\text { cyberbullying }\end{array}$ \\
\hline $\begin{array}{l}\text { Topçu et al. } \\
(2008)\end{array}$ & yes(2.71) & no & $\begin{array}{l}\text { self-report cyberbullying } \\
\text { and cyber-victimization }\end{array}$ & no & $\begin{array}{l}\text { teenagers (range } \\
14-15)\end{array}$ & $\begin{array}{l}\text { Convenience sample survey of } 183 \text { middle } \\
\text { school students on their experience on } \\
\text { cyberbullying and cyber-victimization (only } \\
\text { demographic variables) }\end{array}$ \\
\hline $\begin{array}{l}\text { Treviño et al. } \\
\text { (2006) }\end{array}$ & yes $(1.757)$ & no & self-report cyberbullying & no & $\begin{array}{l}\text { teenagers (grades } \\
7-9 \text { ) }\end{array}$ & $\begin{array}{l}264 \text { students from junior high school; only } \\
\text { studied gender differences (no other variables) }\end{array}$ \\
\hline Udris (2014) & yes $(2.694)$ & no & self-report cyberbullying & disinhibition & $\begin{array}{l}\text { teenagers (mean } \\
16.3 \text { ) }\end{array}$ & $\begin{array}{l}\text { Convenience sample survey of } 887 \text { high } \\
\text { school students on their experience of } \\
\text { cyberbullying }\end{array}$ \\
\hline $\begin{array}{l}\text { Varjas et al. } \\
(2010)(q)\end{array}$ & no & no & $\begin{array}{l}\text { self-report cyberbullying } \\
\text { motivations }\end{array}$ & $\begin{array}{l}\text { anonymity, } \\
\text { disinhibition }\end{array}$ & $\begin{array}{l}\text { teenagers (mean } \\
\text { 18) }\end{array}$ & 20 high school students \\
\hline $\begin{array}{l}\text { Vazsonyi et al. } \\
\text { (2012) }\end{array}$ & yes (1.721) & no & $\begin{array}{l}\text { self-report cyberbullying } \\
\text { and offline bullying }\end{array}$ & no & $\begin{array}{l}\text { children / } \\
\text { teenagers (range } \\
6-16) \\
\end{array}$ & $\begin{array}{l}\text { Random sample survey of } 1,000 \text { youths } \\
\text { (cross-cultural research) }\end{array}$ \\
\hline Walker (2012) & thesis & $\begin{array}{l}\text { social } \\
\text { dominance } \\
\text { theory }\end{array}$ & self-report cyberbullying & no & $\begin{array}{l}\text { university (18- } \\
\text { 24) }\end{array}$ & $\begin{array}{l}438 \text { university students. Focused on the extent } \\
\text { of using technology }\end{array}$ \\
\hline $\begin{array}{l}\text { Walrave and } \\
\text { Heirman } \\
(2011)\end{array}$ & yes $(0.833)$ & no & self-report cyberbullying & no & $\begin{array}{l}\text { teenagers (mean } \\
15.1 \text { ) }\end{array}$ & $\begin{array}{l}1318 \text { secondary school pupils in Belgium for } \\
\text { their cyberbullying experience }\end{array}$ \\
\hline
\end{tabular}




\begin{tabular}{|l|l|l|l|l|l|l|}
\hline Citation & $\begin{array}{l}\text { ISI rated } \\
\text { journal? } \\
\text { (impact } \\
\text { factor) }\end{array}$ & Used theory? & Specific DV & $\begin{array}{l}\text { Examines } \\
\text { effects of the IT } \\
\text { artifact? }\end{array}$ & $\begin{array}{l}\text { Type of } \\
\text { participants } \\
\text { (mean years of } \\
\text { age) }\end{array}$ \\
\hline $\begin{array}{l}\text { Williams and } \\
\text { Guerra (2007) }\end{array}$ & yes (3.612) & no & self-report cyberbullying & no & $\begin{array}{l}\text { Children / } \\
\text { teenagers (grades } \\
5,8,11)\end{array}$ & $\begin{array}{l}3399 \text { youth at 2005 and 2293 in the original } \\
\text { sample at 2006 }\end{array}$ \\
\hline Wright (2014) & yes (2.182) & no & self-report cyberbullying & anonymity & $\begin{array}{l}\text { teenagers (grade } \\
7 \text { and 8) }\end{array}$ & $\begin{array}{l}\text { 274 students (mean age 12.62) in Midwestern } \\
\text { middle school }\end{array}$ \\
\hline $\begin{array}{l}\text { Xiao and } \\
\text { Wong (2013) }\end{array}$ & no & $\begin{array}{l}\text { social cognitive } \\
\text { theory }\end{array}$ & $\begin{array}{l}\text { self-report cyberbullying } \\
\text { and cyber-victimization }\end{array}$ & no & $\begin{array}{l}\text { university } \\
\text { (mainly range } \\
\text { from 18 to 25) }\end{array}$ & $\begin{array}{l}\text { 288 university students in Hong Kong, most of } \\
\text { whom aged 18-25 }\end{array}$ \\
\hline Yang (2012) & yes(0.670) & no & self-report cyberbullying & no & $\begin{array}{l}\text { children / } \\
\text { teenagers (under } \\
18)\end{array}$ & $\begin{array}{l}1,232 \text { sample in 16 elementary, junior, high } \\
\text { schools in Tailai about their cyberbullying } \\
\text { experience }\end{array}$ \\
\hline Ybarra (2004) & yes (2.71) & no & self-report cyberbullying & no & $\begin{array}{l}\text { teenagers (Mean } \\
14.1)\end{array}$ & $\begin{array}{l}\text { An analysis of Youth Internet Safety Survey } \\
\text { result }\end{array}$ \\
\hline
\end{tabular}

(q) = qualitative study (four studies were qualitative; all other studies were empirical surveys) 


\section{APPENDIX B. LITERATURE REVIEW OF LEADING SSSL AND SLT STUDIES}

In this appendix, we briefly review the key literature on SSSL, which further explains and positions the research gaps and opportunities we are building on. Our primary purpose was to review SSSL, and these articles are detailed in Table B.1. Importantly, IT artifacts that foster disinhibition is the key online social structure driver of our SSSL-based model, which is geared toward explaining cyberbullying. The move from the offline to the online context involves a dramatic shift in the structure of the social environment, and the IT artifacts we propose strongly represent that shift and thus influence the social learning constructs that encourage cyberbullying. We further explain our position, based on this review of the SSSL literature.

First, we have good reason to believe that those social structure variables that influence social learning in the physical world, including structural correlates, social organizations, socioeconomic correlates and difference social location in reference groups, are less relevant in studying social learning of cyber deviance. According to O'Keeffe et al. (2011, p. 801), social media provides individuals with the "new forms of socialization", and we contend that this new socialization along with the IT artifact makes these traditional structures less relevant. In other words, different from social learning in the physical world, social structure variables such as age, location and social economic status may not greatly influence the reference groups with whom an individual interacts with through social media. Hence, adopting SSSL in the social media cyberbullying context, it is important to identify social structure variables that are more relevant to one's online network, rather than the personal network in the physical world.

However, according to our review, only two studies (Holt et al. 2010; Morris and Higgins 2010) have investigated cyber deviance using the SSSL framework. But neither Holt et al. (2010) nor Morris and Higgins (2010) have studied how IT artifacts of social media influence the social learning process online. Moreover, the social structure variables investigated in these two studies are mainly adopted from previous SSSL literature in the physical context.

Second, most of the extant studies on SSSL focused on the first, second, and fourth components of social structure variables ${ }^{1}$; however, empirical studies on the third dimension of social structure (i.e. theoretically defined structural variables) and efforts on such theoretical integration are absent and still at the preliminary stage (Akers 2011a). In the offline context, Akers (2011a) suggested that social disorganization and conflict from social disorganization and anomie theories are two possible theory-driven predictors for social learning offline, however, these two theory driven factors are not relevant to the IT artifact of social media, and are less effective in explaining how social media makes the social learning process online different from that in the conventional offline society.

Third, most of the SSSL papers we reviewed in Table B.1 investigated deviant behaviors of adolescents or university students (except one study investigating elderly drinking behavior). Few of them focused on adults' deviant behaviors - particularly adults with work experience. It is not clear whether social learning mechanisms will hold for adults in the context of cyberbullying.

Summarizing the above research opportunities, in this study we specifically emphasize the theoretically defined social structure variables in the SSSL framework and propose that perceived anonymity (with its five subconstructs) is a social media artifact that changes the social learning process and thus influences an increase in cyberbullying in adults.

\footnotetext{
${ }^{1}$ Recall that the four social structure categories are as follows: (1) structural crime correlates, which include geographical, societal, cultural, social, and community differences; (2) sociodemographic and socioeconomic crime correlates, which deal with one's location in the social structure (e.g., age, gender, income, employment, class, and religion); (3) theoretically defined structural causes, such as those involving social disorganization (e.g., class conflict, oppression, and racism); and (4) different social locations of primary and secondary reference groups (e.g., family, peers, church, school, and work).
} 
Table B.1. Overview of Key SSSL studies

\begin{tabular}{|c|c|c|c|c|c|c|c|c|}
\hline Study & $\begin{array}{l}\text { Cyber or } \\
\text { offline } \\
\text { deviance }\end{array}$ & Sample & $\begin{array}{l}\text { Multiple } \\
\text { behaviors } \\
\text { as } \\
\text { dependent } \\
\text { variables } \\
\end{array}$ & $\begin{array}{l}\text { Cross- } \\
\text { sectional } \\
\text { data } \\
\text { collection }\end{array}$ & $\begin{array}{l}\text { Context / } \\
\text { dependent } \\
\text { variable }\end{array}$ & $\begin{array}{l}\text { Social structure } \\
\text { variables }\end{array}$ & $\begin{array}{l}\text { Social learning } \\
\text { variables }\end{array}$ & $\begin{array}{l}\text { Test of mediation } \\
\text { effects (and interaction } \\
\text { effects). }\end{array}$ \\
\hline $\begin{array}{l}\text { Holt et al. } \\
\text { (2010) }\end{array}$ & $\begin{array}{l}\text { Cyber } \\
\text { deviance }\end{array}$ & $\begin{array}{l}\text { University } \\
\text { students }\end{array}$ & Combine & $\begin{array}{l}\text { Cross- } \\
\text { sectional }\end{array}$ & $\begin{array}{l}\text { Cyber- } \\
\text { deviance } \\
\text { frequency } \\
\text { (combine five } \\
\text { deviant } \\
\text { behaviors in } \\
\text { DV) }\end{array}$ & $\begin{array}{l}\text { Race, gender, } \\
\text { employment, } \\
\text { skill, year in } \\
\text { school }\end{array}$ & $\begin{array}{l}\text { Social learning as } \\
\text { second-order } \\
\text { constructs, } \\
\text { including } \\
\text { neutralizing } \\
\text { definition }\end{array}$ & $\begin{array}{l}\text { Social learning } \\
\text { "mediates the effect of } \\
\text { race and gender on } \\
\text { cyber-deviance" (p. 50). }\end{array}$ \\
\hline $\begin{array}{l}\text { Morris } \\
\text { and } \\
\text { Higgins } \\
(2010)\end{array}$ & $\begin{array}{l}\text { Cyber } \\
\text { deviance }\end{array}$ & $\begin{array}{l}\text { University } \\
\text { students }\end{array}$ & $\begin{array}{l}\text { Scenario } \\
\text { (three } \\
\text { vignettes) }\end{array}$ & $\begin{array}{l}\text { Cross- } \\
\text { sectional }\end{array}$ & $\begin{array}{l}\text { Possibility to } \\
\text { engage in } \\
\text { digital piracy }\end{array}$ & $\begin{array}{l}\text { Region, age, } \\
\text { gender, race }\end{array}$ & $\begin{array}{l}\text { Social learning as } \\
\text { second-order } \\
\text { constructs (three } \\
\text { dimensions except } \\
\text { imitation) }\end{array}$ & $\begin{array}{l}\text { Full mediation for age } \\
\text { and gender; partial } \\
\text { mediation for race and } \\
\text { region. }\end{array}$ \\
\hline $\begin{array}{l}\text { Kim et al. } \\
\text { (2013) }\end{array}$ & $\begin{array}{l}\text { Offline } \\
\text { deviance }\end{array}$ & $\begin{array}{l}\text { High school } \\
\text { students }\end{array}$ & Single & $\begin{array}{l}\text { Cross- } \\
\text { sectional }\end{array}$ & $\begin{array}{l}\text { Frequency of } \\
\text { adolescents' } \\
\text { alcohol use }\end{array}$ & $\begin{array}{l}\text { Population } \\
\text { density, gender, } \\
\text { residential } \\
\text { mobility, public } \\
\text { welfare, type of } \\
\text { school, } \\
\text { religiosity }\end{array}$ & $\begin{array}{l}\text { Association } \\
\text { definitions, } \\
\text { reinforcement, } \\
\text { imitation }\end{array}$ & $\begin{array}{l}\text { Influences of social } \\
\text { structural variables } \\
\text { (population density, } \\
\text { residential mobility, type } \\
\text { of school, and } \\
\text { religiosity) were } \\
\text { substantially mediated } \\
\text { by social learning } \\
\text { variables. }\end{array}$ \\
\hline $\begin{array}{l}\text { Capece } \\
\text { and } \\
\text { Lanza- } \\
\text { Kaduce } \\
\text { (2013) }\end{array}$ & $\begin{array}{l}\text { Offline } \\
\text { deviance }\end{array}$ & $\begin{array}{l}\text { University } \\
\text { students }\end{array}$ & Single & $\begin{array}{l}\text { Cross- } \\
\text { sectional }\end{array}$ & $\begin{array}{l}\text { Binge } \\
\text { drinking (in } \\
\text { last two } \\
\text { weeks) }\end{array}$ & $\begin{array}{l}\text { Age, gender, } \\
\text { race, marital } \\
\text { status, } \\
\text { fraternity/sororit } \\
\text { y affiliations, } \\
\text { family } \\
\text { relationship, } \\
\text { academic status, } \\
\text { work and student } \\
\text { status. }\end{array}$ & $\begin{array}{l}\text { Anticipated } \\
\text { rewards, } \\
\text { anticipated } \\
\text { punishers, and the } \\
\text { definition of the } \\
\text { drinking climate } \\
\text { on campus }\end{array}$ & $\begin{array}{l}\text { Both mediations effects } \\
\text { of social learning } \\
\text { variables, and the } \\
\text { interaction effects } \\
\text { among social structure } \\
\text { and social learning } \\
\text { variables are tested. } \\
\text { Some of the mediation } \\
\text { effects are supported, as } \\
\text { well as five interaction } \\
\text { terms. }\end{array}$ \\
\hline
\end{tabular}




\begin{tabular}{|c|c|c|c|c|c|c|c|c|}
\hline $\begin{array}{l}\text { Orcutt } \\
\text { and } \\
\text { Schwabe } \\
(2012)\end{array}$ & $\begin{array}{l}\text { Offline } \\
\text { deviance }\end{array}$ & $\begin{array}{l}\text { African } \\
\text { American } \\
\text { adolescents }\end{array}$ & Single & 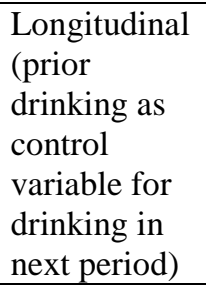 & $\begin{array}{l}\text { Levels of } \\
\text { deviant } \\
\text { drinking }\end{array}$ & Gender, race & $\begin{array}{l}\text { Differential } \\
\text { association and } \\
\text { definition }\end{array}$ & $\begin{array}{l}\text { Mediation effects of } \\
\text { social learning or social } \\
\text { bonding variables are } \\
\text { not supported. }\end{array}$ \\
\hline $\begin{array}{l}\text { Lee et al. } \\
(2004)\end{array}$ & $\begin{array}{l}\text { Offline } \\
\text { deviance }\end{array}$ & $\begin{array}{l}\text { Students } \\
\text { (grades } 7 \\
\text { through 12) }\end{array}$ & $\begin{array}{l}\text { Single } \\
\text { (separate } \\
\text { analysis for } \\
\text { two deviant } \\
\text { behaviors) }\end{array}$ & $\begin{array}{l}\text { Cross- } \\
\text { sectional }\end{array}$ & $\begin{array}{l}\text { Adolescent } \\
\text { alcohol and } \\
\text { marijuana } \\
\text { behavior }\end{array}$ & $\begin{array}{l}\text { Gender, class, } \\
\text { age, family } \\
\text { structure, } \\
\text { community size }\end{array}$ & $\begin{array}{l}\text { Social learning as } \\
\text { second-order } \\
\text { constructs }\end{array}$ & $\begin{array}{l}\text { Social learning variable, } \\
\text { except imitation, has } \\
\text { substantial mediating } \\
\text { effects. }\end{array}$ \\
\hline $\begin{array}{l}\text { Warr } \\
(1993)\end{array}$ & $\begin{array}{l}\text { Offline } \\
\text { deviance }\end{array}$ & $\begin{array}{l}\text { Youth aged } \\
11-21\end{array}$ & $\begin{array}{l}\text { Single } \\
\text { (separate } \\
\text { analysis for } \\
\text { four } \\
\text { deviant } \\
\text { behaviors) }\end{array}$ & $\begin{array}{l}\text { Longitudinal } \\
\text { archive data } \\
\text { (but mainly } \\
\text { cross- } \\
\text { sectional data } \\
\text { analysis) }\end{array}$ & $\begin{array}{l}\text { Various } \\
\text { delinquency, } \\
\text { such as } \\
\text { alcohol use, } \\
\text { marijuana } \\
\text { use, theft, } \\
\text { burglary, } \\
\text { cheating }\end{array}$ & Ages & $\begin{array}{l}\text { Differential } \\
\text { association }\end{array}$ & $\begin{array}{l}\text { Effects of age on } \\
\text { delinquencies are } \\
\text { partially mediated by } \\
\text { social learning. }\end{array}$ \\
\hline $\begin{array}{l}\text { Durkin et } \\
\text { al. (2005) }\end{array}$ & $\begin{array}{l}\text { Offline } \\
\text { deviance }\end{array}$ & $\begin{array}{l}\text { University } \\
\text { students }\end{array}$ & Single & $\begin{array}{l}\text { Cross- } \\
\text { sectional }\end{array}$ & $\begin{array}{l}\text { Binge } \\
\text { drinking (in } \\
\text { last two } \\
\text { weeks) }\end{array}$ & $\begin{array}{l}\text { Gender, race, } \\
\text { fraternity / } \\
\text { sorority } \\
\text { membership }\end{array}$ & $\begin{array}{l}\text { Differential } \\
\text { association (best } \\
\text { friends and } \\
\text { friends with } \\
\text { whom they most } \\
\text { frequently } \\
\text { associate with), } \\
\text { Reinforcement } \\
\text { (punishing / } \\
\text { rewarding } \\
\text { reactions of peers, } \\
\text { relative costs / } \\
\text { rewards), } \\
\text { definition (general } \\
\text { definition, } \\
\text { specific } \\
\text { definition, } \\
\text { neutralization) }\end{array}$ & $\begin{array}{l}\text { Social learning variables } \\
\text { mediate the effects of } \\
\text { social structural } \\
\text { variables. }\end{array}$ \\
\hline $\begin{array}{l}\text { Verrill } \\
(2005) \\
\end{array}$ & $\begin{array}{l}\text { Offline } \\
\text { deviance }\end{array}$ & $\begin{array}{l}\text { High school } \\
\text { and middle }\end{array}$ & $\begin{array}{l}\text { Combine } \\
\text { six }\end{array}$ & $\begin{array}{l}\text { Cross- } \\
\text { sectional }\end{array}$ & $\begin{array}{l}\text { Various } \\
\text { delinquency }\end{array}$ & $\begin{array}{l}\text { Population } \\
\text { density, race }\end{array}$ & $\begin{array}{l}\text { Social learning as } \\
\text { second-order }\end{array}$ & $\begin{array}{l}\text { Social learning variables } \\
\text { partially mediate the }\end{array}$ \\
\hline
\end{tabular}




\begin{tabular}{|c|c|c|c|c|c|c|c|c|}
\hline & & $\begin{array}{l}\text { school } \\
\text { students }\end{array}$ & $\begin{array}{l}\text { different } \\
\text { kinds of } \\
\text { offline } \\
\text { deviances }\end{array}$ & & & $\begin{array}{l}\text { composition, } \\
\text { gender } \\
\text { composition, age } \\
\text { composition, } \\
\text { race, gender, } \\
\text { age, SES, ethnic } \\
\text { heterogeneity, } \\
\text { residential } \\
\text { mobility. }\end{array}$ & $\begin{array}{l}\text { constructs: } \\
\text { differential } \\
\text { association } \\
\text { (number of } \\
\text { delinquent } \\
\text { friends), } \\
\text { differential } \\
\text { reinforcement } \\
\text { (rewards, costs), } \\
\text { and definition } \\
\text { (general negative } \\
\text { definition and } \\
\text { neutralizing } \\
\text { definition). }\end{array}$ & $\begin{array}{l}\text { effects of some social } \\
\text { structural variables. }\end{array}$ \\
\hline $\begin{array}{l}\text { Lanza- } \\
\text { Kaduce et } \\
\text { al. (2006) }\end{array}$ & $\begin{array}{l}\text { Offline } \\
\text { deviance }\end{array}$ & $\begin{array}{l}\text { University } \\
\text { students }\end{array}$ & Single & $\begin{array}{l}\text { Cross- } \\
\text { sectional }\end{array}$ & $\begin{array}{l}\text { Drinking } \\
\text { before sexual } \\
\text { intercourse }\end{array}$ & Gender, Greek & $\begin{array}{l}\text { Reinforcement } \\
\text { (risks and } \\
\text { rewards) }\end{array}$ & $\begin{array}{l}\text { Effects of gender on } \\
\text { drinking before sexual } \\
\text { intercourse is mediated } \\
\text { by social learning. }\end{array}$ \\
\hline $\begin{array}{l}\text { Akers and } \\
\text { Lee } \\
(1999)\end{array}$ & $\begin{array}{l}\text { Offline } \\
\text { deviance }\end{array}$ & $\begin{array}{l}\text { Secondary } \\
\text { school } \\
\text { students }\end{array}$ & Single & $\begin{array}{l}\text { Cross- } \\
\text { sectional }\end{array}$ & $\begin{array}{l}\text { Marijuana } \\
\text { use }\end{array}$ & Age & $\begin{array}{l}\text { Social learning as } \\
\text { second-order } \\
\text { constructs (three } \\
\text { dimensions except } \\
\text { imitation) }\end{array}$ & $\begin{array}{l}\text { Social learning fully } \\
\text { mediates the influence } \\
\text { of age on marijuana use. }\end{array}$ \\
\hline $\begin{array}{l}\text { Holland- } \\
\text { Davis } \\
(2006)\end{array}$ & $\begin{array}{l}\text { Offline } \\
\text { deviance }\end{array}$ & $\begin{array}{l}\text { Adolescents } \\
\text { in grades } 7 \\
\text { through } 12\end{array}$ & $\begin{array}{l}\text { Single } \\
\text { (separate } \\
\text { analysis for } \\
\text { three } \\
\text { deviant } \\
\text { behaviors) }\end{array}$ & $\begin{array}{l}\text { Cross- } \\
\text { sectional }\end{array}$ & $\begin{array}{l}\text { Alcohol use, } \\
\text { marijuana } \\
\text { use, illicit } \\
\text { drug use }\end{array}$ & $\begin{array}{l}\text { Age, gender, } \\
\text { father's } \\
\text { occupation, } \\
\text { population of the } \\
\text { local community } \\
\text { surrounding each } \\
\text { school, poverty, } \\
\text { ethnic } \\
\text { heterogeneity, } \\
\text { residential } \\
\text { mobility }\end{array}$ & $\begin{array}{l}\text { Differential } \\
\text { association } \\
\text { (number of } \\
\text { friends), } \\
\text { differential } \\
\text { reinforcement } \\
\text { (balance of good } \\
\text { vs. bad } \\
\text { outcomes), } \\
\text { definition (general } \\
\text { negative } \\
\text { definition), } \\
\text { imitation. }\end{array}$ & $\begin{array}{l}\text { Influences of most social } \\
\text { structure variables are } \\
\text { substantially mediated } \\
\text { by social learning } \\
\text { predictors. }\end{array}$ \\
\hline $\begin{array}{l}\text { Whaley et } \\
\text { al. (2011) }\end{array}$ & $\begin{array}{l}\text { Offline } \\
\text { deviance }\end{array}$ & $\begin{array}{l}\text { High school } \\
\text { and middle } \\
\text { school } \\
\text { students }\end{array}$ & $\begin{array}{l}\text { Single } \\
\text { (separate } \\
\text { analysis for } \\
\text { four }\end{array}$ & $\begin{array}{l}\text { Cross- } \\
\text { sectional } \\
\text { archive data }\end{array}$ & $\begin{array}{l}\text { Binge } \\
\text { drinking, } \\
\text { marijuana, } \\
\text { ecstasy, }\end{array}$ & $\begin{array}{l}\text { Multi-level } \\
\text { structural } \\
\text { variables: }\end{array}$ & Peer approval & $\begin{array}{l}\text { Most social structure } \\
\text { variables are partially or } \\
\text { fully mediated by peer } \\
\text { approval. }\end{array}$ \\
\hline
\end{tabular}




\begin{tabular}{|c|c|c|c|c|c|c|c|c|}
\hline & & & $\begin{array}{l}\text { deviant } \\
\text { behaviors) }\end{array}$ & & $\begin{array}{l}\text { methampheta } \\
\text { mine use }\end{array}$ & $\begin{array}{l}\text { Level 1: parent } \\
\text { education, grade, } \\
\text { race. } \\
\text { Level 2: } \\
\text { residential } \\
\text { instability, } \\
\text { population size, } \\
\text { race } \\
\text { composition. }\end{array}$ & & \\
\hline $\begin{array}{l}\text { Hoffmann } \\
\text { (2003) }\end{array}$ & $\begin{array}{l}\text { Offline } \\
\text { deviance }\end{array}$ & $\begin{array}{l}\text { Students } \\
\text { (grades } 8 \\
\text { through 10) }\end{array}$ & $\begin{array}{l}\text { Combine } \\
\text { six types of } \\
\text { delinquent } \\
\text { behavior } \\
\text { (conducted } \\
\text { in the past } \\
\text { year) }\end{array}$ & $\begin{array}{l}\text { Longitudinal } \\
\text { study: the } \\
\text { period for } \\
\text { data } \\
\text { collection } \\
\text { lasts for two } \\
\text { years }\end{array}$ & $\begin{array}{l}\text { Various } \\
\text { delinquency }\end{array}$ & $\begin{array}{l}\text { Racial } \\
\text { segregation } \\
\text { index, percent of } \\
\text { female-headed } \\
\text { households, } \\
\text { percent of } \\
\text { jobless males, } \\
\text { and percent of } \\
\text { poverty }\end{array}$ & $\begin{array}{l}\text { Conventional } \\
\text { definitions, and } \\
\text { peer expectations }\end{array}$ & $\begin{array}{l}\text { The direct influence of } \\
\text { community-level social } \\
\text { structure variables on } \\
\text { delinquency is not } \\
\text { mediated by social } \\
\text { learning. }\end{array}$ \\
\hline $\begin{array}{l}\text { Akers } \\
\text { (2011b) }\end{array}$ & $\begin{array}{l}\text { Offline } \\
\text { deviance }\end{array}$ & $\begin{array}{l}\text { Elderly in } \\
\text { Florida and } \\
\text { New Jersey } \\
\text { (aged } 60 \text { and } \\
\text { above) }\end{array}$ & Single & $\begin{array}{l}\text { Cross- } \\
\text { sectional }\end{array}$ & $\begin{array}{l}\text { Heavy } \\
\text { alcohol } \\
\text { drinking }\end{array}$ & $\begin{array}{l}\text { Retirement } \\
\text { community } \\
\text { context (income, } \\
\text { education, age, } \\
\text { density) }\end{array}$ & $\begin{array}{l}\text { Social learning as } \\
\text { second-order } \\
\text { constructs (three } \\
\text { dimensions except } \\
\text { imitation) }\end{array}$ & $\begin{array}{l}\text { Social learning fully } \\
\text { mediates the influence } \\
\text { of community context } \\
\text { on alcohol drinking. }\end{array}$ \\
\hline
\end{tabular}

Note: None of these studies considered IT artifacts of any kind in altering social structures. 


\section{ONLINE APPENDIX C. MEASUREMENT DETAILS}

Here, we document two sets of measures: The first set in Section 1, is asked once before we ask about four cyberbullying behaviors. The second set relates to four specific cyberbullying behaviors and their matched social learning variables.

\section{SECTION 1 Measures: Pre-deviance / cyberbullying questions}

Crucially, the measures in this section are measured ONCE to establish counter-explanations and SSSL contextual variables that affect SL. We essentially replicate Aker's common community context variables (and add a couple related to the Internet) but then uniquely add the technology artifact context of perceived anonymity.

\begin{tabular}{|c|c|}
\hline Construct (Source) & Scaling, Prompt, and Items \\
\hline Age & Age [logic: must be 18 or older or not eligible for study] \\
\hline Web browsing years & $\begin{array}{l}\text { Approximately which was the first year you started using any form of graphical Web browser? (e.g., } \\
\text { Internet Explorer, Chrome, Firefox, Safari, Opera, Netscape, Mosaic) } \\
\text { [logic: must be } 5 \text { years or more] }\end{array}$ \\
\hline Hours per day on social media & $\begin{array}{l}\text { On average, how many hours do you spend each day using social media? [logic: must be }>0 \text { or not } \\
\text { eligible for study] } \\
\text { - } 0 \text { minutes (none) } \\
\text { - } 1 \text { to } 15 \text { minutes } \\
\text { - } 16 \text { to } 30 \text { minutes } \\
\text { - } \quad 31 \text { minutes to } 1 \text { hour } \\
\text { - }>1 \text { hour }<=2 \text { hours } \\
\text { - }>4 \text { hours }<=4 \text { hours }<=7 \text { hours } \\
\text { - } \quad>7 \text { hours }<=12 \text { hours } \\
\text { - } \quad>12 \text { hours }<=18 \text { hours } \\
\text { - } \quad>18 \text { hours }\end{array}$ \\
\hline Social media type & $\begin{array}{l}\text { Prompt: Please consider all forms of social media in the last year (12 months) that you have used } \\
\text { at least once to cyberbully other people. Select the one form of social media you have most used for } \\
\text { cyberbullying: } \\
\text { - } \quad \text { Facebook } \\
\text { - } \quad \text { Twitter } \\
\text { - } \quad \text { Online discussion forum, including blogs, Reddit, Disqus, Tumblr, etc. } \\
\text { - Instant Messaging (IM), including Snapchat, WhatsApp, WeChat, etc. } \\
\text { - Instagram } \\
\text { - } \\
\text { Ask.fm }\end{array}$ \\
\hline
\end{tabular}




\begin{tabular}{|c|c|}
\hline & $\begin{array}{l}\text { - } \text { Google+ } \\
\text { - } \text { Pinterest } \\
\text { - Yine } \\
\text { - } \text { Other social media (specify) } \\
\text { - I have not used any form of social media to cyberbully others in last } 12 \text { months } \\
\text { [logic: not eligible for study if they select last choice] }\end{array}$ \\
\hline Residence & $\begin{array}{l}\text { In which country do you currently live? [Logic: full country drop down; must only select the US or } \\
\text { not eligible for study] }\end{array}$ \\
\hline Gender & Gender (male, female, other) \\
\hline Education & $\begin{array}{l}\text { Education: } \\
\text { - less than high school } \\
\text { - high school or equivalent } \\
\text { - } \text { some university but no degree } \\
\text { - } \text { associate's degree } \\
\text { - } \text { masteror's degree } \\
\text { - doctoral degree }\end{array}$ \\
\hline Employment status & What is your employment status?: student, unemployed, part-time, full-time \\
\hline Income & $\begin{array}{ll}\text { Select your current yearly income range, including all sources: } \\
\text { - } & \$ 0 \\
\text { - } & \$ 1 \text { to } \$ 10,000 \\
\text { - } & \$ 30,001 \text { to } \$ 30,000 \\
\text { - } & \$ 50,001 \text { to } \$ 50,000 \\
\text { - } & \$ 70,001 \text { to } \$ 100,000 \\
\text { - } & \$ 100,001 \text { to } \$ 150,000 \\
\text { - } & \$ 150,001 \text { to } \$ 200,000 \\
\text { - } & \$ 300,001 \text { to } \$ 300,000 \\
\text { - } & \$ 500,000 \text { to } \$ 500,000 \\
\text { - } & \$ 1,000,001+ \\
\end{array}$ \\
\hline Work years & How many total years have you worked full time in your lifetime? \\
\hline $\begin{array}{l}\text { Organizational commitment (OC) (Herath and Rao } \\
\text { 2009) }\end{array}$ & $\begin{array}{l}\text { Prompt: "To what degree do the following statements accurately represent you and your current } \\
\text { work organization or the last place you worked (if you're a student, think of the school where you } \\
\text { study)?” }\end{array}$ \\
\hline \multirow{2}{*}{$\begin{array}{l}\text { Reflective first-order [outside of model; used as a } \\
\text { marker variable to detect any potential common- }\end{array}$} & Scaling: 7-point Likert-type scale anchored on 1=very strongly disagree...7=very strongly agree. \\
\hline & OC1. I am willing to put in a great deal of effort, beyond what is normally expected, in order to help \\
\hline
\end{tabular}




\begin{tabular}{|c|c|}
\hline \multirow[t]{3}{*}{ method bias] } & my organization be successful. \\
\hline & OC2. I really care about the fate of my organization. \\
\hline & OC3. For me, my organization is the best of all possible organizations for which to work. \\
\hline \multirow[t]{11}{*}{$\begin{array}{l}\text { cyberbullying anonymity modified from social } \\
\text { anonymity measures by Lowry et al. (2009) } \\
\text { Social anonymity is second-order factor composed of } \\
\text { the following reflective constructs: }\end{array}$} & $\begin{array}{l}\text { Prompt: You indicated that you have used [social media] in the past year for cyberbullying. We } \\
\text { would like to know your beliefs about using [social media] for cyberbullying. When cyberbullying } \\
\text { other people using [social media] which of the following best describes your opinions about [the } \\
\text { social media itself] in bullying others? "I believe that..." } \\
\text { Scaling: } 7 \text {-point Likert-type scale anchored on 1=very strongly disagree...7=very strongly agree. }\end{array}$ \\
\hline & A-LI1. ...my personal identity won’t be provided. \\
\hline & A-LI2. ...my cyberbullying is entirely secret. \\
\hline & A-CS1....the system(s) will not identify me without my permission. \\
\hline & A-CS2.... no names will be attached to the systems' internal records unless that is what I want. \\
\hline & A-DR1. ... it is impossible to make me more accountable than others for cyberbullying. \\
\hline & A-DR2. ... it is impossible to blame me personally for any cyberbullying. \\
\hline & $\begin{array}{l}\text { A-PX1....others can't physically see what I am doing on my computer screen (e.g., walk by and see } \\
\text { what I'm writing). }\end{array}$ \\
\hline & $\begin{array}{l}\text { A-PX2. ...I feel assured that no one can physically observe me in the act of cyberbullying (e.g., } \\
\text { look over my shoulder when I'm typing). }\end{array}$ \\
\hline & $\begin{array}{l}\text { A-KO1....my behavior(s) do NOT have enough distinguishing characteristics that would allow } \\
\text { other people to identify me as the originator of the cyberbullying. }\end{array}$ \\
\hline & $\begin{array}{l}\text { A-KO2.... it is impossible to identify me as the origin of the cyberbullying based on my personal } \\
\text { characteristics. }\end{array}$ \\
\hline
\end{tabular}




\section{SECTION 2 MEASURES: Questions Asked for Each of the Four Forms of cyberbullying}

To get a strong sample without a heavy cognitive burden, each respondent will provide their attitudes about four separately presented cyberbullying behaviors. They will only be asked about ONE behavior at a time. Each behavior will also be randomly ordered in presentation to mitigate any potential ordering effects. After asking about their participation in the ONE behavior, they will be asked about the social learning variables that relate only to that behavior.

Crucially, these questions are framed as current attitudes/beliefs about the behaviors, as is done in most of Aker's studies (e.g., Akers 2011a) and many others in the SLT literature. The assumption is that these attitudes are based on their experiences and general cognitions, so there is no attempt to ask the respondents what they were thinking when they committed the behavior (if they have done so) or if they would commit the behavior in the future. Then, similar to Holt et al. (2010), these responses are aggregated into a larger model-thus ensuring one-to-one correspondence of the variance of the social learning variables to the reported frequency of each specific deviant behavior. Also, like Aker's studies, we ask them about their attitudes toward the behavior even if they have not committed the specific behavior in the last year. This better tests the model by providing fully orthogonal responses solely on their attitudes, whether then have done the behavior or not.

\begin{tabular}{|c|c|}
\hline \multirow[t]{4}{*}{ The frequency scaling is from Akers et al. (1989) } & $\begin{array}{l}\text { Logic: Again, only one behavior will be shown at a time and this will be matched to one selected } \\
\text { social media artifact they have used most for cyberbullying in the last year. Each respondent will fill } \\
\text { out the social learning variables only for this behavior, and they will do this four times, in random } \\
\text { presentation order, from the following set of four cyberbullying behaviors. } \\
\text { Prompt: Instructions: At this point in the survey, we want to know your honest opinions about } \\
\text { performing a specific form of cyberbullying on [selected tool], whether or not you have done this } \\
\text { behavior. } \\
\text { The cyberbullying behavior we want you to think about doing is: [selected behavior] } \\
\text { Going forward, EVERY question we ask only pertains to this cyberbullying behavior on [tool]. } \\
\text { First, for this particular behavior, in the past year, what is the frequency you have done this one } \\
\text { behavior on [tool]? } \\
\text { - Never } \\
\text { - One time } \\
\text { - Monthly (up to 2-3 times a month) } \\
\text { - Weekly (up to 3-4 times a week) }\end{array}$ \\
\hline & CBF-B1. Post something hurtful, rude, inappropriate, or mean that targets someone. \\
\hline & $\begin{array}{l}\text { CBF-B2. Publicly embarrass or prank someone with true information or photos that are potentially } \\
\text { harmful. }\end{array}$ \\
\hline & CBF-B3. Spread a rumor or untrue information about someone. \\
\hline
\end{tabular}




\begin{tabular}{|c|c|}
\hline & CBF-B4. Send threatening or harassing messages, or send messages after someone told you to stop. \\
\hline \multirow[t]{3}{*}{$\begin{array}{l}\text { Cyberbullying situational moral beliefs (SM); } \\
\text { adapted from Hu et al. (2011) } \\
\text { [maps to social learning definitions: positive] }\end{array}$} & $\begin{array}{l}\text { Prompt: Again, going forward, we want to know your honest beliefs about this behavior [behavior] } \\
\text { on [tool]. There are no right or wrong answers, so please do your best to provide us with an accurate } \\
\text { response. } \\
\text { Enter your agreement with the following statements about committing this behavior on [tool]. } \\
\text { "In moral or ethical terms, this behavior is... } \\
\text { SM1. ...morally unacceptable." }\end{array}$ \\
\hline & SM2. ... against my moral beliefs.” \\
\hline & SM3. ...the wrong thing to do.” \\
\hline \multirow[t]{2}{*}{$\begin{array}{l}\text { Cyberbullying negative social influence: norms } \\
\text { (NSIN); based on subjective norms scaling suggested } \\
\text { by Ajzen (1991) }\end{array}$} & $\begin{array}{l}\text { Prompt: 'The following people think it is okay / acceptable to engage in this behavior [behavior] on } \\
\text { [tool]" }\end{array}$ \\
\hline & NSN1. My "real world” friends. \\
\hline \multirow{5}{*}{$\begin{array}{l}\text { Norms modified for Aker et al.’s (1989) differential } \\
\text { association (norms) construct of those in one’s social } \\
\text { circle. Subjective norms are the degree to which one } \\
\text { perceives important referent others approve / } \\
\text { disapprove of specific behaviors (Ajzen 1991). }\end{array}$} & NSN2. My family members. \\
\hline & NSN3. My work colleagues. \\
\hline & NSN4. Other people who are important to me. \\
\hline & NSN5. Other online friends. \\
\hline & NSN6. Other anonymous people online whom I follow or chat with. \\
\hline \multirow[t]{8}{*}{$\begin{array}{l}\text { cyberbullying negative social influence: frequency } \\
\text { (NSIF) } \\
\text { Based on NSIN modified for Aker et al.'s (1989) } \\
\text { differential association (frequency) construct of } \\
\text { those in one's social circle. } \\
\text { [maps to social learning differential association: } \\
\text { frequency] }\end{array}$} & $\begin{array}{l}\text { To the best of your knowledge, about how often have each of the following people done the same } \\
\text { behavior [behavior] on [tool] in the past year? } \\
\text { - Never } \\
\text { - One time } \\
\text { - Monthly (up to 2-3 times a month) } \\
\text { - Weekly (up to 3-4 times a week) } \\
\text { - Daily } \\
\text { - Not sure }\end{array}$ \\
\hline & NSF1. My “real world” friends. \\
\hline & NSF2. My family members. \\
\hline & NSF3. My work colleagues. \\
\hline & NSF4. Other people who are important to me. \\
\hline & NSF5. Other online friends. \\
\hline & NSF6. Other anonymous people online whom I follow or chat with. \\
\hline & Prompt: "Considering all factors, I feel that doing this behavior [behavior] on [tool] would...” \\
\hline
\end{tabular}




\begin{tabular}{|c|c|}
\hline cyberbullying benefits (BEN); adapted from & \\
\hline Bulgurcu et al. (2010) & BEN1. ... be favorable to me. \\
\hline & BEN2. ... result in benefits to me. \\
\hline [maps to social learning differential reinforcement & BEN3. ...create advantages for me. \\
\hline (negative)] & BEN4. ...provide gains to me. \\
\hline cyberbullying costs (CST); adapted from Bulgurcu & CST1....be harmful to me. \\
\hline et al. (2010) & CST2. ...impact me negatively. \\
\hline & CST3. ...create disadvantages for me. \\
\hline $\begin{array}{l}\text { [maps to social learning differential reinforcement } \\
\text { (positive)] }\end{array}$ & CST4....generate losses for me. \\
\hline $\begin{array}{l}\text { Neutralization explanation: To decrease cognitive } \\
\text { major kind of neutralization, and we continue to trea } \\
\text { respondent's current attitudes about the behavior-n } \\
\text { [maps to social learning definitions: neutralization ( }\end{array}$ & $\begin{array}{l}\text { d and to follow Aker's (2011a) approach to neutralization, we have provided only one item for each } \\
\text { as a formative construct. Importantly, this is framed like Aker's approach to be about the } \\
\text { thinking about the neutralization technique they used to justify the behavior. } \\
\text { gative)] }\end{array}$ \\
\hline $\begin{array}{l}\text { Neutralization: Denial of responsibility (N-DR); } \\
\text { Original from Sykes and Matza (1957); } \\
\text { item from Siegal (2011) }\end{array}$ & N1. “It is okay to do if you aren’t really intending to do it and it just happens.” \\
\hline $\begin{array}{l}\text { Neutralization: Denial of injury (N-DI); Original } \\
\text { from Sykes and Matza (1957); item from Siegal } \\
\text { (2011) }\end{array}$ & N2. "It isn’t a big deal. There is no possible meaningful harm.” \\
\hline $\begin{array}{l}\text { Neutralization: Denial of victim (N-DV); Original } \\
\text { from Sykes and Matza (1957); item from Cromwell } \\
\text { and Thurman (2003) }\end{array}$ & N3. "It is okay if the target person(s) deserve it; what comes around goes around (i.e., karma).” \\
\hline $\begin{array}{l}\text { Neutralization: Condemning } \\
\text { the condemners (N-CC); Original from Sykes and } \\
\text { Matza (1957); item from Siegal (2011) and } \\
\text { Cromwell and Thurman (2003) }\end{array}$ & N4. "People who condemn this behavior often do worse things themselves online.” \\
\hline $\begin{array}{l}\text { Neutralization: Appealing to higher loyalties (N- } \\
\text { AH); Original from Sykes and Matza (1957); item } \\
\text { from Hinduja (2007) }\end{array}$ & N5. "It is okay if it helps a person accomplish a greater good, such as for friends, family, or work." \\
\hline $\begin{array}{l}\text { Neutralization: Defense of necessity (N-DN); } \\
\text { Original from Minor (1981); item from Eliason and } \\
\text { Dodder (1999) and Puhakainen and Ahonen (2006) }\end{array}$ & N6. "It is okay do if the circumstances require it." \\
\hline
\end{tabular}

Scaling: 7-point Likert-type scale anchored on 1=very strongly disagree....7=very strongly agree. 


\section{ONLINE APPENDIX D. DETAILS FOR ESTABLISHING FACTORIAL VALIDITY AND}

\section{RELIABILITIES}

\section{Formative or Reflective Constructs?}

A key step in preparing to assessing factorial validity is to determine which constructs are formative and which are reflective (Diamantopoulos and Winklhofer 2001). ${ }^{\text {i }}$ We used (Cenfetelli and Bassellier 2009; Diamantopoulos and Winklhofer 2001; Petter et al. 2007) as the basis for determining which constructs were formative and which were reflective. In this assessment, the most important consideration is to see how the constructs were theoretically formed and validated in other literature, to make sure no contradictions exist in their current use, and to model the constructs consistently.

First, we reaffirmed that cyberbullying anonymity was a second-order factor composed of reflective subconstructs. We also reaffirmed that neutralization was formative, as defined in the literature (e.g., Siponen and Vance 2010). Finally, cyberbullying was also treated as formative, as each individual behavior was assessed with its own independent set of social learning independent variables. All other latent constructs were first-order reflective constructs. We thus performed factorial validity according to these classifications.

\section{Factorial Validity for the Reflective Constructs}

Factorial validity of reflective constructs is established by establishing both convergent validity and discriminant validity, two highly interrelated concepts that must coexist. Importantly, factorial validity is established in different ways for reflective and formative constructs; thus, we discuss these analyses separately.

To establish the factorial validity of our reflective constructs, we followed procedures shown by Straub Gefen and Straub (2005) and Lowry and Gaskin (2014). For an especially conservative analysis, we used two established techniques to establish convergent validity and two established techniques to establish discriminant validity. First, we examined the outer model loadings, summarized in Table D.1. Following Gefen and Straub (2005), convergent validity can be established when the $t$-values of the outer model loadings are significant. All items in the model passed these checks. Moreover, all loadings were above the 0.500 threshold.

As a second check, we correlated the latent variable scores against the indicators as a form of factor loadings and then examined the indicator loadings and cross-loadings to establish convergent validity (see Table D.2). Although this approach is typically used to establish discriminant validity (Gefen and Straub 2005), convergent validity and discriminant validity are interdependent and help establish each other (Straub et al. 2004). Thus, convergent validity is also established when each loading for a latent variable is substantially higher than those for other latent variables.

We also used two approaches to establish discriminant validity, as described in Gefen and Straub (2005) and Lowry and Gaskin (2014). First, as with convergent validity, we examined the factor loadings, but this time to ensure significant overlap did not exist between the constructs. To be extra conservative, and since we had more reflective items than was minimally needed, we dropped any items that had cross-loadings below 0.700 . Second, we used the approach of examining the square roots of the AVEs described in Fornell and Larcker (1981); Staples et al. $(1999)^{i i}$ To be extra conservative, we also ensured that all AVEs were 0.500 or higher. Strong discriminant validity was shown for all subconstructs, using both approaches. All of the AVE thresholds were exceeded for all latent constructs, as summarized in Table D.3, which also displays the measurement model statistics for all first-order reflective constructs.

\section{Mono-Method Bias}

Several steps were taken a priori to decrease the likelihood of common-method bias from occurring in our data collection, as discussed in the main text. However, all data was collected using a similar-looking online survey; thus, we tested for common-method bias to establish that it was not a likely negative factor in the data remaining for our analysis.

The most important problem of common-method bias is that it causes the constructs of a model to be highly correlated with each other. Thus, our main approach was simply to examine a correlation matrix of the constructs and to determine if any of the correlations were above 0.90 , which is evidence that common-method bias may exist (Pavlou et al. 2007). These correlations—all of which were significantly below the 0.90 threshold—are presented in 
the measurement model statistics in Table D.3. ${ }^{\text {ii }}$

In addition, we had gathered a marker variable, organizational commitment, which we could use to further establish that common-method bias exists. A marker variable is one that is prone to social desirability bias (i.e., people are likely to respond highly in the affirmative) and that is unrelated to the theoretical model being tested. The idea here is that if common-method bias existed, then all (or most) constructs would be highly correlated, including the marker variable. The simplest way to test this was to run the marker variable in the correlation matrix of all variables. We did so against all the major constructs of our model and found trivial to low correlations (see Table D.4a). This provides further evidence common-method bias is likely not a legitimate threat to this study.

\section{Checking for Multicollinearity}

Another key threat to check for with SEM is the potential threat of multicollinearity, and this is especially important to assess with models that have formative second-order measurement. We followed the latest standards in checking for multicollinearity with all construct items. All of the first-order reflective constructs had VIFs well below the conservative threshold of 5.0 (the highest had a VIF of 3.980; most were below 3.0). All of the formative second-order constructs had VIFs well below the conservative threshold of 3.3 (the highest had a VIF of 2.597). Variance inflation factors (VIFs) less than 10 are traditionally viewed as justification for a model's lack of multicollinearity, with 5.0 being ideal. However our results are in line with the latest most stringent standards (reflective constructs should be below 5.0 and formative should be below 3.3) (Cenfetelli and Bassellier 2009). Hence, we conclude that our model does not suffer from multicollinearity. See Table D.4b.

\section{Reliabilities}

As a product of our rigorous pre-analysis, all our reflective subconstructs exhibited high levels of reliability. To establish reliability, PLS computes a composite reliability score as part of its integrated model analysis. This score is a more accurate measurement of reliability than Cronbach's alpha because it does not assume that loadings or error terms of the items are equal. However, we also included Cronbach's alpha as a conservative check, and all these values were above the minimum threshold of 0.700 . These values are summarized in Table D.4b and indicate strong reliabilities.

\section{Factorial Validity of Formative Constructs}

Again, cyberbullying anonymity is a second-order formative construct composed of first-order reflective subconstructs, and all have been theoretically and empirically validated in the previous literature. Likewise, cyberbullying and neutralization are both treated as first-order formative constructs. In this section, we further rigorously establish validity of these constructs to improve our analysis. Establishing factorial validity for formative indicators is more challenging than validating reflective indicators, because the established procedures that exist to determine the validity of reflective measures do not apply to formative measures (Petter et al. 2007; Straub et al. 2004), and the procedures for validating formative measures are less known and established (Diamantopoulos and Winklhofer 2001) though standards are beginning to emerge (Cenfetelli and Bassellier 2009). ${ }^{\text {iv }}$ We use these latest standards published in (Cenfetelli and Bassellier 2009).

However, the biggest potential issue that must be addressed is multicollinearity (Cenfetelli and Bassellier 2009). We thus assessed the possibility of multicollinearity among all the indicators in the model, as performed in the previous section. Variance inflation factors (VIFs) less than 10 are traditionally viewed as justification for a model's lack of multicollinearity, with 5.0 being ideal, but formative methodologists have recently called for a more stringent cutoff of less than 3.3 to be used (Cenfetelli and Bassellier 2009; Diamantopoulos and Siguaw 2006; Petter et al. 2007). Again, this conservative threshold was established for all reflective and formatives constructs in our model-whether they were second- or first-order formative.

A final step for validating our three second-order formative constructs, we assessed the absolute indicator contributions (i.e., zero-order correlations) of the individual items for each second-order construct against the overall average of for each construct. The goal in this step is to improve internal validity by removing items not exhibiting a significant association with the overall construct (Cenfetelli and Bassellier 2009; Diamantopoulos and Winklhofer 2001). ${ }^{v}$ All of the items showed significant associations with the overall measure at the 0.05 level of significance, and thus none of these items were removed during this step. We also performed inter-item correlational diagnostics to assess if there were unusually high correlations amongst the formative indicators, as these can significantly 
weaken formative measures (Diamantopoulos and Siguaw 2006). As expected, all of the cyberbullying items were correlated but all were well below a high correlation threshold of 0.900 . These statistics are summarized in Tables B.5a-B.5c for cyberbullying, neutralization, and cyberbullying anonymity, respectively.

\section{Summary of Pre-Analysis Validation}

Our pre-analyses show that our data exhibit strong factorial validity of the reflective and formative constructs, little multicollinearity, strong reliabilities, and that they lack mono-method bias. In summary, the results of our validation procedures show that our model data meets or exceeds the rigorous validation standards expected in modern research (Straub et al. 2004) - particularly for PLS analysis for reflective constructs (Gefen and Straub 2005) and formative constructs (Cenfetelli and Bassellier 2009; Diamantopoulos and Siguaw 2006; Petter et al. 2007).

Table D.1. Outer Model Weights to Establish Convergent Validity

\begin{tabular}{|c|c|c|c|}
\hline Second-order construct & First-order construct & Items & Loading \\
\hline \multirow{10}{*}{$\begin{array}{l}\text { cyberbullying } \\
\text { anonymity }\end{array}$} & \multirow[t]{2}{*}{ Confidence in the system } & a_cs1 & $0.931 * * *$ \\
\hline & & a_cs2 & $0.920 * * *$ \\
\hline & \multirow[t]{2}{*}{ Diffused responsibility } & a_dr1 & $0.828 * * *$ \\
\hline & & a_dr2 & $0.927 * * *$ \\
\hline & \multirow[t]{2}{*}{ Knowledge of others } & a_ko1 & $0.878 * * *$ \\
\hline & & a_ko2 & $0.922 * * *$ \\
\hline & \multirow[t]{2}{*}{ Lack of identification } & a_li1 & $0.889 * * *$ \\
\hline & & a_li2 & $0.930 * * *$ \\
\hline & \multirow[t]{2}{*}{ Proximity } & a_px1 & $0.920 * * *$ \\
\hline & & a_px2 & $0.893 * * *$ \\
\hline \multirow[t]{16}{*}{ cyberbullying Benefits } & \multirow[t]{4}{*}{ B1 benefits } & b1_ben1 & $0.916 * * *$ \\
\hline & & b1_ben2 & $0.933 * * *$ \\
\hline & & b1_ben3 & $0.924 * * *$ \\
\hline & & b1_ben4 & $0.933 * * *$ \\
\hline & \multirow[t]{4}{*}{ B2 benefits } & b2_ben1 & $0.916 * * *$ \\
\hline & & b2_ben2 & $0.939 * * *$ \\
\hline & & b2_ben3 & $0.918 * * *$ \\
\hline & & b2_ben4 & $0.924 * * *$ \\
\hline & \multirow[t]{4}{*}{ B3 benefits } & b3_ben1 & $0.932 * * *$ \\
\hline & & b3_ben2 & $0.920 * * *$ \\
\hline & & b3_ben3 & $0.911^{* * *}$ \\
\hline & & b3_ben4 & $0.924 * * *$ \\
\hline & \multirow[t]{4}{*}{ B4 benefits } & b4_ben1 & $0.932 * * *$ \\
\hline & & b4_ben2 & $0.942 * * *$ \\
\hline & & b4_ben3 & $0.920 * * *$ \\
\hline & & b4_ben4 & $0.925 * * *$ \\
\hline \multirow[t]{4}{*}{ cyberbullying costs } & \multirow[t]{4}{*}{ B1 costs } & b1_cst1 & $0.918 * * *$ \\
\hline & & b1_cst2 & $0.939 * * *$ \\
\hline & & b1_cst3 & $0.927 * * *$ \\
\hline & & b1_cst4 & $0.909 * * *$ \\
\hline
\end{tabular}




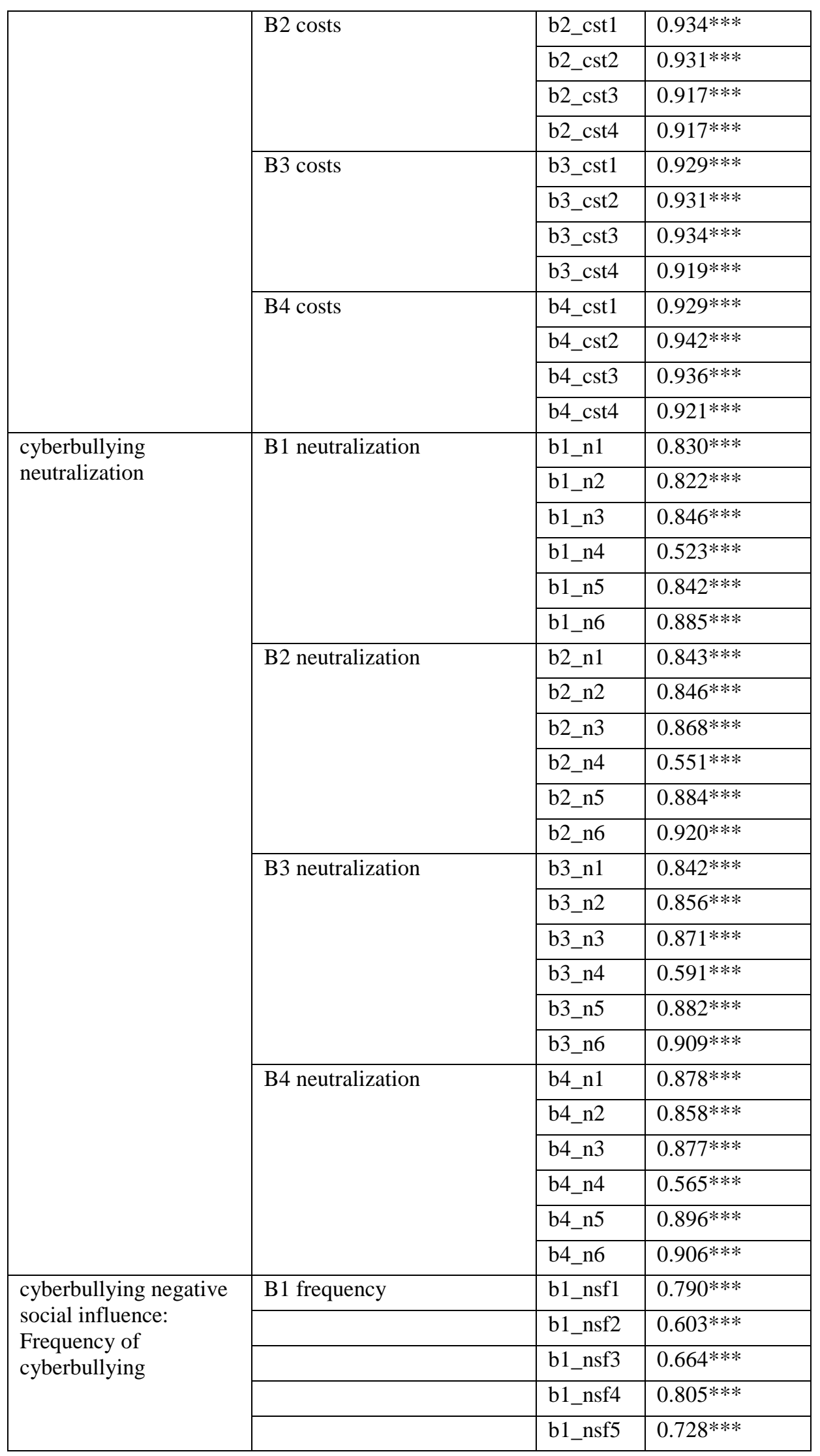




\begin{tabular}{|c|c|c|c|}
\hline & & b1_nsf6 & $0.795 * * *$ \\
\hline & B2 frequency & b2_nsf1 & $0.809 * * *$ \\
\hline & & b2_nsf2 & $0.697 * * *$ \\
\hline & & b2_nsf3 & $0.733 * * *$ \\
\hline & & b2_nsf4 & $0.831^{* * *}$ \\
\hline & & b2_nsf5 & $0.772 * * *$ \\
\hline & & b2_nsf6 & $0.693 * * *$ \\
\hline & B3 frequency & b3_nsf1 & $0.795 * * *$ \\
\hline & & b3_nsf2 & $0.681 * * *$ \\
\hline & & b3_nsf3 & $0.723 * * *$ \\
\hline & & b3_nsf4 & $0.789 * * *$ \\
\hline & & b3_nsf5 & $0.786 * * *$ \\
\hline & & b3_nsf6 & $0.723 * * *$ \\
\hline & B4 frequency & b4_nsf1 & $0.811^{* * *}$ \\
\hline & & b4_nsf2 & $0.655 * * *$ \\
\hline & & b4_nsf3 & $0.697 * * *$ \\
\hline & & b4_nsf4 & $0.794 * * *$ \\
\hline & & b4_nsf5 & $0.764 * * *$ \\
\hline & & b4_nsf6 & $0.688 * * *$ \\
\hline cyberbullying negative & B1 norms & b1_nsn1 & $0.828 * * *$ \\
\hline social influence: Norms & & b1_nsn2 & $0.709 * * *$ \\
\hline & & b1_nsn3 & $0.745 * * *$ \\
\hline & & b1_nsn4 & $0.853 * * *$ \\
\hline & & b1_nsn5 & $0.836 * * *$ \\
\hline & & b1_nsn6 & $0.737 * * *$ \\
\hline & B2 norms & b2_nsn1 & $0.874 * * *$ \\
\hline & & b2_nsn2 & $0.809 * * *$ \\
\hline & & b2_nsn3 & $0.802^{* * *}$ \\
\hline & & b2_nsn4 & $0.888 * * *$ \\
\hline & & b2_nsn5 & $0.852 * * *$ \\
\hline & & b2_nsn6 & $0.751 * * *$ \\
\hline & B3 norms & b3_nsn1 & $0.845^{* * *}$ \\
\hline & & b3_nsn2 & $0.767 * * *$ \\
\hline & & b3_nsn3 & $0.803 * * *$ \\
\hline & & b3_nsn4 & $0.871 * * *$ \\
\hline & & b3_nsn5 & $0.817 * * *$ \\
\hline & & b3_nsn6 & $0.721 * * *$ \\
\hline & B4 norms & b4_nsn1 & $0.861^{* * *}$ \\
\hline & & b4_nsn2 & $0.788 * * *$ \\
\hline & & b4_nsn3 & $0.810 * * *$ \\
\hline & & b4_nsn4 & $0.890 * * *$ \\
\hline
\end{tabular}




\begin{tabular}{|c|c|c|c|}
\hline & & b4_nsn5 & $0.830 * * *$ \\
\hline & & b4_nsn6 & $0.719 * * *$ \\
\hline \multirow{12}{*}{$\begin{array}{l}\text { cyberbullying } \\
\text { Situational morality }\end{array}$} & \multirow[t]{3}{*}{ B1 situational morality } & b1_sm1 & $0.947 * * *$ \\
\hline & & b1_sm2 & $0.940 * * *$ \\
\hline & & b1_sm3 & $0.939 * * *$ \\
\hline & \multirow[t]{3}{*}{ B2 situational morality } & b2_sm1 & $0.958 * * *$ \\
\hline & & b2_sm2 & $0.960 * * *$ \\
\hline & & b2_sm3 & $0.949 * * *$ \\
\hline & \multirow[t]{3}{*}{ B3 situational morality } & b3_sm1 & $0.936 * * *$ \\
\hline & & b3_sm2 & $0.942 * * *$ \\
\hline & & b3_sm3 & $0.938 * * *$ \\
\hline & \multirow[t]{3}{*}{ B4 situational morality } & b4_sm1 & $0.948 * * *$ \\
\hline & & b4_sm2 & $0.959 * * *$ \\
\hline & & b4_sm3 & $0.954 * * *$ \\
\hline
\end{tabular}

*** $=p<0.001$; no items were dropped; B1 = Post something hurtful, rude, inappropriate, or mean that targets someone; B2 = Publicly embarrass or prank someone with true information or photos that are potentially harmful; B3 = Spread a rumor or untrue information about someone; B4 = Send threatening or harassing messages, or send messages after someone told you to stop. 
Table D.2. Correlations of Latent Variable Scores against the Indicators to Establish Convergent and Discriminant Validity) (Part 1 of 3)

\begin{tabular}{|c|c|c|c|c|c|c|c|c|c|c|}
\hline Items & A-CS & a-dr & a-ko & a-li & $a-p x$ & $\begin{array}{l}\text { benefits } \\
\text { B1 }\end{array}$ & $\begin{array}{l}\text { benefits } \\
\text { B2 }\end{array}$ & $\begin{array}{l}\text { benefits } \\
\text { B3 }\end{array}$ & $\begin{array}{l}\text { benefits } \\
\text { B4 }\end{array}$ & costs B1 \\
\hline a_cs1 & 0.931 & 0.551 & 0.598 & 0.690 & 0.377 & 0.105 & 0.083 & 0.181 & 0.133 & -0.168 \\
\hline a_cs2 & 0.920 & 0.524 & 0.609 & 0.705 & 0.395 & 0.122 & 0.076 & 0.146 & 0.143 & -0.206 \\
\hline a_dr1 & 0.480 & 0.828 & 0.562 & 0.534 & 0.368 & 0.125 & 0.110 & 0.174 & 0.129 & -0.237 \\
\hline a_dr2 & 0.540 & 0.927 & 0.601 & 0.599 & 0.334 & 0.149 & 0.133 & 0.232 & 0.197 & -0.207 \\
\hline a_ko1 & 0.579 & 0.588 & 0.878 & 0.664 & 0.403 & 0.081 & 0.030 & 0.141 & 0.121 & -0.197 \\
\hline a_ko2 & 0.595 & 0.602 & 0.922 & 0.672 & 0.403 & 0.111 & 0.069 & 0.131 & 0.134 & -0.169 \\
\hline a_li1 & 0.769 & 0.580 & 0.693 & 0.889 & 0.437 & 0.131 & 0.070 & 0.179 & 0.134 & -0.193 \\
\hline a_li2 & 0.620 & 0.595 & 0.661 & 0.930 & 0.422 & 0.133 & 0.107 & 0.224 & 0.181 & -0.198 \\
\hline a_px1 & 0.356 & 0.309 & 0.387 & 0.384 & 0.920 & 0.100 & 0.072 & 0.108 & 0.083 & -0.171 \\
\hline a_px2 & 0.403 & 0.410 & 0.427 & 0.476 & 0.893 & 0.086 & 0.070 & 0.104 & 0.059 & -0.166 \\
\hline b1_ben1 & 0.112 & 0.135 & 0.094 & 0.122 & 0.068 & 0.916 & 0.452 & 0.489 & 0.502 & -0.438 \\
\hline b1_ben2 & 0.119 & 0.140 & 0.101 & 0.142 & 0.108 & 0.933 & 0.476 & 0.505 & 0.508 & -0.394 \\
\hline b1_ben3 & 0.109 & 0.154 & 0.097 & 0.136 & 0.104 & 0.924 & 0.490 & 0.511 & 0.522 & -0.379 \\
\hline b1_ben4 & 0.115 & 0.154 & 0.108 & 0.138 & 0.104 & 0.933 & 0.489 & 0.506 & 0.491 & -0.408 \\
\hline b2_ben1 & 0.071 & 0.119 & 0.031 & 0.078 & 0.063 & 0.465 & 0.916 & 0.491 & 0.429 & -0.217 \\
\hline b2_ben2 & 0.098 & 0.136 & 0.062 & 0.099 & 0.089 & 0.474 & 0.939 & 0.491 & 0.456 & -0.191 \\
\hline b2_ben3 & 0.068 & 0.122 & 0.058 & 0.111 & 0.061 & 0.472 & 0.918 & 0.480 & 0.445 & -0.210 \\
\hline b2_ben4 & 0.082 & 0.139 & 0.060 & 0.078 & 0.077 & 0.494 & 0.924 & 0.474 & 0.463 & -0.202 \\
\hline b3_ben1 & 0.172 & 0.241 & 0.161 & 0.220 & 0.129 & 0.510 & 0.506 & 0.932 & 0.477 & -0.277 \\
\hline b3_ben2 & 0.165 & 0.209 & 0.148 & 0.217 & 0.092 & 0.502 & 0.477 & 0.920 & 0.497 & -0.244 \\
\hline b3_ben3 & 0.162 & 0.193 & 0.110 & 0.184 & 0.089 & 0.494 & 0.469 & 0.911 & 0.455 & -0.261 \\
\hline b3_ben4 & 0.155 & 0.223 & 0.133 & 0.205 & 0.120 & 0.493 & 0.479 & 0.924 & 0.447 & -0.224 \\
\hline b4_ben1 & 0.145 & 0.166 & 0.133 & 0.156 & 0.071 & 0.511 & 0.452 & 0.465 & 0.932 & -0.254 \\
\hline b4_ben2 & 0.131 & 0.169 & 0.122 & 0.149 & 0.072 & 0.517 & 0.462 & 0.480 & 0.942 & -0.234 \\
\hline b4_ben3 & 0.128 & 0.189 & 0.140 & 0.171 & 0.078 & 0.492 & 0.433 & 0.467 & 0.920 & -0.226 \\
\hline b4_ben4 & 0.149 & 0.191 & 0.135 & 0.177 & 0.074 & 0.507 & 0.454 & 0.480 & 0.925 & -0.222 \\
\hline b1_cst1 & -0.165 & -0.227 & -0.178 & -0.197 & -0.151 & -0.410 & -0.223 & -0.265 & -0.233 & 0.918 \\
\hline
\end{tabular}




\begin{tabular}{|c|c|c|c|c|c|c|c|c|c|c|}
\hline b1_cst2 & -0.178 & -0.228 & -0.169 & -0.188 & -0.173 & -0.428 & -0.211 & -0.268 & -0.255 & 0.939 \\
\hline b1_cst3 & -0.201 & -0.244 & -0.208 & -0.207 & -0.179 & -0.409 & -0.211 & -0.265 & -0.244 & 0.927 \\
\hline b1_cst4 & -0.202 & -0.209 & -0.191 & -0.204 & -0.186 & -0.362 & -0.170 & -0.203 & -0.192 & 0.909 \\
\hline b2_cst1 & -0.103 & -0.152 & -0.077 & -0.125 & -0.112 & -0.252 & -0.464 & -0.246 & -0.234 & 0.486 \\
\hline b2_cst2 & -0.122 & -0.169 & -0.092 & -0.139 & -0.125 & -0.259 & -0.487 & -0.262 & -0.253 & 0.468 \\
\hline b2_cst3 & -0.109 & -0.141 & -0.091 & -0.142 & -0.109 & -0.208 & -0.431 & -0.212 & -0.224 & 0.468 \\
\hline b2_cst4 & -0.126 & -0.166 & -0.086 & -0.128 & -0.114 & -0.192 & -0.426 & -0.217 & -0.217 & 0.474 \\
\hline b3_cst1 & -0.256 & -0.299 & -0.253 & -0.308 & -0.169 & -0.235 & -0.230 & -0.431 & -0.259 & 0.546 \\
\hline b3_cst2 & -0.283 & -0.280 & -0.251 & -0.323 & -0.195 & -0.243 & -0.253 & -0.442 & -0.281 & 0.512 \\
\hline b3_cst3 & -0.269 & -0.302 & -0.278 & -0.324 & -0.202 & -0.217 & -0.225 & -0.428 & -0.254 & 0.528 \\
\hline b3_cst4 & -0.255 & -0.268 & -0.235 & -0.322 & -0.201 & -0.213 & -0.215 & -0.429 & -0.243 & 0.511 \\
\hline b4_cst1 & -0.205 & -0.248 & -0.190 & -0.236 & -0.121 & -0.289 & -0.202 & -0.281 & -0.516 & 0.456 \\
\hline b4_cst2 & -0.219 & -0.243 & -0.211 & -0.261 & -0.131 & -0.312 & -0.233 & -0.316 & -0.543 & 0.485 \\
\hline b4_cst3 & -0.204 & -0.234 & -0.218 & -0.281 & -0.140 & -0.268 & -0.221 & -0.277 & -0.513 & 0.457 \\
\hline b4_cst4 & -0.195 & -0.229 & -0.204 & -0.271 & -0.134 & -0.232 & -0.178 & -0.237 & -0.467 & 0.492 \\
\hline b1_n1 & 0.137 & 0.268 & 0.180 & 0.182 & 0.166 & 0.414 & 0.285 & 0.297 & 0.297 & -0.397 \\
\hline b1_n2 & 0.209 & 0.305 & 0.209 & 0.242 & 0.223 & 0.454 & 0.263 & 0.270 & 0.297 & -0.527 \\
\hline b1_n3 & 0.147 & 0.214 & 0.132 & 0.156 & 0.167 & 0.444 & 0.274 & 0.251 & 0.260 & -0.489 \\
\hline b1_n4 & 0.084 & 0.116 & 0.079 & 0.069 & 0.143 & 0.252 & 0.155 & 0.189 & 0.194 & -0.217 \\
\hline b1_n5 & 0.128 & 0.222 & 0.142 & 0.163 & 0.163 & 0.470 & 0.314 & 0.333 & 0.339 & -0.440 \\
\hline b1_n6 & 0.115 & 0.212 & 0.114 & 0.130 & 0.159 & 0.478 & 0.273 & 0.268 & 0.269 & -0.511 \\
\hline b2_n1 & 0.040 & 0.135 & 0.048 & 0.046 & 0.057 & 0.264 & 0.512 & 0.255 & 0.281 & -0.185 \\
\hline b2_n2 & 0.097 & 0.135 & 0.073 & 0.094 & 0.020 & 0.294 & 0.536 & 0.287 & 0.327 & -0.218 \\
\hline b2_n3 & 0.075 & 0.121 & 0.054 & 0.062 & 0.069 & 0.318 & 0.508 & 0.257 & 0.304 & -0.272 \\
\hline b2_n4 & 0.030 & 0.039 & 0.001 & -0.008 & 0.067 & 0.190 & 0.289 & 0.184 & 0.168 & -0.124 \\
\hline b2_n5 & 0.036 & 0.092 & 0.028 & 0.042 & 0.050 & 0.315 & 0.555 & 0.279 & 0.329 & -0.205 \\
\hline b2_n6 & 0.062 & 0.125 & 0.061 & 0.070 & 0.075 & 0.365 & 0.561 & 0.294 & 0.337 & -0.276 \\
\hline b3_n1 & 0.170 & 0.275 & 0.189 & 0.202 & 0.148 & 0.325 & 0.345 & 0.469 & 0.348 & -0.234 \\
\hline b3_n2 & 0.231 & 0.277 & 0.187 & 0.250 & 0.124 & 0.372 & 0.375 & 0.517 & 0.418 & -0.274 \\
\hline b3_n3 & 0.206 & 0.285 & 0.240 & 0.265 & 0.156 & 0.339 & 0.312 & 0.520 & 0.348 & -0.295 \\
\hline
\end{tabular}




\begin{tabular}{|c|c|c|c|c|c|c|c|c|c|c|}
\hline b3_n4 & 0.078 & 0.103 & 0.083 & 0.071 & 0.081 & 0.214 & 0.217 & 0.317 & 0.245 & -0.117 \\
\hline b3_n5 & 0.218 & 0.262 & 0.201 & 0.255 & 0.142 & 0.345 & 0.325 & 0.507 & 0.354 & -0.250 \\
\hline b3_n6 & 0.181 & 0.257 & 0.170 & 0.220 & 0.111 & 0.358 & 0.334 & 0.533 & 0.372 & -0.266 \\
\hline b4_n1 & 0.136 & 0.229 & 0.151 & 0.151 & 0.088 & 0.321 & 0.299 & 0.328 & 0.600 & -0.216 \\
\hline b4_n2 & 0.170 & 0.247 & 0.167 & 0.196 & 0.112 & 0.352 & 0.285 & 0.340 & 0.617 & -0.277 \\
\hline b4_n3 & 0.138 & 0.207 & 0.154 & 0.163 & 0.089 & 0.337 & 0.290 & 0.296 & 0.557 & -0.298 \\
\hline b4_n4 & 0.039 & 0.078 & 0.073 & 0.035 & 0.030 & 0.201 & 0.166 & 0.192 & 0.306 & -0.098 \\
\hline b4_n5 & 0.137 & 0.199 & 0.156 & 0.166 & 0.117 & 0.363 & 0.297 & 0.310 & 0.611 & -0.227 \\
\hline b4_n6 & 0.118 & 0.186 & 0.142 & 0.146 & 0.108 & 0.362 & 0.290 & 0.323 & 0.606 & -0.270 \\
\hline b1_sm1 & -0.076 & -0.131 & -0.070 & -0.077 & -0.155 & -0.410 & -0.280 & -0.223 & -0.229 & 0.551 \\
\hline b1_sm2 & -0.083 & -0.152 & -0.087 & -0.092 & -0.165 & -0.398 & -0.276 & -0.226 & -0.224 & 0.563 \\
\hline b1_sm3 & -0.090 & -0.147 & -0.089 & -0.101 & -0.163 & -0.418 & -0.275 & -0.217 & -0.222 & 0.540 \\
\hline b2_sm1 & -0.003 & -0.055 & 0.011 & -0.018 & -0.036 & -0.248 & -0.506 & -0.222 & -0.247 & 0.269 \\
\hline b2_sm2 & -0.015 & -0.074 & 0.003 & -0.018 & -0.060 & -0.274 & -0.528 & -0.242 & -0.273 & 0.273 \\
\hline b2_sm3 & -0.032 & -0.065 & -0.002 & -0.039 & -0.067 & -0.277 & -0.526 & -0.239 & -0.259 & 0.276 \\
\hline b3_sm1 & -0.205 & -0.192 & -0.165 & -0.196 & -0.109 & -0.315 & -0.308 & -0.461 & -0.294 & 0.299 \\
\hline b3_sm2 & -0.222 & -0.233 & -0.194 & -0.221 & -0.135 & -0.309 & -0.305 & -0.502 & -0.333 & 0.293 \\
\hline b3_sm3 & -0.216 & -0.235 & -0.200 & -0.245 & -0.126 & -0.321 & -0.302 & -0.467 & -0.318 & 0.296 \\
\hline b4_sm1 & -0.119 & -0.175 & -0.125 & -0.138 & -0.085 & -0.331 & -0.257 & -0.277 & -0.504 & 0.286 \\
\hline b4_sm2 & -0.126 & -0.177 & -0.135 & -0.158 & -0.105 & -0.366 & -0.285 & -0.326 & -0.548 & 0.322 \\
\hline b4_sm3 & -0.152 & -0.218 & -0.150 & -0.167 & -0.107 & -0.354 & -0.275 & -0.318 & -0.531 & 0.317 \\
\hline b1_nsf1 & $\begin{array}{l}-0.068 \\
\end{array}$ & -0.012 & -0.047 & -0.052 & -0.032 & 0.209 & 0.157 & 0.135 & 0.123 & -0.156 \\
\hline b1_nsf2 & -0.024 & 0.013 & -0.046 & -0.045 & -0.034 & 0.132 & 0.132 & 0.101 & 0.124 & -0.022 \\
\hline b1_nsf3 & -0.035 & -0.001 & -0.026 & -0.013 & -0.012 & 0.074 & 0.067 & 0.066 & 0.064 & -0.041 \\
\hline b1_nsf4 & -0.060 & -0.014 & -0.045 & -0.040 & -0.023 & 0.171 & 0.160 & 0.109 & 0.147 & -0.114 \\
\hline b1_nsf5 & 0.012 & 0.050 & 0.049 & 0.034 & 0.098 & 0.123 & 0.093 & 0.073 & 0.038 & -0.143 \\
\hline b1_nsf6 & 0.012 & 0.042 & 0.050 & 0.028 & 0.095 & 0.129 & 0.068 & 0.086 & 0.044 & -0.158 \\
\hline b2_nsf1 & -0.048 & -0.021 & -0.044 & -0.064 & -0.042 & 0.076 & 0.325 & 0.127 & 0.138 & -0.008 \\
\hline b2_nsf2 & -0.050 & 0.006 & -0.067 & -0.024 & -0.058 & 0.092 & 0.271 & 0.113 & 0.162 & 0.029 \\
\hline b2_nsf3 & -0.025 & 0.002 & -0.043 & 0.009 & -0.044 & 0.063 & 0.205 & 0.130 & 0.108 & -0.016 \\
\hline
\end{tabular}




\begin{tabular}{|c|c|c|c|c|c|c|c|c|c|c|}
\hline b2_nsf4 & -0.028 & 0.011 & -0.039 & -0.020 & -0.026 & 0.114 & 0.297 & 0.146 & 0.159 & -0.016 \\
\hline b2_nsf5 & -0.035 & -0.006 & -0.026 & -0.049 & 0.016 & 0.112 & 0.275 & 0.114 & 0.109 & -0.053 \\
\hline b2_nsf6 & -0.040 & -0.012 & -0.016 & -0.041 & 0.031 & 0.100 & 0.213 & 0.107 & 0.078 & -0.057 \\
\hline b3_nsf1 & 0.022 & 0.076 & 0.045 & 0.047 & -0.022 & 0.123 & 0.185 & 0.279 & 0.158 & -0.090 \\
\hline b3_nsf2 & 0.010 & 0.091 & 0.024 & 0.022 & -0.041 & 0.112 & 0.150 & 0.212 & 0.168 & -0.014 \\
\hline b3_nsf3 & -0.007 & 0.054 & 0.004 & 0.006 & -0.044 & 0.041 & 0.111 & 0.172 & 0.128 & 0.002 \\
\hline b3_nsf4 & 0.034 & 0.058 & 0.029 & 0.060 & -0.006 & 0.113 & 0.175 & 0.208 & 0.185 & -0.021 \\
\hline b3_nsf5 & 0.049 & 0.112 & 0.075 & 0.069 & 0.074 & 0.106 & 0.139 & 0.234 & 0.102 & -0.068 \\
\hline b3_nsf6 & 0.011 & 0.082 & 0.066 & 0.047 & 0.065 & 0.074 & 0.097 & 0.159 & 0.075 & -0.068 \\
\hline b4_nsf1 & -0.004 & 0.060 & 0.030 & 0.015 & -0.022 & 0.109 & 0.139 & 0.145 & 0.325 & -0.019 \\
\hline b4_nsf2 & -0.022 & 0.047 & -0.036 & -0.010 & -0.054 & 0.083 & 0.111 & 0.118 & 0.261 & 0.019 \\
\hline b4_nsf3 & 0.027 & 0.043 & -0.002 & 0.039 & 0.012 & 0.049 & 0.117 & 0.100 & 0.228 & 0.001 \\
\hline b4_nsf4 & -0.005 & 0.040 & -0.016 & -0.001 & -0.057 & 0.108 & 0.141 & 0.137 & 0.280 & -0.034 \\
\hline b4_nsf5 & 0.044 & 0.066 & 0.042 & 0.055 & 0.042 & 0.121 & 0.126 & 0.128 & 0.259 & -0.054 \\
\hline b4_nsf6 & 0.050 & 0.074 & 0.071 & 0.071 & 0.104 & 0.087 & 0.079 & 0.115 & 0.216 & -0.084 \\
\hline b1_nsn1 & -0.071 & 0.034 & -0.037 & -0.087 & -0.023 & 0.323 & 0.249 & 0.201 & 0.218 & -0.235 \\
\hline b1_nsn2 & -0.086 & 0.004 & -0.070 & -0.095 & -0.071 & 0.244 & 0.215 & 0.152 & 0.166 & -0.129 \\
\hline b1_nsn3 & -0.069 & -0.033 & -0.069 & -0.104 & -0.056 & 0.242 & 0.186 & 0.183 & 0.152 & -0.157 \\
\hline b1_nsn4 & -0.081 & -0.020 & -0.072 & -0.119 & -0.043 & 0.313 & 0.260 & 0.190 & 0.225 & -0.226 \\
\hline b1_nsn5 & -0.013 & 0.030 & -0.004 & -0.040 & 0.084 & 0.298 & 0.185 & 0.144 & 0.133 & -0.305 \\
\hline b1_nsn6 & 0.020 & 0.051 & 0.031 & -0.002 & 0.099 & 0.280 & 0.144 & 0.145 & 0.109 & -0.276 \\
\hline b2_nsn1 & -0.090 & -0.023 & -0.077 & -0.112 & -0.084 & 0.176 & 0.459 & 0.199 & 0.225 & -0.059 \\
\hline b2_nsn2 & -0.094 & -0.026 & -0.094 & -0.117 & -0.105 & 0.131 & 0.375 & 0.150 & 0.178 & 0.007 \\
\hline b2_nsn3 & -0.101 & -0.081 & -0.152 & -0.133 & -0.087 & 0.138 & 0.378 & 0.173 & 0.179 & -0.022 \\
\hline b2_nsn4 & -0.087 & -0.050 & -0.114 & -0.147 & -0.090 & 0.203 & 0.456 & 0.208 & 0.230 & -0.081 \\
\hline b2_nsn5 & -0.061 & 0.007 & -0.042 & -0.082 & -0.004 & 0.187 & 0.374 & 0.185 & 0.170 & -0.091 \\
\hline b2_nsn6 & -0.028 & -0.008 & -0.021 & -0.048 & 0.041 & 0.189 & 0.319 & 0.171 & 0.153 & -0.136 \\
\hline b3_nsn1 & 0.004 & 0.059 & 0.013 & 0.039 & -0.032 & 0.222 & 0.241 & 0.385 & 0.265 & -0.066 \\
\hline b3_nsn2 & 0.045 & 0.092 & 0.029 & 0.051 & -0.055 & 0.188 & 0.222 & 0.309 & 0.260 & -0.033 \\
\hline b3_nsn3 & 0.027 & 0.067 & 0.005 & 0.030 & -0.014 & 0.161 & 0.195 & 0.269 & 0.216 & -0.036 \\
\hline
\end{tabular}




\begin{tabular}{|c|c|c|c|c|c|c|c|c|c|c|}
\hline b3_nsn4 & 0.013 & 0.067 & -0.009 & 0.022 & -0.045 & 0.245 & 0.282 & 0.388 & 0.279 & -0.093 \\
\hline b3_nsn5 & 0.062 & 0.113 & 0.082 & 0.075 & 0.044 & 0.209 & 0.222 & 0.303 & 0.193 & -0.115 \\
\hline b3_nsn6 & 0.059 & 0.081 & 0.096 & 0.073 & 0.064 & 0.190 & 0.171 & 0.264 & 0.135 & -0.131 \\
\hline b4_nsn1 & 0.028 & 0.076 & 0.053 & 0.028 & -0.017 & 0.262 & 0.276 & 0.298 & 0.522 & -0.127 \\
\hline b4_nsn2 & 0.015 & 0.054 & 0.017 & -0.004 & -0.043 & 0.216 & 0.264 & 0.246 & 0.422 & -0.044 \\
\hline b4_nsn3 & 0.026 & 0.062 & -0.010 & 0.000 & -0.005 & 0.211 & 0.273 & 0.255 & 0.417 & -0.078 \\
\hline b4_nsn4 & 0.031 & 0.064 & 0.016 & 0.002 & -0.040 & 0.296 & 0.307 & 0.286 & 0.499 & -0.121 \\
\hline b4_nsn5 & 0.043 & 0.104 & 0.085 & 0.071 & 0.058 & 0.223 & 0.217 & 0.220 & 0.403 & -0.122 \\
\hline b4_nsn6 & 0.048 & 0.104 & 0.092 & 0.077 & 0.093 & 0.184 & 0.180 & 0.179 & 0.352 & -0.130 \\
\hline
\end{tabular}

Table D.2. Correlations of Latent Variable Scores against the Indicators to Establish Convergent and Discriminant Validity) (Part 2 of 3)

\begin{tabular}{|c|c|c|c|c|c|c|c|c|c|c|c|}
\hline Items & costs B2 & costs B3 & costs B4 & $\begin{array}{l}\text { neutral } \\
\text { B1 }\end{array}$ & $\begin{array}{l}\text { neutral } \\
\text { B2 }\end{array}$ & $\begin{array}{l}\text { neutral } \\
\text { B3 }\end{array}$ & $\begin{array}{l}\text { neutral } \\
\text { B4 }\end{array}$ & $\begin{array}{l}\text { moral } \\
\text { B1 }\end{array}$ & $\begin{array}{l}\text { moral } \\
\text { B2 }\end{array}$ & $\begin{array}{l}\text { moral } \\
\text { B3 }\end{array}$ & $\begin{array}{l}\text { moral } \\
\text { B4 }\end{array}$ \\
\hline a_cs1 & -0.092 & -0.258 & -0.192 & 0.139 & 0.049 & 0.203 & 0.126 & -0.070 & -0.011 & -0.212 & -0.127 \\
\hline a_cs2 & -0.139 & -0.273 & -0.218 & 0.184 & 0.083 & 0.214 & 0.158 & -0.095 & -0.022 & -0.211 & -0.131 \\
\hline a_dr1 & -0.153 & -0.278 & -0.240 & 0.245 & 0.094 & 0.217 & 0.152 & -0.126 & -0.028 & -0.168 & -0.143 \\
\hline a_dr2 & -0.150 & -0.273 & -0.218 & 0.260 & 0.137 & 0.302 & 0.247 & -0.142 & -0.081 & -0.236 & -0.199 \\
\hline a_ko1 & -0.080 & -0.272 & -0.227 & 0.179 & 0.037 & 0.203 & 0.180 & -0.096 & 0.011 & -0.165 & -0.158 \\
\hline a_ko2 & -0.088 & -0.227 & -0.177 & 0.154 & 0.064 & 0.194 & 0.135 & -0.065 & -0.002 & -0.191 & -0.106 \\
\hline a_li1 & -0.101 & -0.287 & -0.223 & 0.178 & 0.039 & 0.225 & 0.128 & -0.080 & -0.001 & -0.191 & -0.104 \\
\hline a_li2 & -0.156 & -0.335 & -0.284 & 0.190 & 0.080 & 0.252 & 0.190 & -0.093 & -0.042 & -0.235 & -0.184 \\
\hline a_px1 & -0.116 & -0.185 & -0.112 & 0.196 & 0.061 & 0.119 & 0.099 & -0.162 & -0.042 & -0.104 & -0.097 \\
\hline a_px2 & -0.110 & -0.189 & -0.147 & 0.189 & 0.057 & 0.164 & 0.105 & -0.148 & -0.063 & -0.138 & -0.092 \\
\hline b1_ben1 & -0.220 & -0.247 & -0.282 & 0.513 & 0.328 & 0.366 & 0.358 & -0.430 & -0.255 & -0.305 & -0.338 \\
\hline b1_ben2 & -0.211 & -0.215 & -0.267 & 0.492 & 0.337 & 0.372 & 0.363 & -0.401 & -0.254 & -0.318 & -0.342 \\
\hline b1_ben3 & -0.235 & -0.203 & -0.270 & 0.471 & 0.328 & 0.373 & 0.367 & -0.377 & -0.257 & -0.316 & -0.336 \\
\hline b1_ben4 & -0.253 & -0.239 & -0.278 & 0.494 & 0.332 & 0.360 & 0.362 & -0.399 & -0.268 & -0.305 & -0.349 \\
\hline b2_ben1 & -0.478 & -0.244 & -0.219 & 0.298 & 0.565 & 0.362 & 0.296 & -0.247 & -0.528 & -0.282 & -0.249 \\
\hline b2_ben2 & -0.468 & -0.226 & -0.210 & 0.298 & 0.573 & 0.349 & 0.300 & -0.270 & -0.519 & -0.303 & -0.270 \\
\hline b2_ben3 & -0.428 & -0.236 & -0.209 & 0.307 & 0.543 & 0.362 & 0.295 & -0.279 & -0.473 & -0.298 & -0.257 \\
\hline
\end{tabular}




\begin{tabular}{|c|c|c|c|c|c|c|c|c|c|c|c|}
\hline b2_ben4 & -0.438 & -0.213 & -0.192 & 0.326 & 0.571 & 0.359 & 0.327 & -0.292 & -0.493 & -0.319 & -0.285 \\
\hline b3_ben1 & -0.252 & -0.458 & -0.297 & 0.328 & 0.315 & 0.566 & 0.347 & -0.239 & -0.249 & -0.503 & -0.311 \\
\hline b3_ben2 & -0.229 & -0.422 & -0.271 & 0.293 & 0.275 & 0.506 & 0.329 & -0.212 & -0.224 & -0.457 & -0.309 \\
\hline b3_ben3 & -0.229 & -0.418 & -0.267 & 0.312 & 0.288 & 0.524 & 0.320 & -0.212 & -0.199 & -0.438 & -0.282 \\
\hline b3_ben4 & -0.229 & -0.420 & -0.268 & 0.316 & 0.289 & 0.543 & 0.334 & -0.207 & -0.231 & -0.475 & -0.291 \\
\hline b4_ben1 & -0.235 & -0.290 & -0.541 & 0.337 & 0.349 & 0.393 & 0.648 & -0.227 & -0.250 & -0.314 & -0.541 \\
\hline b4_ben2 & -0.250 & -0.243 & -0.511 & 0.330 & 0.339 & 0.392 & 0.625 & -0.233 & -0.273 & -0.310 & -0.511 \\
\hline b4_ben3 & -0.229 & -0.255 & -0.485 & 0.314 & 0.322 & 0.381 & 0.608 & -0.213 & -0.247 & -0.305 & -0.496 \\
\hline b4_ben4 & -0.222 & -0.251 & -0.499 & 0.316 & 0.325 & 0.404 & 0.607 & -0.213 & -0.242 & -0.320 & -0.511 \\
\hline b1_cst1 & 0.482 & 0.528 & 0.462 & -0.529 & -0.255 & -0.294 & -0.280 & 0.548 & 0.265 & 0.286 & 0.290 \\
\hline b1_cst2 & 0.473 & 0.534 & 0.481 & -0.534 & -0.264 & -0.300 & -0.283 & 0.559 & 0.276 & 0.306 & 0.312 \\
\hline b1_cst3 & 0.484 & 0.524 & 0.470 & -0.490 & -0.234 & -0.261 & -0.259 & 0.531 & 0.284 & 0.304 & 0.319 \\
\hline b1_cst4 & 0.452 & 0.499 & 0.456 & -0.473 & -0.213 & -0.228 & -0.227 & 0.525 & 0.223 & 0.263 & 0.273 \\
\hline b2_cst1 & 0.934 & 0.481 & 0.467 & -0.324 & -0.527 & -0.268 & -0.223 & 0.351 & 0.529 & 0.235 & 0.244 \\
\hline b2_cst2 & 0.931 & 0.466 & 0.416 & -0.327 & -0.560 & -0.285 & -0.222 & 0.367 & 0.557 & 0.280 & 0.244 \\
\hline b2_cst3 & 0.917 & 0.489 & 0.460 & -0.273 & -0.487 & -0.226 & -0.193 & 0.330 & 0.507 & 0.221 & 0.236 \\
\hline b2_cst4 & 0.917 & 0.479 & 0.452 & -0.279 & -0.487 & -0.236 & -0.192 & 0.323 & 0.499 & 0.220 & 0.227 \\
\hline b3_cst1 & 0.479 & 0.929 & 0.543 & -0.356 & -0.240 & -0.446 & -0.275 & 0.318 & 0.229 & 0.428 & 0.280 \\
\hline b3_cst2 & 0.477 & 0.931 & 0.555 & -0.318 & -0.240 & -0.430 & -0.284 & 0.304 & 0.247 & 0.452 & 0.286 \\
\hline b3_cst3 & 0.494 & 0.934 & 0.537 & -0.345 & -0.253 & -0.438 & -0.277 & 0.298 & 0.238 & 0.405 & 0.259 \\
\hline b3_cst4 & 0.467 & 0.919 & 0.521 & -0.286 & -0.218 & -0.422 & -0.252 & 0.272 & 0.207 & 0.407 & 0.252 \\
\hline b4_cst1 & 0.429 & 0.528 & 0.929 & -0.324 & -0.249 & -0.301 & -0.563 & 0.259 & 0.230 & 0.300 & 0.501 \\
\hline b4_cst2 & 0.456 & 0.556 & 0.942 & -0.311 & -0.253 & -0.308 & -0.566 & 0.289 & 0.256 & 0.304 & 0.522 \\
\hline b4_cst3 & 0.459 & 0.536 & 0.936 & -0.302 & -0.246 & -0.271 & -0.534 & 0.262 & 0.225 & 0.278 & 0.468 \\
\hline b4_cst4 & 0.460 & 0.545 & 0.921 & -0.306 & -0.231 & -0.258 & -0.522 & 0.268 & 0.217 & 0.248 & 0.455 \\
\hline b1_n1 & -0.253 & -0.295 & -0.268 & 0.830 & 0.443 & 0.520 & 0.450 & -0.476 & -0.274 & -0.279 & -0.312 \\
\hline b1_n2 & -0.280 & -0.342 & -0.326 & 0.822 & 0.394 & 0.467 & 0.406 & -0.564 & -0.266 & -0.314 & -0.335 \\
\hline b1_n3 & -0.283 & -0.278 & -0.274 & 0.846 & 0.478 & 0.467 & 0.440 & -0.544 & -0.273 & -0.277 & -0.272 \\
\hline b1_n4 & -0.150 & -0.169 & -0.143 & d0.523 & 0.315 & 0.317 & 0.338 & -0.264 & -0.180 & -0.154 & -0.240 \\
\hline b1_n5 & -0.267 & -0.288 & -0.291 & 0.842 & 0.458 & 0.515 & 0.491 & -0.504 & -0.292 & -0.298 & -0.351 \\
\hline
\end{tabular}




\begin{tabular}{|c|c|c|c|c|c|c|c|c|c|c|c|}
\hline b1_n6 & -0.310 & -0.289 & -0.262 & 0.885 & 0.472 & 0.469 & 0.431 & -0.620 & -0.309 & -0.277 & -0.298 \\
\hline b2_n1 & -0.447 & -0.216 & -0.198 & 0.446 & 0.843 & 0.466 & 0.398 & -0.256 & -0.510 & -0.290 & -0.229 \\
\hline b2_n2 & -0.523 & -0.244 & -0.251 & 0.402 & 0.846 & 0.468 & 0.391 & -0.291 & -0.586 & -0.344 & -0.267 \\
\hline b2_n3 & -0.471 & -0.218 & -0.230 & 0.511 & 0.868 & 0.483 & 0.435 & -0.345 & -0.542 & -0.314 & -0.273 \\
\hline b2_n4 & -0.243 & -0.101 & -0.084 & 0.339 & d0.551 & 0.333 & 0.269 & -0.155 & -0.259 & -0.153 & -0.141 \\
\hline b2_n5 & -0.488 & -0.216 & -0.229 & 0.452 & 0.884 & 0.463 & 0.420 & -0.279 & -0.545 & -0.300 & -0.282 \\
\hline b2_n6 & -0.530 & -0.242 & -0.263 & 0.508 & 0.920 & 0.484 & 0.441 & -0.339 & -0.587 & -0.331 & -0.317 \\
\hline b3_n1 & -0.219 & -0.365 & -0.233 & 0.506 & 0.462 & 0.842 & 0.447 & -0.245 & -0.257 & -0.484 & -0.271 \\
\hline b3_n2 & -0.277 & -0.444 & -0.307 & 0.463 & 0.458 & 0.856 & 0.465 & -0.282 & -0.308 & -0.580 & -0.347 \\
\hline b3_n3 & -0.258 & -0.448 & -0.282 & 0.540 & 0.489 & 0.871 & 0.483 & -0.299 & -0.276 & -0.555 & -0.308 \\
\hline b3_n4 & -0.109 & -0.163 & -0.107 & 0.369 & 0.348 & d0.591 & 0.371 & -0.141 & -0.152 & -0.266 & -0.202 \\
\hline b3_n5 & -0.232 & -0.406 & -0.264 & 0.494 & 0.458 & 0.882 & 0.473 & -0.241 & -0.244 & -0.526 & -0.276 \\
\hline b3_n6 & -0.246 & -0.435 & -0.282 & 0.515 & 0.498 & 0.909 & 0.498 & -0.272 & -0.279 & -0.568 & -0.313 \\
\hline b4_n1 & -0.206 & -0.260 & -0.504 & 0.452 & 0.413 & 0.484 & 0.878 & -0.249 & -0.273 & -0.299 & -0.563 \\
\hline b4_n2 & -0.193 & -0.281 & -0.545 & 0.437 & 0.368 & 0.485 & 0.858 & -0.311 & -0.271 & -0.355 & -0.618 \\
\hline b4_n3 & -0.226 & -0.257 & -0.517 & 0.514 & 0.466 & 0.482 & 0.877 & -0.325 & -0.293 & -0.298 & -0.551 \\
\hline b4_n4 & -0.068 & -0.128 & -0.260 & 0.325 & 0.290 & 0.325 & d0.565 & -0.149 & -0.120 & -0.134 & -0.283 \\
\hline b4_n5 & -0.183 & -0.231 & -0.501 & 0.460 & 0.419 & 0.479 & 0.896 & -0.263 & -0.248 & -0.276 & -0.565 \\
\hline b4_n6 & -0.213 & -0.281 & -0.553 & 0.480 & 0.434 & 0.483 & 0.906 & -0.320 & -0.267 & -0.323 & -0.602 \\
\hline b1_sm1 & 0.348 & 0.293 & 0.274 & -0.576 & -0.307 & -0.261 & -0.307 & 0.947 & 0.423 & 0.357 & 0.441 \\
\hline b1_sm2 & 0.361 & 0.319 & 0.287 & -0.622 & -0.343 & -0.312 & -0.317 & 0.940 & 0.433 & 0.406 & 0.418 \\
\hline b1_sm3 & 0.340 & 0.295 & 0.256 & -0.584 & -0.316 & -0.279 & -0.306 & 0.939 & 0.422 & 0.374 & 0.421 \\
\hline b2_sm1 & 0.522 & 0.229 & 0.226 & -0.313 & -0.585 & -0.280 & -0.278 & 0.417 & 0.958 & 0.363 & 0.384 \\
\hline b2_sm2 & 0.563 & 0.242 & 0.247 & -0.335 & -0.628 & -0.303 & -0.310 & 0.455 & 0.960 & 0.398 & 0.419 \\
\hline b2_sm3 & 0.539 & 0.240 & 0.240 & -0.314 & -0.583 & -0.304 & -0.273 & 0.423 & 0.949 & 0.367 & 0.368 \\
\hline b3_sm1 & 0.239 & 0.420 & 0.270 & -0.297 & -0.325 & -0.549 & -0.289 & 0.385 & 0.369 & 0.936 & 0.400 \\
\hline b3_sm2 & 0.243 & 0.444 & 0.289 & -0.335 & -0.341 & -0.616 & -0.344 & 0.381 & 0.368 & 0.942 & 0.415 \\
\hline b3_sm3 & 0.250 & 0.420 & 0.295 & -0.323 & -0.342 & -0.554 & -0.336 & 0.370 & 0.372 & 0.938 & 0.415 \\
\hline b4_sm1 & 0.244 & 0.260 & 0.471 & -0.333 & -0.276 & -0.306 & -0.586 & 0.415 & 0.393 & 0.385 & 0.948 \\
\hline b4_sm2 & 0.255 & 0.283 & 0.511 & -0.375 & -0.318 & -0.345 & -0.642 & 0.441 & 0.405 & 0.436 & 0.959 \\
\hline
\end{tabular}




\begin{tabular}{|c|c|c|c|c|c|c|c|c|c|c|c|}
\hline b4_sm3 & 0.238 & 0.286 & 0.509 & -0.372 & -0.294 & -0.341 & -0.622 & 0.436 & 0.371 & 0.424 & 0.954 \\
\hline b1_nsf1 & -0.107 & -0.069 & -0.071 & 0.264 & 0.166 & 0.131 & 0.146 & -0.273 & -0.173 & -0.154 & -0.171 \\
\hline b1_nsf2 & -0.099 & -0.031 & -0.060 & 0.149 & 0.176 & 0.107 & 0.107 & -0.131 & -0.155 & -0.095 & -0.090 \\
\hline b1_nsf3 & -0.054 & 0.001 & -0.010 & 0.131 & 0.075 & 0.042 & 0.067 & -0.140 & -0.101 & -0.051 & -0.077 \\
\hline b1_nsf4 & -0.112 & -0.054 & -0.078 & 0.217 & 0.178 & 0.091 & 0.158 & -0.254 & -0.190 & -0.108 & -0.169 \\
\hline b1_nsf5 & -0.085 & -0.054 & -0.036 & 0.249 & 0.146 & 0.069 & 0.079 & -0.186 & -0.111 & -0.080 & -0.043 \\
\hline b1_nsf6 & -0.067 & -0.081 & -0.047 & 0.221 & 0.104 & 0.074 & 0.082 & -0.186 & -0.071 & -0.081 & -0.035 \\
\hline b2_nsf1 & -0.313 & -0.058 & -0.076 & 0.079 & 0.409 & 0.145 & 0.154 & -0.071 & -0.393 & -0.149 & -0.129 \\
\hline b2_nsf2 & -0.211 & -0.013 & -0.074 & 0.066 & 0.320 & 0.073 & 0.132 & -0.050 & -0.290 & -0.103 & -0.121 \\
\hline b2_nsf3 & -0.193 & -0.050 & -0.063 & 0.068 & 0.247 & 0.119 & 0.128 & -0.063 & -0.278 & -0.133 & -0.107 \\
\hline b2_nsf4 & -0.248 & -0.054 & -0.091 & 0.086 & 0.333 & 0.147 & 0.165 & -0.073 & -0.325 & -0.150 & -0.163 \\
\hline b2_nsf5 & -0.248 & -0.041 & -0.061 & 0.122 & 0.398 & 0.156 & 0.133 & -0.071 & -0.325 & -0.143 & -0.083 \\
\hline b2_nsf6 & -0.189 & -0.039 & -0.045 & 0.124 & 0.329 & 0.137 & 0.117 & -0.087 & -0.256 & -0.128 & -0.050 \\
\hline b3_nsf1 & -0.099 & -0.219 & -0.109 & 0.130 & 0.170 & 0.298 & 0.145 & -0.063 & -0.172 & -0.330 & -0.146 \\
\hline b3_nsf2 & -0.081 & -0.123 & -0.099 & 0.105 & 0.146 & 0.210 & 0.144 & -0.029 & -0.152 & -0.219 & -0.143 \\
\hline b3_nsf3 & -0.045 & -0.090 & -0.037 & 0.066 & 0.108 & 0.165 & 0.130 & -0.021 & -0.100 & -0.177 & -0.091 \\
\hline b3_nsf4 & -0.071 & -0.125 & -0.090 & 0.104 & 0.179 & 0.234 & 0.186 & -0.047 & -0.161 & -0.231 & -0.157 \\
\hline b3_nsf5 & -0.092 & -0.176 & -0.065 & 0.159 & 0.209 & 0.293 & 0.178 & -0.072 & -0.152 & -0.277 & -0.096 \\
\hline b3_nsf6 & -0.075 & -0.130 & -0.045 & 0.129 & 0.158 & 0.212 & 0.141 & -0.079 & -0.125 & -0.191 & -0.055 \\
\hline b4_nsf1 & -0.080 & -0.060 & -0.221 & 0.092 & 0.176 & 0.142 & 0.338 & -0.098 & -0.133 & -0.165 & -0.301 \\
\hline b4_nsf2 & -0.080 & -0.024 & -0.170 & 0.052 & 0.135 & 0.089 & 0.227 & -0.041 & -0.105 & -0.097 & -0.223 \\
\hline b4_nsf3 & -0.074 & -0.032 & -0.174 & 0.060 & 0.101 & 0.085 & 0.201 & -0.060 & -0.064 & -0.103 & -0.198 \\
\hline b4_nsf4 & -0.087 & -0.057 & -0.207 & 0.079 & 0.140 & 0.098 & 0.279 & -0.103 & -0.111 & -0.162 & -0.304 \\
\hline b4_nsf5 & -0.084 & -0.093 & -0.230 & 0.133 & 0.160 & 0.130 & 0.321 & -0.096 & -0.113 & -0.139 & -0.226 \\
\hline b4_nsf6 & -0.078 & -0.104 & -0.218 & 0.138 & 0.141 & 0.144 & 0.321 & -0.116 & -0.115 & -0.156 & -0.209 \\
\hline b1_nsn1 & -0.162 & -0.080 & -0.090 & 0.431 & 0.268 & 0.234 & 0.233 & -0.419 & -0.219 & -0.191 & -0.209 \\
\hline b1_nsn2 & -0.128 & -0.040 & -0.055 & 0.321 & 0.237 & 0.169 & 0.179 & -0.320 & -0.191 & -0.131 & -0.159 \\
\hline b1_nsn3 & -0.096 & -0.063 & -0.047 & 0.304 & 0.188 & 0.162 & 0.149 & -0.315 & -0.149 & -0.130 & -0.154 \\
\hline b1_nsn4 & -0.159 & -0.100 & -0.103 & 0.406 & 0.276 & 0.213 & 0.239 & -0.407 & -0.225 & -0.172 & -0.225 \\
\hline b1_nsn5 & -0.180 & -0.135 & -0.100 & 0.459 & 0.270 & 0.221 & 0.205 & -0.406 & -0.185 & -0.147 & -0.168 \\
\hline
\end{tabular}




\begin{tabular}{|c|c|c|c|c|c|c|c|c|c|c|c|}
\hline b1_nsn6 & -0.129 & -0.140 & -0.105 & 0.413 & 0.205 & 0.202 & 0.181 & -0.328 & -0.101 & -0.119 & -0.124 \\
\hline b2_nsn1 & -0.378 & -0.075 & -0.078 & 0.182 & 0.552 & 0.257 & 0.209 & -0.149 & -0.539 & -0.232 & -0.158 \\
\hline b2_nsn2 & -0.320 & -0.027 & -0.060 & 0.131 & 0.441 & 0.175 & 0.170 & -0.089 & -0.489 & -0.173 & -0.144 \\
\hline b2_nsn3 & -0.306 & -0.049 & -0.061 & 0.096 & 0.402 & 0.151 & 0.150 & -0.100 & -0.465 & -0.159 & -0.138 \\
\hline b2_nsn4 & -0.366 & -0.084 & -0.096 & 0.178 & 0.509 & 0.228 & 0.213 & -0.172 & -0.541 & -0.219 & -0.204 \\
\hline b2_nsn5 & -0.330 & -0.090 & -0.090 & 0.243 & 0.521 & 0.258 & 0.211 & -0.153 & -0.456 & -0.184 & -0.135 \\
\hline b2_nsn6 & -0.305 & -0.139 & -0.113 & 0.254 & 0.453 & 0.267 & 0.216 & -0.160 & -0.382 & -0.183 & -0.126 \\
\hline b3_nsn1 & -0.106 & -0.203 & -0.136 & 0.204 & 0.252 & 0.418 & 0.242 & -0.119 & -0.207 & -0.411 & -0.208 \\
\hline b3_nsn2 & -0.090 & -0.151 & -0.113 & 0.183 & 0.209 & 0.318 & 0.208 & -0.098 & -0.202 & -0.336 & -0.180 \\
\hline b3_nsn3 & -0.089 & -0.125 & -0.076 & 0.146 & 0.179 & 0.283 & 0.165 & -0.076 & -0.178 & -0.299 & -0.146 \\
\hline b3_nsn4 & -0.138 & -0.221 & -0.126 & 0.223 & 0.279 & 0.389 & 0.246 & -0.146 & -0.236 & -0.396 & -0.229 \\
\hline b3_nsn5 & -0.122 & -0.212 & -0.119 & 0.266 & 0.309 & 0.413 & 0.228 & -0.116 & -0.202 & -0.365 & -0.159 \\
\hline b3_nsn6 & -0.099 & -0.197 & -0.109 & 0.237 & 0.216 & 0.346 & 0.184 & -0.123 & -0.163 & -0.314 & -0.122 \\
\hline b4_nsn1 & -0.159 & -0.144 & -0.351 & 0.273 & 0.279 & 0.313 & 0.533 & -0.181 & -0.205 & -0.270 & -0.488 \\
\hline b4_nsn2 & -0.150 & -0.086 & -0.239 & 0.208 & 0.254 & 0.267 & 0.389 & -0.121 & -0.202 & -0.221 & -0.380 \\
\hline b4_nsn3 & -0.163 & -0.114 & -0.256 & 0.185 & 0.232 & 0.236 & 0.388 & -0.143 & -0.186 & -0.215 & -0.367 \\
\hline b4_nsn4 & -0.183 & -0.132 & -0.323 & 0.269 & 0.283 & 0.287 & 0.493 & -0.206 & -0.217 & -0.262 & -0.468 \\
\hline b4_nsn5 & -0.184 & -0.136 & -0.324 & 0.302 & 0.308 & 0.271 & 0.490 & -0.182 & -0.182 & -0.212 & -0.407 \\
\hline b4_nsn6 & -0.136 & -0.117 & -0.291 & 0.279 & 0.243 & 0.240 & 0.435 & -0.171 & -0.137 & -0.181 & -0.332 \\
\hline
\end{tabular}

$\mathrm{d}=$ dropped for conservative improvement of discriminant validity (loading was below 0.700 )

Table D.2. Correlations of Latent Variable Scores against the Indicators to Establish Convergent and Discriminant Validity) (Part 3 of 3)

\begin{tabular}{|l|r|r|r|r|r|r|r|r|}
\hline Items & \multicolumn{1}{c|}{ nsf B1 } & \multicolumn{1}{c|}{ nsf B2 } & \multicolumn{1}{c|}{ nsf B3 } & \multicolumn{1}{c|}{ nsf B4 } & \multicolumn{1}{c|}{ nsn B1 } & \multicolumn{1}{c|}{ nsn B2 } & \multicolumn{1}{c|}{ nsn B3 } & \multicolumn{1}{c|}{ nsn B4 } \\
\hline a_cs1 & -0.032 & -0.032 & 0.036 & 0.018 & -0.073 & -0.091 & 0.031 & 0.020 \\
\hline a_cs2 & -0.050 & -0.062 & 0.015 & 0.018 & -0.032 & -0.078 & 0.048 & 0.054 \\
\hline a_dr1 & 0.026 & -0.019 & 0.076 & 0.037 & 0.023 & -0.044 & 0.060 & 0.062 \\
\hline a_dr2 & 0.004 & 0.006 & 0.106 & 0.086 & 0.013 & -0.021 & 0.106 & 0.100 \\
\hline a_ko1 & -0.008 & -0.056 & 0.043 & 0.046 & -0.026 & -0.122 & 0.038 & 0.062 \\
\hline a_ko2 & -0.026 & -0.039 & 0.056 & -0.002 & -0.043 & -0.060 & 0.042 & 0.039 \\
\hline a_li1 & -0.044 & -0.057 & 0.010 & 0.014 & -0.072 & -0.120 & 0.041 & 0.015 \\
\hline
\end{tabular}




\begin{tabular}{|c|c|c|c|c|c|c|c|c|}
\hline a_li2 & -0.007 & -0.026 & 0.088 & 0.049 & -0.087 & -0.112 & 0.066 & 0.050 \\
\hline a_px1 & 0.015 & -0.035 & -0.014 & 0.011 & 0.020 & -0.062 & -0.012 & 0.010 \\
\hline a_px2 & 0.011 & -0.014 & 0.031 & -0.007 & -0.002 & -0.054 & -0.001 & 0.009 \\
\hline b1_ben1 & 0.207 & 0.075 & 0.106 & 0.137 & 0.335 & 0.176 & 0.213 & 0.245 \\
\hline b1_ben2 & 0.177 & 0.101 & 0.113 & 0.095 & 0.344 & 0.183 & 0.244 & 0.261 \\
\hline b1_ben3 & 0.178 & 0.144 & 0.143 & 0.125 & 0.341 & 0.208 & 0.259 & 0.284 \\
\hline b1_ben4 & 0.199 & 0.136 & 0.120 & 0.119 & 0.332 & 0.203 & 0.225 & 0.268 \\
\hline b2_ben1 & 0.131 & 0.320 & 0.192 & 0.122 & 0.225 & 0.452 & 0.273 & 0.289 \\
\hline b2_ben2 & 0.166 & 0.333 & 0.180 & 0.152 & 0.239 & 0.461 & 0.252 & 0.290 \\
\hline b2_ben3 & 0.169 & 0.315 & 0.165 & 0.176 & 0.244 & 0.404 & 0.241 & 0.269 \\
\hline b2_ben4 & 0.147 & 0.338 & 0.179 & 0.152 & 0.256 & 0.445 & 0.261 & 0.293 \\
\hline b3_ben1 & 0.138 & 0.163 & 0.283 & 0.172 & 0.194 & 0.226 & 0.393 & 0.287 \\
\hline b3_ben2 & 0.110 & 0.117 & 0.234 & 0.150 & 0.187 & 0.191 & 0.359 & 0.276 \\
\hline b3_ben3 & 0.125 & 0.144 & 0.258 & 0.146 & 0.207 & 0.193 & 0.361 & 0.285 \\
\hline b3_ben4 & 0.134 & 0.171 & 0.277 & 0.157 & 0.195 & 0.199 & 0.362 & 0.268 \\
\hline b4_ben1 & 0.111 & 0.148 & 0.152 & 0.343 & 0.198 & 0.208 & 0.249 & 0.491 \\
\hline b4_ben2 & 0.120 & 0.161 & 0.159 & 0.328 & 0.199 & 0.232 & 0.263 & 0.516 \\
\hline b4_ben3 & 0.130 & 0.158 & 0.185 & 0.327 & 0.183 & 0.202 & 0.256 & 0.479 \\
\hline b4_ben4 & 0.133 & 0.157 & 0.183 & 0.336 & 0.206 & 0.212 & 0.273 & 0.502 \\
\hline b1_cst1 & -0.141 & -0.021 & -0.040 & -0.011 & -0.268 & -0.074 & -0.069 & -0.113 \\
\hline b1_cst2 & -0.145 & -0.015 & -0.070 & -0.041 & -0.293 & -0.079 & -0.118 & -0.134 \\
\hline b1_cst3 & -0.165 & -0.071 & -0.099 & -0.072 & -0.273 & -0.097 & -0.110 & -0.140 \\
\hline b1_cst4 & -0.116 & 0.016 & -0.010 & -0.018 & -0.250 & -0.041 & -0.065 & -0.084 \\
\hline b2_cst1 & -0.139 & -0.295 & -0.101 & -0.102 & -0.196 & -0.395 & -0.135 & -0.184 \\
\hline b2_cst2 & -0.118 & -0.303 & -0.106 & -0.101 & -0.182 & -0.406 & -0.147 & -0.198 \\
\hline b2_cst3 & -0.112 & -0.282 & -0.090 & -0.103 & -0.154 & -0.345 & -0.114 & -0.172 \\
\hline b2_cst4 & -0.097 & -0.275 & -0.090 & -0.097 & -0.154 & -0.345 & -0.098 & -0.182 \\
\hline b3_cst1 & -0.072 & -0.040 & -0.164 & -0.065 & -0.123 & -0.082 & -0.216 & -0.138 \\
\hline b3_cst2 & -0.042 & -0.039 & -0.168 & -0.074 & -0.102 & -0.082 & -0.200 & -0.128 \\
\hline b3_cst3 & -0.091 & -0.086 & -0.209 & -0.095 & -0.122 & -0.110 & -0.218 & -0.151 \\
\hline
\end{tabular}




\begin{tabular}{|c|c|c|c|c|c|c|c|c|}
\hline b3_cst4 & -0.056 & -0.045 & -0.195 & -0.082 & -0.117 & -0.079 & -0.230 & -0.143 \\
\hline b4_cst1 & -0.063 & -0.086 & -0.102 & -0.254 & -0.110 & -0.111 & -0.139 & -0.360 \\
\hline b4_cst2 & -0.081 & -0.093 & -0.101 & -0.278 & -0.112 & -0.106 & -0.141 & -0.349 \\
\hline b4_cst3 & -0.068 & -0.092 & -0.088 & -0.261 & -0.101 & -0.089 & -0.137 & -0.336 \\
\hline b4_cst4 & -0.067 & -0.067 & -0.088 & -0.238 & -0.089 & -0.071 & -0.111 & -0.324 \\
\hline b1_n1 & 0.219 & 0.085 & 0.161 & 0.098 & 0.405 & 0.190 & 0.248 & 0.265 \\
\hline b1_n2 & 0.214 & 0.041 & 0.073 & 0.070 & 0.386 & 0.131 & 0.181 & 0.225 \\
\hline b1_n3 & 0.237 & 0.092 & 0.103 & 0.092 & 0.429 & 0.181 & 0.195 & 0.230 \\
\hline b1_n4 & 0.211 & 0.138 & 0.149 & 0.125 & 0.285 & 0.167 & 0.192 & 0.233 \\
\hline b1_n5 & 0.266 & 0.132 & 0.170 & 0.152 & 0.433 & 0.212 & 0.248 & 0.312 \\
\hline b1_n6 & 0.281 & 0.113 & 0.115 & 0.087 & 0.476 & 0.195 & 0.205 & 0.246 \\
\hline b2_n1 & 0.151 & 0.384 & 0.196 & 0.161 & 0.249 & 0.490 & 0.260 & 0.257 \\
\hline b2_n2 & 0.154 & 0.407 & 0.174 & 0.153 & 0.220 & 0.518 & 0.252 & 0.266 \\
\hline b2_n3 & 0.185 & 0.352 & 0.158 & 0.165 & 0.302 & 0.484 & 0.264 & 0.290 \\
\hline b2_n4 & 0.147 & 0.275 & 0.161 & 0.130 & 0.216 & 0.315 & 0.207 & 0.202 \\
\hline b2_n5 & 0.177 & 0.400 & 0.203 & 0.173 & 0.260 & 0.520 & 0.250 & 0.299 \\
\hline b2_n6 & 0.201 & 0.408 & 0.199 & 0.190 & 0.301 & 0.532 & 0.275 & 0.308 \\
\hline b3_n1 & 0.116 & 0.151 & 0.278 & 0.139 & 0.257 & 0.248 & 0.385 & 0.279 \\
\hline b3_n2 & 0.077 & 0.136 & 0.260 & 0.115 & 0.198 & 0.232 & 0.392 & 0.295 \\
\hline b3_n3 & 0.114 & 0.158 & 0.271 & 0.132 & 0.233 & 0.220 & 0.385 & 0.266 \\
\hline b3_n4 & 0.122 & 0.141 & 0.241 & 0.129 & 0.185 & 0.194 & 0.317 & 0.264 \\
\hline b3_n5 & 0.093 & 0.139 & 0.280 & 0.146 & 0.193 & 0.228 & 0.380 & 0.276 \\
\hline b3_n6 & 0.124 & 0.146 & 0.278 & 0.136 & 0.237 & 0.244 & 0.410 & 0.288 \\
\hline b4_n1 & 0.122 & 0.170 & 0.190 & 0.340 & 0.198 & 0.199 & 0.220 & 0.472 \\
\hline b4_n2 & 0.096 & 0.131 & 0.171 & 0.316 & 0.203 & 0.179 & 0.228 & 0.479 \\
\hline b4_n3 & 0.164 & 0.188 & 0.178 & 0.344 & 0.236 & 0.219 & 0.215 & 0.480 \\
\hline b4_n4 & 0.139 & 0.115 & 0.162 & 0.238 & 0.209 & 0.155 & 0.222 & 0.332 \\
\hline b4_n5 & 0.117 & 0.150 & 0.161 & 0.334 & 0.207 & 0.210 & 0.216 & 0.521 \\
\hline b4_n6 & 0.164 & 0.167 & 0.185 & 0.363 & 0.249 & 0.230 & 0.258 & 0.519 \\
\hline b1_sm1 & -0.261 & $\begin{array}{l}-0.078 \\
\end{array}$ & -0.061 & -0.117 & -0.445 & -0.151 & -0.128 & -0.199 \\
\hline
\end{tabular}




\begin{tabular}{|c|c|c|c|c|c|c|c|c|}
\hline b1_sm2 & -0.271 & -0.097 & -0.066 & -0.109 & -0.461 & -0.178 & -0.152 & -0.205 \\
\hline b1_sm3 & -0.273 & -0.081 & -0.072 & -0.107 & -0.425 & -0.146 & -0.119 & -0.181 \\
\hline b2_sm1 & -0.179 & -0.388 & -0.190 & -0.133 & -0.208 & -0.551 & -0.237 & -0.205 \\
\hline b2_sm2 & -0.196 & -0.412 & -0.187 & -0.158 & -0.248 & -0.572 & -0.251 & -0.246 \\
\hline b2_sm3 & -0.183 & -0.387 & -0.180 & -0.132 & -0.193 & -0.533 & -0.219 & -0.207 \\
\hline b3_sm1 & -0.110 & -0.154 & -0.278 & -0.150 & -0.190 & -0.225 & -0.402 & -0.246 \\
\hline b3_sm2 & -0.133 & -0.171 & -0.314 & -0.187 & -0.185 & -0.220 & -0.425 & -0.275 \\
\hline b3_sm3 & -0.149 & -0.175 & -0.319 & -0.192 & -0.162 & -0.214 & -0.419 & -0.263 \\
\hline b4_sm1 & -0.124 & -0.137 & -0.136 & -0.295 & -0.199 & -0.172 & -0.201 & -0.466 \\
\hline b4_sm2 & -0.161 & -0.148 & -0.162 & -0.333 & -0.228 & -0.189 & -0.216 & -0.493 \\
\hline b4_sm3 & -0.137 & -0.133 & -0.145 & -0.328 & -0.203 & -0.159 & -0.205 & -0.474 \\
\hline b1_nsf1 & 0.790 & 0.441 & 0.444 & 0.411 & 0.415 & 0.249 & 0.296 & 0.236 \\
\hline b1_nsf2 & d0.603 & 0.382 & 0.377 & 0.369 & 0.304 & 0.265 & 0.255 & 0.213 \\
\hline b1_nsf3 & d0.664 & 0.423 & 0.449 & 0.398 & 0.279 & 0.185 & 0.256 & 0.157 \\
\hline b1_nsf4 & 0.805 & 0.524 & 0.489 & 0.481 & 0.402 & 0.285 & 0.309 & 0.265 \\
\hline b1_nsf5 & 0.728 & 0.386 & 0.411 & 0.408 & 0.343 & 0.172 & 0.240 & 0.173 \\
\hline b1_nsf6 & d0.644 & 0.309 & 0.390 & 0.343 & 0.280 & 0.130 & 0.214 & 0.139 \\
\hline b2_nsf1 & 0.417 & 0.809 & 0.429 & 0.385 & 0.231 & 0.550 & 0.306 & 0.251 \\
\hline b2_nsf2 & 0.402 & d0.697 & 0.380 & 0.387 & 0.170 & 0.436 & 0.248 & 0.222 \\
\hline b2_nsf3 & 0.460 & 0.733 & 0.466 & 0.404 & 0.175 & 0.393 & 0.258 & 0.200 \\
\hline b2_nsf4 & 0.464 & 0.831 & 0.478 & 0.445 & 0.219 & 0.464 & 0.307 & 0.261 \\
\hline b2_nsf5 & 0.453 & 0.772 & 0.477 & 0.418 & 0.244 & 0.476 & 0.301 & 0.251 \\
\hline b2_nsf6 & 0.469 & d0.693 & 0.459 & 0.394 & 0.254 & 0.406 & 0.298 & 0.227 \\
\hline b3_nsf1 & 0.447 & 0.427 & 0.795 & 0.429 & 0.194 & 0.262 & 0.486 & 0.252 \\
\hline b3_nsf2 & 0.413 & 0.382 & d0.681 & 0.390 & 0.175 & 0.234 & 0.408 & 0.220 \\
\hline b3_nsf3 & 0.434 & 0.421 & 0.723 & 0.395 & 0.150 & 0.219 & 0.402 & 0.179 \\
\hline b3_nsf4 & 0.467 & 0.498 & 0.789 & 0.481 & 0.203 & 0.274 & 0.463 & 0.279 \\
\hline b3_nsf5 & 0.464 & 0.481 & 0.786 & 0.456 & 0.225 & 0.289 & 0.452 & 0.271 \\
\hline b3_nsf6 & 0.478 & 0.448 & 0.723 & 0.425 & 0.197 & 0.238 & 0.380 & 0.226 \\
\hline b4_nsf1 & 0.429 & 0.432 & 0.435 & 0.811 & 0.164 & 0.224 & 0.257 & 0.436 \\
\hline
\end{tabular}




\begin{tabular}{|c|c|c|c|c|c|c|c|c|}
\hline b4_nsf2 & 0.382 & 0.377 & 0.387 & d0.655 & 0.139 & 0.162 & 0.223 & 0.337 \\
\hline b4_nsf3 & 0.385 & 0.374 & 0.412 & d0.697 & 0.134 & 0.139 & 0.226 & 0.325 \\
\hline b4_nsf4 & 0.450 & 0.442 & 0.456 & 0.794 & 0.172 & 0.210 & 0.287 & 0.433 \\
\hline b4_nsf5 & 0.418 & 0.359 & 0.401 & 0.764 & 0.186 & 0.159 & 0.259 & 0.377 \\
\hline b4_nsf6 & 0.442 & 0.375 & 0.449 & d0.688 & 0.155 & 0.160 & 0.259 & 0.366 \\
\hline b1_nsn1 & 0.416 & 0.250 & 0.212 & 0.196 & 0.828 & 0.379 & 0.406 & 0.401 \\
\hline b1_nsn2 & 0.357 & 0.221 & 0.215 & 0.181 & 0.709 & 0.373 & 0.342 & 0.331 \\
\hline b1_nsn3 & 0.397 & 0.251 & 0.238 & 0.169 & 0.745 & 0.353 & 0.373 & 0.315 \\
\hline b1_nsn4 & 0.444 & 0.288 & 0.236 & 0.196 & 0.853 & 0.416 & 0.399 & 0.386 \\
\hline b1_nsn5 & 0.377 & 0.198 & 0.180 & 0.171 & 0.836 & 0.329 & 0.355 & 0.332 \\
\hline b1_nsn6 & 0.313 & 0.162 & 0.158 & 0.115 & 0.737 & 0.275 & 0.350 & 0.288 \\
\hline b2_nsn1 & 0.245 & 0.534 & 0.268 & 0.210 & 0.379 & 0.874 & 0.414 & 0.372 \\
\hline b2_nsn2 & 0.220 & 0.465 & 0.235 & 0.181 & 0.315 & 0.809 & 0.362 & 0.352 \\
\hline b2_nsn3 & 0.276 & 0.513 & 0.290 & 0.206 & 0.315 & 0.802 & 0.385 & 0.343 \\
\hline b2_nsn4 & 0.280 & 0.546 & 0.305 & 0.231 & 0.374 & 0.888 & 0.432 & 0.394 \\
\hline b2_nsn5 & 0.249 & 0.501 & 0.295 & 0.193 & 0.407 & 0.852 & 0.436 & 0.358 \\
\hline b2_nsn6 & 0.269 & 0.450 & 0.296 & 0.183 & 0.407 & 0.751 & 0.429 & 0.350 \\
\hline b3_nsn1 & 0.299 & 0.294 & 0.476 & 0.285 & 0.381 & 0.392 & 0.845 & 0.436 \\
\hline b3_nsn2 & 0.273 & 0.264 & 0.445 & 0.266 & 0.328 & 0.390 & 0.767 & 0.411 \\
\hline b3_nsn3 & 0.321 & 0.319 & 0.465 & 0.287 & 0.350 & 0.399 & 0.803 & 0.395 \\
\hline b3_nsn4 & 0.323 & 0.340 & 0.508 & 0.315 & 0.403 & 0.434 & 0.871 & 0.454 \\
\hline b3_nsn5 & 0.298 & 0.328 & 0.477 & 0.270 & 0.406 & 0.409 & 0.817 & 0.397 \\
\hline b3_nsn6 & 0.283 & 0.281 & 0.423 & 0.229 & 0.390 & 0.368 & 0.721 & 0.335 \\
\hline b4_nsn1 & 0.209 & 0.229 & 0.223 & 0.415 & 0.366 & 0.356 & 0.412 & 0.861 \\
\hline b4_nsn2 & 0.196 & 0.237 & 0.247 & 0.381 & 0.292 & 0.347 & 0.399 & 0.788 \\
\hline b4_nsn3 & 0.237 & 0.262 & 0.274 & 0.402 & 0.323 & 0.358 & 0.417 & 0.810 \\
\hline b4_nsn4 & 0.242 & 0.281 & 0.276 & 0.450 & 0.357 & 0.385 & 0.439 & 0.890 \\
\hline b4_nsn5 & 0.266 & 0.278 & 0.284 & 0.471 & 0.402 & 0.367 & 0.417 & 0.830 \\
\hline b4_nsn6 & 0.247 & 0.243 & 0.271 & 0.415 & 0.379 & 0.324 & 0.390 & 0.719 \\
\hline
\end{tabular}

$\mathrm{d}=$ dropped for conservative improvement of discriminant validity (loading was below 0.700 ) 
Table D.3. First-Order Measurement Model Statistics (Part 1 of 3)

\begin{tabular}{|c|c|c|c|c|c|c|c|c|c|c|c|c|c|}
\hline Latent construct & AVE & Mean & SD & Marker & (1) & (2) & (3) & (4) & (5) & (6) & (7) & (8) & (9) \\
\hline Marker variable $^{\dagger}$ & $\mathrm{n} / \mathrm{a}$ & 4.55 & 0.15 & $\mathrm{n} / \mathrm{a}$ & & & & & & & & & \\
\hline b1_freq (1) & $\mathrm{n} / \mathrm{a}$ & 2.30 & 0.79 & -.142 & $\mathrm{n} / \mathrm{a}$ & & & & & & & & \\
\hline b2_freq (2) & $\mathrm{n} / \mathrm{a}$ & 1.63 & 0.79 & .026 & .234 & $\mathrm{n} / \mathrm{a}$ & & & & & & & \\
\hline b3_freq (3) & $\mathrm{n} / \mathrm{a}$ & 1.65 & 0.81 & -.048 & .284 & .292 & $\mathrm{n} / \mathrm{a}$ & & & & & & \\
\hline b4_freq (4) & $\mathrm{n} / \mathrm{a}$ & 1.60 & 0.80 & -.018 & .287 & .241 & .310 & $\mathrm{n} / \mathrm{a}$ & & & & & \\
\hline A_LI (5) & .827 & 3.75 & 1.75 & -.109 & .144 & .036 & .192 & .131 & .910 & & & & \\
\hline A-CS (6) & .857 & 3.90 & 1.78 & -.096 & .115 & .009 & .174 & .098 & .765 & .926 & & & \\
\hline A_DR (7) & .773 & 3.78 & 1.53 & -.121 & .150 & .057 & .212 & .128 & .641 & .576 & .879 & & \\
\hline A_PX (8) & .822 & 4.93 & 1.63 & -.139 & .146 & .019 & .095 & .054 & .476 & .419 & .403 & .907 & \\
\hline A_KO (9) & .811 & 4.04 & 1.66 & -.095 & .151 & .027 & .170 & .104 & .744 & .652 & .659 & .449 & .900 \\
\hline SM_B1 (10) & .887 & 4.81 & 1.51 & .226 & -.459 & -.130 & -.059 & -.115 & -.095 & -.089 & -.151 & -.170 & -.088 \\
\hline SM_B2 (11) & .913 & 5.31 & 1.55 & .113 & -.171 & -.518 & -.112 & -.122 & -.023 & -.018 & -.062 & -.058 & .005 \\
\hline SM_B3 (12) & .881 & 5.33 & 1.45 & .199 & -.212 & -.186 & -.468 & -.220 & -.232 & -.229 & -.228 & -.133 & -.197 \\
\hline SM_B4 (13) & .910 & 5.62 & 1.41 & .142 & -.241 & -.182 & -.180 & -.496 & -.156 & -.138 & -.193 & -.103 & -.146 \\
\hline NSN_B1 (14) & .619 & 3.62 & 1.37 & -.107 & .299 & .122 & .061 & .056 & -.093 & -.061 & .016 & -.001 & -.045 \\
\hline NSN_B2 (15) & .690 & 3.20 & 1.49 & -.012 & .057 & .459 & .105 & .053 & -.127 & -.091 & -.038 & -.063 & -.101 \\
\hline NSN_B3 (16) & .649 & 3.08 & 1.35 & -.134 & .136 & .211 & .364 & .132 & .060 & .045 & .095 & -.004 & .047 \\
\hline NSN_B4 (17) & .669 & 2.84 & 1.36 & -.021 & .130 & .167 & .155 & .395 & .036 & .041 & .093 & .014 & .057 \\
\hline NSF_B1 (18) & .654 & 2.38 & 0.91 & -.082 & .461 & .200 & .178 & .191 & .004 & -.024 & .031 & .031 & -.001 \\
\hline NSF_B2 (19) & .651 & 1.90 & 0.88 & .015 & .171 & .541 & .221 & .157 & -.031 & -.034 & -.003 & -.035 & -.043 \\
\hline NSF_B3 (20) & .603 & 2.05 & 0.88 & -.053 & .209 & .231 & .436 & .206 & .078 & .054 & .085 & .018 & .059 \\
\hline NSF_B4 (21) & .678 & 1.82 & 0.87 & .018 & .226 & .204 & .245 & .492 & .039 & .015 & .050 & -.022 & .025 \\
\hline BEN_B1 (22) & .859 & 3.05 & 1.41 & -.164 & .327 & .197 & .178 & .175 & .145 & .123 & .155 & .103 & .107 \\
\hline BEN_B2 (23) & .855 & 2.71 & 1.44 & -.070 & .169 & .448 & .196 & .117 & .096 & .086 & .137 & .078 & .055 \\
\hline BEN_B3 (24) & .849 & 2.79 & 1.46 & -.148 & .171 & .194 & .424 & .191 & .221 & .176 & .229 & .116 & .150 \\
\hline BEN_B4 (25) & .864 & 2.48 & 1.43 & -.078 & .149 & .198 & .220 & .464 & .172 & .149 & .185 & .078 & .142 \\
\hline
\end{tabular}




\begin{tabular}{|c|c|c|c|c|c|c|c|c|c|c|c|c|c|}
\hline CST_B1 (26) & .853 & 4.04 & 1.62 & .213 & -.407 & -.088 & -.059 & -.123 & -.215 & -.203 & -.251 & -.186 & -.203 \\
\hline CST_B2 (27) & .856 & 4.48 & 1.69 & .082 & -.193 & -.397 & -.070 & -.138 & -.141 & -.126 & -.171 & -.124 & -.093 \\
\hline CST_B3 (28) & .862 & 4.56 & 1.69 & .171 & -.239 & -.109 & -.325 & -.175 & -.341 & -.287 & -.312 & -.207 & -.276 \\
\hline CST_B4 (29) & .868 & 4.86 & 1.75 & .067 & -.218 & -.118 & -.167 & -.457 & -.277 & -.221 & -.260 & -.143 & -.223 \\
\hline NET_B1 (30) & .641 & 3.95 & 1.49 & -.195 & .459 & .164 & .138 & .163 & .203 & .173 & .285 & .206 & .182 \\
\hline NET_B2 (31) & .685 & 3.41 & 1.60 & -.088 & .179 & .519 & .183 & .159 & .068 & .071 & .135 & .063 & .059 \\
\hline NET_B3 (32) & .692 & 3.31 & 1.54 & -.172 & .195 & .246 & .503 & .222 & .271 & .230 & .301 & .158 & .227 \\
\hline NET_B4 (33) & .703 & 3.11 & 1.59 & -.094 & .177 & .196 & .213 & .524 & .180 & .157 & .229 & .116 & .176 \\
\hline
\end{tabular}

${ }^{\dagger} \mathrm{MV}=$ marker variable (used organizational commitment as unrelated, marker variable to further establish likely lack of common method bias); bolded and underlined diagonal elements are the square roots of the AVEs; all AVEs for the latent constructs were above minimum threshold of 0.500.

Table D.3. First-Order Measurement Model Statistics (Part 2 of 3)

\begin{tabular}{|c|c|c|c|c|c|c|c|c|c|c|c|c|}
\hline Latent construct & (10) & (11) & (12) & (13) & (14) & (15) & (16) & (17) & (18) & (19) & (20) & $(21)$ \\
\hline SM_B1 (10) &.$\underline{942}$ & & & & & & & & & & & \\
\hline SM_B2 (11) & .452 & .956 & & & & & & & & & & \\
\hline SM_B3 (12) & .403 & .394 & .939 & & & & & & & & & \\
\hline SM_B4 (13) & .452 & .409 & .435 & .954 & & & & & & & & \\
\hline NSN_B1 (14) & -.466 & -.226 & -.189 & -.219 & .787 & & & & & & & \\
\hline NSN_B2 (15) & -.166 & -.576 & -.232 & -.181 & .448 & .831 & & & & & & \\
\hline NSN_B3 (16) & -.141 & -.245 & -.439 & -.215 & .472 & .496 & $\underline{.806}$ & & & & & \\
\hline NSN_B4 (17) & -.207 & -.229 & -.277 & -.498 & .436 & .436 & .504 & .818 & & & & \\
\hline NSF_B1 (18) & -.308 & -.168 & -.127 & -.149 & .464 & .248 & .324 & .254 & .809 & & & \\
\hline NSF_B2 (19) & -.084 & -.414 & -.157 & -.126 & .269 & .586 & .348 & .285 & .515 & .807 & & \\
\hline NSF_B3 (20) & -.055 & -.170 & -.304 & -.137 & .232 & .309 & .549 & .296 & .529 & .579 & .776 & \\
\hline NSF_B4 (21) & -.125 & -.132 & -.163 & -.328 & .217 & .215 & .306 & .490 & .537 & .502 & .529 & .824 \\
\hline BEN_B1 (22) & -.433 & -.278 & -.335 & -.367 & .361 & .206 & .252 & .284 & .208 & .106 & .112 & .124 \\
\hline BEN_B2 (23) & -.294 & -.544 & -.325 & -.286 & .262 & .474 & .275 & .307 & .154 & .337 & .180 & .151 \\
\hline BEN_B3 (24) & -.236 & -.245 & -.508 & -.322 & .215 & .218 & .396 & .301 & .130 & .155 & .290 & .147 \\
\hline BEN_B4 (25) & -.238 & -.272 & -.335 & -.553 & .212 & .228 & .277 & .532 & .115 & .143 & .172 & .337 \\
\hline CST_B1 (26) & .585 & .283 & .314 & .322 & -.282 & -.077 & -.098 & -.128 & -.203 & -.041 & -.058 & -.047 \\
\hline
\end{tabular}




\begin{tabular}{|c|c|c|c|c|c|c|c|c|c|c|c|c|}
\hline CST_B2 (27) & .370 & .565 & .258 & .257 & -.180 & -.401 & -.132 & -.199 & -.111 & -.340 & -.106 & -.083 \\
\hline CST_B3 (28) & .321 & .248 & .456 & .289 & -.119 & -.094 & -.231 & -.150 & -.091 & -.085 & -.211 & -.099 \\
\hline CST_B4 (29) & .289 & .248 & .302 & .520 & -.106 & -.100 & -.140 & -.367 & -.082 & -.111 & -.101 & -.281 \\
\hline NET_B1 (30) & -.637 & -.333 & -.338 & -.366 & .491 & .213 & .253 & .301 & .317 & .108 & .128 & .121 \\
\hline NET_B2 (31) & -.346 & -.631 & -.359 & -.312 & .302 & .576 & .295 & .324 & .177 & .446 & .197 & .178 \\
\hline NET_B3 (32) & -.306 & -.311 & -.619 & -.344 & .251 & .265 & .442 & .319 & .121 & .171 & .314 & .140 \\
\hline NET_B4 (33) & -.332 & -.305 & -.347 & -.651 & .244 & .234 & .254 & .556 & .157 & .183 & .195 & .399 \\
\hline
\end{tabular}

Bolded and underlined diagonal elements are the square roots of the AVEs 
Table D.3. First-Order Measurement Model Statistics (Part 3 of 3)

\begin{tabular}{|c|c|c|c|c|c|c|c|c|c|c|c|c|}
\hline $\begin{array}{l}\text { Latent } \\
\text { construct }\end{array}$ & (22) & (23) & (24) & (25) & (26) & (27) & (28) & (29) & (30) & (31) & (32) & (33) \\
\hline BEN_B1 (22) & .927 & & & & & & & & & & & \\
\hline BEN_B2 (23) & .515 & .926 & & & & & & & & & & \\
\hline BEN_B3 (24) & .542 & .523 & .922 & & & & & & & & & \\
\hline BEN_B4 (25) & .545 & .484 & .509 & .930 & & & & & & & & \\
\hline CST_B1 (26) & -.435 & -.221 & -.271 & -.250 & .924 & & & & & & & \\
\hline CST_B2 (27) & -.246 & -.488 & -.253 & -.251 & .512 & .925 & & & & & & \\
\hline CST_B3 (28) & -.244 & -.248 & -.466 & -.279 & .564 & .517 & .928 & & & & & \\
\hline CST_B4 (29) & -.295 & -.223 & -.297 & -.546 & .507 & .485 & .581 & .931 & & & & \\
\hline NET_B1 (30) & .531 & .332 & .333 & .342 & -.555 & -.326 & -.349 & -.333 & .801 & & & \\
\hline NET_B2 (31) & .356 & .609 & .312 & .359 & -.264 & -.558 & -.259 & -.267 & .530 & .828 & & \\
\hline NET_B3 (32) & .397 & .385 & .581 & .419 & -.300 & -.279 & -.479 & -.312 & .574 & .539 & .832 & \\
\hline NET_B4 (33) & .391 & .330 & .359 & .672 & -.290 & -.230 & -.294 & -.590 & .523 & .478 & .540 & .838 \\
\hline
\end{tabular}

Bolded and underlined diagonal elements are the square roots of the AVEs 
Table D.4a. Highest Order Latent Variable Correlations against the Marker Variable, Organization Commitment (OC)

\begin{tabular}{|l|r|r|r|r|r|l|l|l|l|}
\hline Latent construct & Mean & SD & MV & (1) & (2) & (3) & (4) & (5) & (6) \\
\hline Marker variable $^{\dagger}$ & 4.55 & 1.51 & & & & & & \\
\hline cyberbullying frequency (first-order formative) (1) & 1.80 & 0.54 & -.067 & & & & & \\
\hline cyberbullying anonymity (second-order formative) (2) & 4.08 & 1.36 & -.137 & .201 & & & & & \\
\hline $\begin{array}{l}\text { cyberbullying situational morality (second-order formative) } \\
(3)\end{array}$ & 5.27 & 1.12 & .225 & -.473 & -.200 & & & & \\
\hline $\begin{array}{l}\text { cyberbullying negative social influence (second-order } \\
\text { formative) (4) }\end{array}$ & 2.62 & 0.91 & -.087 & .346 & -.014 & -.484 & & & \\
\hline cyberbullying benefits (second-order formative) (5) & 2.76 & 1.47 & -.144 & .442 & .207 & -.576 & .484 & & \\
\hline cyberbullying costs (second-order formative) (6) & 4.49 & 1.36 & .164 & -.379 & -.325 & .580 & -.282 & -.488 & \\
\hline cyberbullying neutralization (second-order formative) (7) & 3.45 & 1.25 & -.169 & .488 & .262 & -.673 & .534 & .652 & -.549 \\
\hline
\end{tabular}

This table represents the correlations of the latent constructs at their highest level; $2^{\text {nd }}=$ second-order formative construct formed of first-order reflective constructs; ${ }^{\dagger} \mathrm{MV}=$ marker variable (used organizational commitment as unrelated, marker variable to further establish likely lack of common method bias) 
Table D.4b. Collinearity Statistics and Reliabilities for All Constructs

\begin{tabular}{|c|c|c|c|c|c|c|}
\hline & & Collinearity & Statistics & Reliab & Inforn & \\
\hline Latent construct & Construct type & Tolerance & VIF & $\begin{array}{l}\# \text { of } \\
\text { items }\end{array}$ & $\mathbf{C R}$ & $\begin{array}{l}\text { Alpha } \\
(\alpha)\end{array}$ \\
\hline Anonymity: Lack of identification (A_LI) & First-order reflective & .267 & 3.740 & 2 & .906 & .794 \\
\hline Anonymity: Confidence in the system to function (A-CS) & First-order reflective & .382 & 2.614 & 2 & .923 & .833 \\
\hline Anonymity: Denial of responsibility (A_DR) & First-order reflective & .444 & 2.250 & 2 & .872 & .716 \\
\hline Anonymity: Lack of proximity (A_PX) & First-order reflective & .705 & 1.419 & 2 & .902 & .784 \\
\hline Anonymity: Knowledge of others (A_KO) & First-order reflective & .356 & 2.806 & 2 & .896 & .769 \\
\hline CB anonymity (second-order) & Second-order formative & .635 & 1.575 & 10 & $\mathrm{n} / \mathrm{a}$ & $\mathrm{n} / \mathrm{a}$ \\
\hline CB frequency & First-order formative & .531 & 1.884 & 4 & $\mathrm{n} / \mathrm{a}$ & $\mathrm{n} / \mathrm{a}$ \\
\hline Situational morality: Behavior 1 (SM_B1) & First-order reflective & .342 & 2.922 & 3 & .959 & .937 \\
\hline Situational morality: Behavior 2 (SM_B2) & First-order reflective & .339 & 2.951 & 3 & .969 & .953 \\
\hline Situational morality: Behavior 3 (SM_B3) & First-order reflective & .393 & 2.545 & 3 & .957 & .933 \\
\hline Situational morality: Behavior 4 (SM_B4) & First-order reflective & .391 & 2.557 & 3 & .968 & .950 \\
\hline CB situational morality (second-order) & Second-order formative & .437 & 2.286 & 12 & $\mathrm{n} / \mathrm{a}$ & $\mathrm{n} / \mathrm{a}$ \\
\hline CB negative social influence, norms: Behavior 1 (NSN_B1) & First-order reflective & .413 & 2.424 & 6 & .906 & .878 \\
\hline CB negative social influence, norms: Behavior 2 (NSN_B2) & First-order reflective & .315 & 3.172 & 6 & .930 & .910 \\
\hline CB negative social influence, norms: Behavior 3 (NSN_B3) & First-order reflective & .373 & 2.678 & 6 & .917 & .891 \\
\hline CB negative social influence, norms: Behavior 4 (NSN_B4) & First-order reflective & .393 & 2.545 & 6 & .927 & .900 \\
\hline CB negative social influence, frequency: Behavior 1 (NSF_B1) & First-order reflective & .417 & 2.398 & 3 & .850 & .735 \\
\hline CB negative social influence, frequency: Behavior 2 (NSF_B2) & First-order reflective & .338 & 2.958 & 4 & .882 & .821 \\
\hline CB negative social influence, frequency: Behavior 3 (NSF_B3) & First-order reflective & .376 & 2.662 & 5 & .883 & .836 \\
\hline CB negative social influence, frequency: Behavior 4 (NSF_B4) & First-order reflective & .407 & 2.460 & 3 & .863 & .762 \\
\hline CB negative social influence (second-order) & Second-order formative & .621 & 1.610 & 39 & $\mathrm{n} / \mathrm{a}$ & $\mathrm{n} / \mathrm{a}$ \\
\hline CB benefits: Behavior 1 (BEN_B1) & First-order reflective & .392 & 2.551 & 4 & .960 & .945 \\
\hline CB benefits: Behavior 2 (BEN_B2) & First-order reflective & .357 & 2.802 & 4 & .959 & .943 \\
\hline CB benefits: Behavior 3 (BEN_B3) & First-order reflective & .367 & 2.724 & 4 & .958 & .941 \\
\hline CB benefits: Behavior 4 (BEN_B4) & First-order reflective & .328 & 3.052 & 4 & .962 & .948 \\
\hline CB benefits (second-order) & Second-order formative & .499 & 2.002 & 12 & $\mathrm{n} / \mathrm{a}$ & $\mathrm{n} / \mathrm{a}$ \\
\hline
\end{tabular}




\begin{tabular}{|c|c|c|c|c|c|c|}
\hline CB costs: Behavior 1 (CST_B1) & First-order reflective & .351 & 2.848 & 4 & .959 & .943 \\
\hline CB costs: Behavior 2 (CST_B2) & First-order reflective & .318 & 3.141 & 4 & .959 & .944 \\
\hline CB costs: Behavior 3 (CST_B3) & First-order reflective & .348 & 2.874 & 4 & .961 & .947 \\
\hline CB costs: Behavior 4 (CST_B4) & First-order reflective & .306 & 3.273 & 4 & .963 & .950 \\
\hline CB costs (second-order) & Second-order formative & .570 & 1.753 & 12 & $\mathrm{n} / \mathrm{a}$ & $\mathrm{n} / \mathrm{a}$ \\
\hline CB neutralization: Behavior 1 (NET_B1) & First-order reflective & .268 & 3.728 & 5 & .913 & .883 \\
\hline CB neutralization: Behavior 2 (NET_B2) & First-order reflective & .264 & 3.783 & 5 & .927 & .904 \\
\hline CB neutralization: Behavior 3 (NET_B3) & First-order reflective & .287 & 3.488 & 5 & .930 & .908 \\
\hline CB neutralization: Behavior 4 (NET_B4) & First-order reflective & .251 & 3.980 & 5 & .933 & .912 \\
\hline Neutralization (second-order) & Second-order formative & .385 & 2.597 & 20 & $\mathrm{n} / \mathrm{a}$ & $\mathrm{n} / \mathrm{a}$ \\
\hline
\end{tabular}

B1 = Post something hurtful, rude, inappropriate, or mean that targets someone; B2 = Publicly embarrass or prank someone with true information or photos that are potentially harmful; B3 = Spread a rumor or untrue information about someone; B4 = Send threatening or harassing messages, or send messages after someone told you to stop.

\section{Table D.5a. CB Zero-order Correlations and Inter-item Correlational Diagnostics}

\begin{tabular}{|l|l|l|l|l|}
\hline cyberbullying behavior & $\begin{array}{l}\text { cyberbullying } \\
\text { (formative) }\end{array}$ & $\mathbf{( 1 )}$ & (2) & (3) \\
\hline Behavior 1 frequency (1) & .666 & & & \\
\hline Behavior 2 frequency (2) & .651 & .234 & & \\
\hline Behavior 3 frequency (3) & .703 & .284 & .292 & \\
\hline Behavior 4 frequency (4) & .682 & .287 & .241 & .310 \\
\hline
\end{tabular}

Note: the first highlighted column shows the zero-order correlations of the latent construct's items against the overall average of the latent construct.

B1 = Post something hurtful, rude, inappropriate, or mean that targets someone; B2 = Publicly embarrass or prank someone with true information or photos that are potentially harmful; B3 = Spread a rumor or untrue information about someone; B4 = Send threatening or harassing messages, or send messages after someone told you to stop. 
Table D.5b. Neutralization Zero-order Correlations and Inter-item Correlational Diagnostics (Part 1 of 2)

\begin{tabular}{|c|c|c|c|c|c|c|c|c|c|c|c|c|c|}
\hline Items & $\begin{array}{l}\text { Neutralization } \\
\text { (formative) }\end{array}$ & b4_n1 & b4_n2 & b4_n3 & b4_n4 & b4_n5 & b4_n6 & b3_n1 & b3_n2 & b3_n3 & b3_n4 & b3_n5 & b3_n6 \\
\hline b4_n1 & .684 & & & & & & & & & & & & \\
\hline b4_n2 & .655 & .757 & & & & & & & & & & & \\
\hline b4_n3 & .725 & .711 & .653 & & & & & & & & & & \\
\hline b4_n4 & .516 & .433 & .419 & .427 & & & & & & & & & \\
\hline b4_n5 & .694 & .729 & .728 & .725 & .441 & & & & & & & & \\
\hline b4_n6 & .712 & .718 & .682 & .810 & .444 & .811 & & & & & & & \\
\hline b3_n1 & .690 & .465 & .410 & .358 & .260 & .378 & .361 & & & & & & \\
\hline b3_n2 & .678 & .431 & .507 & .368 & .219 & .389 & .382 & .687 & & & & & \\
\hline b3_n3 & .736 & .384 & .382 & .515 & .264 & .402 & .450 & .640 & .667 & & & & \\
\hline b3_n4 & .566 & .318 & .272 & .291 & .529 & .303 & .300 & .463 & .411 & .478 & & & \\
\hline b3_n5 & .704 & .392 & .399 & .397 & .261 & .470 & .434 & .673 & .694 & .726 & .436 & & \\
\hline b3_n6 & .739 & .419 & .420 & .468 & .240 & .437 & .470 & .694 & .718 & .800 & .452 & .790 & \\
\hline b2_n1 & .663 & .435 & .311 & .346 & .228 & .338 & .330 & .509 & .389 & .370 & .281 & .373 & .393 \\
\hline b2_n2 & .640 & .348 & .377 & .368 & .188 & .320 & .331 & .375 & .495 & .403 & .219 & .376 & .417 \\
\hline b2_n3 & .715 & .331 & .299 & .497 & .245 & .357 & .434 & .375 & .363 & .513 & .290 & .400 & .460 \\
\hline b2_n4 & .512 & .204 & .170 & .236 & .498 & .195 & .214 & .262 & .231 & .282 & .571 & .226 & .259 \\
\hline b2_n5 & .682 & .338 & .308 & .398 & .217 & .430 & .389 & .375 & .354 & .408 & .262 & .452 & .438 \\
\hline b2_n6 & .724 & .368 & .323 & .443 & .224 & .397 & .425 & .388 & .399 & .442 & .282 & .411 & .471 \\
\hline b1_n1 & .680 & .466 & .380 & .400 & .240 & .375 & .377 & .556 & .414 & .441 & .291 & .422 & .446 \\
\hline b1_n2 & .627 & .356 & .426 & .367 & .205 & .330 & .324 & .420 & .481 & .407 & .227 & .364 & .390 \\
\hline b1_n3 & .687 & .328 & .310 & .499 & .253 & .358 & .441 & .353 & .334 & .521 & .284 & .395 & .437 \\
\hline b1_n4 & .508 & .267 & .245 & .285 & .545 & .248 & .272 & .267 & .215 & .265 & .573 & .222 & .219 \\
\hline b1_n5 & .702 & .397 & .386 & .450 & .272 & .502 & .440 & .425 & .378 & .464 & .291 & .511 & .475 \\
\hline b1_n6 & .688 & .337 & .327 & .452 & .200 & .365 & .438 & .373 & .356 & .465 & .261 & .407 & .455 \\
\hline
\end{tabular}


Table D.5b. Neutralization Zero-order Correlations and Inter-item Correlational Diagnostics (Part 2 of 2)

\begin{tabular}{|l|l|l|l|l|l|l|l|l|l|l|l|}
\hline Items & b2_n1 & b2_n2 & b2_n3 & b2_n4 & b2_n5 & b2_n6 & b1_n1 & b1_n2 & b1_n3 & b1_n4 & b1_n5 \\
\hline b2_n2 & .687 & & & & & & & & & & \\
\hline b2_n3 & .661 & .643 & & & & & & & & \\
\hline b2_n4 & .400 & .375 & .429 & & & & & & & \\
\hline b2_n5 & .681 & .670 & .723 & .414 & & & & & & \\
\hline b2_n6 & .705 & .708 & .811 & .432 & .806 & & & & & \\
\hline b1_n1 & .490 & .328 & .377 & .241 & .351 & .398 & & & & \\
\hline b1_n2 & .324 & .408 & .335 & .202 & .296 & .356 & .652 & & & \\
\hline b1_n3 & .366 & .330 & .551 & .263 & .383 & .470 & .613 & .599 & & & \\
\hline b1_n4 & .245 & .192 & .273 & .561 & .231 & .245 & .380 & .354 & .362 & & \\
\hline b1_n5 & .338 & .306 & .415 & .271 & .473 & .453 & .611 & .602 & .658 & .346 & \\
\hline b1_n6 & .359 & .335 & .492 & .247 & .404 & .483 & .654 & .647 & .788 & .375 & .712 \\
\hline
\end{tabular}

Note: the first highlighted column shows the zero-order correlations of the latent construct's items against the overall average of the latent construct. 
Table D.5c. cyberbullying Anonymity Zero-order Correlations and Inter-item Correlational Diagnostics

\begin{tabular}{|c|c|c|c|c|c|c|c|c|c|c|}
\hline Items & $\begin{array}{l}\text { Anonymity } \\
\left(2^{\text {nd}}-\text { Order }\right)\end{array}$ & a_li1 & a_li2 & a_cs1 & a_cs2 & a_dr1 & a_dr2 & a_px1 & a_px2 & a_ko1 \\
\hline a_li1 & 838 & & & & & & & & & \\
\hline a_li2 & .791 & .658 & & & & & & & & \\
\hline a_cs1 & .780 & .708 & .565 & & & & & & & \\
\hline a_cs2 & .786 & .717 & .583 & .714 & & & & & & \\
\hline a_dr1 & .686 & .463 & .506 & .454 & .433 & & & & & \\
\hline a_dr2 & .720 & .550 & .543 & .512 & .486 & .558 & & & & \\
\hline a_px1 & .575 & .377 & .329 & .321 & .338 & 290 & . 264 & & & \\
\hline a_px2 & .643 & .419 & .445 & .366 & .381 & .385 & .349 & .645 & & \\
\hline a_ko1 & .770 & .620 & .593 & .535 & .537 & .502 & .535 & .347 & .387 & \\
\hline a_ko2 & .781 & .628 & .599 & .543 & .559 & .511 & .549 & .351 & .384 & .624 \\
\hline
\end{tabular}

Note: the first highlighted column shows the zero-order correlations of the latent construct's items against the overall average of the latent construct. 
Table D.6. Detailed Results of PLS Analysis on Hypotheses Only $(n=1003)$

\begin{tabular}{|l|l|l|l|}
\hline Tested path & $\boldsymbol{\beta}$ & $\begin{array}{l}\boldsymbol{t} \text { - } \\
\text { statistic }\end{array}$ & Supported? \\
\hline $\begin{array}{l}\text { H1: cyberbullying anonymity } \rightarrow \text { cyberbullying negative social } \\
\text { influence }\end{array}$ & .202 & $2.12^{*}$ & Yes \\
\hline H2: cyberbullying anonymity $\rightarrow(-)$ cyberbullying costs & $(-.356)$ & $9.66^{* * *}$ & Yes \\
\hline H3: cyberbullying anonymity $\rightarrow$ cyberbullying benefits & .274 & $7.58^{* * *}$ & Yes \\
\hline H4: cyberbullying anonymity $\rightarrow$ cyberbullying neutralization & .360 & $9.59^{* * *}$ & Yes \\
\hline H5: cyberbullying anonymity $\rightarrow(-)$ cyberbullying situational morality & $(-.306)$ & $8.36^{* * *}$ & Yes \\
\hline $\begin{array}{l}\text { H6: cyberbullying negative social influence } \rightarrow \text { cyberbullying } \\
\text { frequency }\end{array}$ & .276 & $6.75^{* * *}$ & Yes \\
\hline H7a: cyberbullying costs $\rightarrow(-)$ cyberbullying frequency & $(-.127)$ & $3.18^{* *}$ & Yes \\
\hline H7b: cyberbullying benefits $\rightarrow$ cyberbullying frequency & .075 & $1.81(\mathrm{n} / \mathrm{s})$ & No \\
\hline H8a: cyberbullying neutralization $\rightarrow$ cyberbullying frequency & .127 & $2.34^{*}$ & Yes \\
\hline H8b: cyberbullying situational morality $\rightarrow(-)$ cyberbullying frequency & $(-.244)$ & $5.52^{* * *}$ & Yes \\
\hline
\end{tabular}

$p<0.05, p<0.01, p<0.001, \mathrm{n} / \mathrm{s}=$ not significant

Table D.7. Detailed Results of PLS Analysis on All Relationships and Controls ( $n=1003)$

\begin{tabular}{|l|l|l|l|}
\hline Tested path & $\boldsymbol{\beta}$ & $\boldsymbol{t}$-statistic & Supported? \\
\hline $\begin{array}{l}\text { H1: cyberbullying anonymity } \rightarrow \text { cyberbullying negative social } \\
\text { influence }\end{array}$ & .114 & $1.55(\mathrm{n} / \mathrm{s})$ & No \\
\hline H2: cyberbullying anonymity $\rightarrow(-)$ cyberbullying costs & $(-.348)$ & $7.96^{* * *}$ & Yes \\
\hline H3: cyberbullying anonymity $\rightarrow$ cyberbullying benefits & .274 & $7.19^{* * *}$ & Yes \\
\hline H4: cyberbullying anonymity $\rightarrow$ cyberbullying neutralization & .338 & $7.78^{* * *}$ & Yes \\
\hline H5: cyberbullying anonymity $\rightarrow(-)$ cyberbullying situational morality & $(-.266)$ & $6.39^{* * *}$ & Yes \\
\hline $\begin{array}{l}\text { H6: cyberbullying negative social influence } \rightarrow \text { cyberbullying } \\
\text { frequency }\end{array}$ & .219 & $4.39^{* * *}$ & Yes \\
\hline H7a: cyberbullying costs $\rightarrow(-)$ cyberbullying frequency & $(-.098)$ & $2.43^{*}$ & Yes \\
\hline H7b: cyberbullying benefits $\rightarrow$ cyberbullying frequency & .087 & $1.81(\mathrm{n} / \mathrm{s})$ & No \\
\hline H8a: cyberbullying neutralization $\rightarrow$ cyberbullying frequency & .173 & $3.31^{* *}$ & Yes \\
\hline H8b: cyberbullying situational morality $\rightarrow(-)$ cyberbullying frequency & $(-.223)$ & $4.64^{* * *}$ & Yes \\
\hline \begin{tabular}{l|l|l|}
\hline \\
Contribution of cyberbullying Anonymity Subconstructs to cyberbullying Anonymity
\end{tabular} \\
\hline Lack of identification $\rightarrow$ cyberbullying anonymity & .323 & $7.02^{* * *}$ & Yes \\
\hline Diffused responsibility $\rightarrow$ cyberbullying anonymity & .324 & $10.80^{* * *}$ & Yes \\
\hline Lack of proximity $\rightarrow$ cyberbullying anonymity & .197 & $7.31^{* * *}$ & Yes \\
\hline Knowledge of others $\rightarrow$ cyberbullying anonymity & .165 & $4.18^{* * *}$ & Yes \\
\hline Confidence in the system to work $\rightarrow$ cyberbullying anonymity & .203 & $5.76^{* * *}$ & Yes \\
\hline \multicolumn{2}{|l|}{}
\end{tabular}




\begin{tabular}{|c|c|c|c|}
\hline \multicolumn{4}{|c|}{$\begin{array}{c}\text { SM Community Social Structure and Sociodemographic Variables on social learning Constructs } \\
\end{array}$} \\
\hline Age $\rightarrow$ cyberbullying negative social influence & $(-.051)$ & $1.13(\mathrm{n} / \mathrm{s})$ & No \\
\hline Age $\rightarrow$ cyberbullying benefits & $(-.005)$ & $1.14(\mathrm{n} / \mathrm{s})$ & No \\
\hline Age $\rightarrow$ cyberbullying costs & $(-.054)$ & $0.87(\mathrm{n} / \mathrm{s})$ & No \\
\hline Age $\rightarrow$ cyberbullying neutralization & $(-.056)$ & $0.72(\mathrm{n} / \mathrm{s})$ & No \\
\hline Age $\rightarrow$ cyberbullying situational morality & .064 & $1.10(\mathrm{n} / \mathrm{s})$ & No \\
\hline Gender (female) $\rightarrow$ cyberbullying negative social influence & $(-.069)$ & $0.80(\mathrm{n} / \mathrm{s})$ & No \\
\hline Gender (female) $\rightarrow$ cyberbullying benefits & $(-.108)$ & $3.01^{* *}$ & Yes \\
\hline Gender (female) $\rightarrow$ cyberbullying costs & .128 & $3.59 * * *$ & Yes \\
\hline Gender (female) $\rightarrow$ cyberbullying neutralization & $(-.050)$ & $1.10(\mathrm{n} / \mathrm{s})$ & No \\
\hline Gender (female) $\rightarrow$ cyberbullying situational morality & .064 & $1.56(\mathrm{n} / \mathrm{s})$ & No \\
\hline Education $\rightarrow$ cyberbullying negative social influence & $(-.080)$ & $1.97 *$ & Yes \\
\hline Education $\rightarrow$ cyberbullying benefits & $(-.015)$ & $0.26(\mathrm{n} / \mathrm{s})$ & No \\
\hline Education $\rightarrow$ cyberbullying costs & .053 & $0.78(\mathrm{n} / \mathrm{s})$ & No \\
\hline Education $\rightarrow$ cyberbullying neutralization & $(-.073)$ & $1.27(\mathrm{n} / \mathrm{s})$ & No \\
\hline Education $\rightarrow$ cyberbullying situational morality & .083 & $1.80(\mathrm{n} / \mathrm{s})$ & No \\
\hline Employment status $\rightarrow$ cyberbullying negative social influence & $(-.058)$ & $0.80(\mathrm{n} / \mathrm{s})$ & No \\
\hline Employment status $\rightarrow$ cyberbullying benefits & .067 & $1.34(\mathrm{n} / \mathrm{s})$ & No \\
\hline Employment status $\rightarrow$ cyberbullying costs & $(-.038)$ & $0.72(\mathrm{n} / \mathrm{s})$ & No \\
\hline Employment status $\rightarrow$ cyberbullying neutralization & $(-.001)$ & $0.02(\mathrm{n} / \mathrm{s})$ & No \\
\hline Employment status $\rightarrow$ cyberbullying situational morality & $(-.002)$ & $0.02(\mathrm{n} / \mathrm{s})$ & No \\
\hline Income $\rightarrow$ cyberbullying negative social influence & $(-.039)$ & $0.43(\mathrm{n} / \mathrm{s})$ & No \\
\hline Income $\rightarrow$ cyberbullying benefits & .011 & $0.17(\mathrm{n} / \mathrm{s})$ & No \\
\hline Income $\rightarrow$ cyberbullying costs & $(-.036)$ & $0.42(\mathrm{n} / \mathrm{s})$ & No \\
\hline Income $\rightarrow$ cyberbullying neutralization & .008 & $0.13(\mathrm{n} / \mathrm{s})$ & No \\
\hline Income $\rightarrow$ cyberbullying situational morality & .018 & $0.38(\mathrm{n} / \mathrm{s})$ & No \\
\hline $\begin{array}{l}\text { Hours per day on social media } \rightarrow \text { cyberbullying negative social } \\
\text { influence }\end{array}$ & .177 & $4.40^{* * *}$ & Yes \\
\hline Hours per day on social media $\rightarrow$ cyberbullying benefits & .084 & $2.09 *$ & Yes \\
\hline Hours per day on social media $\rightarrow$ cyberbullying costs & $(-.044)$ & $0.95(\mathrm{n} / \mathrm{s})$ & No \\
\hline Hours per day on social media $\rightarrow$ cyberbullying neutralization & .078 & $2.02 *$ & Yes \\
\hline Hours per day on social media $\rightarrow$ cyberbullying situational morality & $(-.107)$ & $2.89 * *$ & Yes \\
\hline \multicolumn{4}{|c|}{ Exploratory Controls on Cyberbullying Frequency } \\
\hline Age $\rightarrow$ cyberbullying frequency & $(-.038)$ & $1.20(\mathrm{n} / \mathrm{s})$ & No \\
\hline Gender (female) $\rightarrow$ cyberbullying frequency & $(-.064)$ & $2.03 *$ & Yes \\
\hline Education $\rightarrow$ cyberbullying frequency & $(-.021)$ & $0.80(\mathrm{n} / \mathrm{s})$ & No \\
\hline Employment status $\rightarrow$ cyberbullying frequency & $(-.052)$ & $1.62(\mathrm{n} / \mathrm{s})$ & No \\
\hline Income $\rightarrow$ cyberbullying frequency & .082 & $1.85(\mathrm{n} / \mathrm{s})$ & No \\
\hline
\end{tabular}




\begin{tabular}{|c|c|c|c|}
\hline Hours per day on social media $\rightarrow$ cyberbullying frequency & .087 & $2.97 * *$ & Yes \\
\hline
\end{tabular}

Table D.8. Basic Results for Four Separately Run Behavior Models (n=1003)

\begin{tabular}{|c|c|c|c|c|c|c|c|c|}
\hline \multirow[b]{2}{*}{ Tested path } & \multicolumn{2}{|c|}{ Behavior B1 } & \multicolumn{2}{|c|}{ Behavior B2 } & \multicolumn{2}{|c|}{ Behavior B3 } & \multicolumn{2}{|c|}{ Behavior B4 } \\
\hline & $\beta$ & $t$-statistic & $\beta$ & $t$-statistic & $\beta$ & $t$-statistic & $\beta$ & $t$-statistic \\
\hline $\begin{array}{l}\text { H1: cyberbullying anonymity } \rightarrow \text { cyberbullying } \\
\text { negative social influence }\end{array}$ & .088 & $1.05(\mathrm{n} / \mathrm{s})$ & $(-.013)$ & $0.19(\mathrm{n} / \mathrm{s})$ & .123 & $2.59 * *$ & .129 & $2.55 * *$ \\
\hline $\begin{array}{l}\text { H2: cyberbullying anonymity } \rightarrow(-) \text { cyberbullying } \\
\text { costs }\end{array}$ & $(-.279)$ & $7.68 * * *$ & $(-.215)$ & $4.48 * * *$ & $(-.359)$ & $10.43^{* * *}$ & $(-.287)$ & $8.14^{* * *}$ \\
\hline $\begin{array}{l}\text { H3: cyberbullying anonymity } \rightarrow \text { cyberbullying } \\
\text { benefits }\end{array}$ & .169 & $4.12 * * *$ & .169 & $3.88 * * *$ & .270 & $7.63 * * *$ & .214 & $6.30 * * *$ \\
\hline $\begin{array}{l}\text { H4: cyberbullying anonymity } \rightarrow \text { cyberbullying } \\
\text { neutralization }\end{array}$ & .341 & $9.72 * * *$ & .161 & $3.45 * * *$ & .333 & $9.33 * * *$ & .282 & $7.65 * * *$ \\
\hline $\begin{array}{l}\text { H5: cyberbullying anonymity } \rightarrow(-) \text { cyberbullying } \\
\text { situational morality }\end{array}$ & $(-.197)$ & $5.11 * * *$ & $(-.114)$ & $2.09 *$ & $(-.280)$ & $7.63 * * *$ & $(-.240)$ & $6.63 * * *$ \\
\hline $\begin{array}{l}\text { H6: cyberbullying negative social influence } \rightarrow \\
\text { cyberbullying frequency }\end{array}$ & .284 & $7.39 * * *$ & .357 & $9.68 * * *$ & .265 & $7.21 * * *$ & .306 & $7.24 * * *$ \\
\hline $\begin{array}{l}\text { H7a: cyberbullying costs } \rightarrow(-) \text { cyberbullying } \\
\text { frequency }\end{array}$ & $(-.132)$ & $3.24 * * *$ & $(-.017)$ & $0.49(\mathrm{n} / \mathrm{s})$ & $(-.037)$ & $1.17(\mathrm{n} / \mathrm{s})$ & $(-.156)$ & $3.87 * * *$ \\
\hline $\begin{array}{l}\text { H7b: cyberbullying benefits } \rightarrow \text { cyberbullying } \\
\text { frequency }\end{array}$ & .056 & $1.59(\mathrm{n} / \mathrm{s})$ & .107 & $2.47 * *$ & .105 & $2.63 * *$ & .052 & $1.13(\mathrm{n} / \mathrm{s})$ \\
\hline $\begin{array}{l}\text { H8a: cyberbullying neutralization } \rightarrow \text { cyberbullying } \\
\text { frequency }\end{array}$ & .151 & $3.26 * * *$ & .194 & $4.36^{* * *}$ & .218 & $4.87 * * *$ & .099 & $1.72(\mathrm{n} / \mathrm{s})$ \\
\hline $\begin{array}{l}\text { H8b: cyberbullying situational morality } \rightarrow(-) \\
\text { cyberbullying frequency }\end{array}$ & $(.188)$ & $4.40 * * *$ & $(-.175)$ & $4.32 * * *$ & $(-.148)$ & $3.39 * * *$ & $(-.204)$ & $4.56 * * *$ \\
\hline
\end{tabular}

$p<0.05, p<0.01, p<0.001, \mathrm{n} / \mathrm{s}=$ not significant

B1. Post something hurtful, rude, inappropriate, or mean that targets someone.

B2. Publicly embarrass or prank someone with true information or photos that are potentially harmful.

B3. Spread a rumor or untrue information about someone.

B4. Send threatening or harassing messages, or send messages after someone told you to stop. 


\section{ANALYSES FOR MEDIATION}

Our model proposing one level of full mediation to adhere to the assumption of SSSL that the social learning constructs act as full mediators. Testing for this kind of complex mediation at the same time is not possible with PLS (or any other tool, for that matter); however, this can be accurately tested using advanced bootstrapping tests on the construct confidence intervals of the mediation effects, as shown in this section.

The traditional tests for mediation have been the Baron and Kenny (1986) and Sobel (1982) tests. However, with more computing power available to researchers, other methods have become more prevalent. The bootstrapping method represents one such approach which has gained in popularity in recent times (Hayes 2009; MacKinnon) and has been recently introduced in IS research (e.g., Vance et al. 2015). This method has several advantages (Vance et al. 2015): it provides greater statistical power, allows for the direct measurement of "indirect effects," and does not assume normal distribution such as that in the Sobel (1982) method.

Our mediation testing with bootstrapping follows Baron and Kenny's (1986) guidelines for evaluating the three paths shown in Figure D.1. The paths in question are: (1) from the independent to the mediating variable (a), (2) from the mediating to the dependent variable (b), and (3) from the independent to the dependent variable (path $c$, or $c^{\prime}$ when considered simultaneously with paths $a$ and $b$ ).

Figure D.1. Overview of Baron and Kenny's (1986) Approach to Mediation

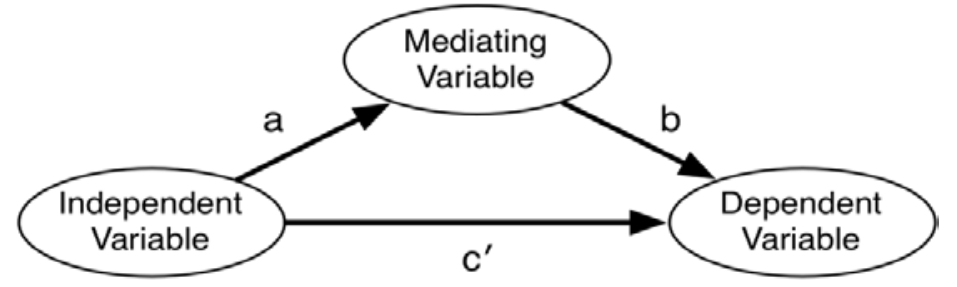

In the bootstrap method, we resample (from the obtained sample) with replacement 5000 times. In each resample, we obtain the product (of $a b$ ) by multiplying the coefficients in paths $a$ and $b$, which estimates the indirect effect in the resample (MacKinnon 2008). The coefficient corresponding to $c^{\prime}$ is also obtained. This process is repeated at least 1000 times; preferably this should be close to 5000 times or more (Hayes 2009). We used 5000 resamples. Of course, our mediation model is more complex than depicted in Figure A2.1, but the same principals and logic hold. Figure D.2 depicts the mediation mapping we used for the social learning constructs.

Figure D.2. Mediation Mapping to Test social learning Constructs as Full Mediators

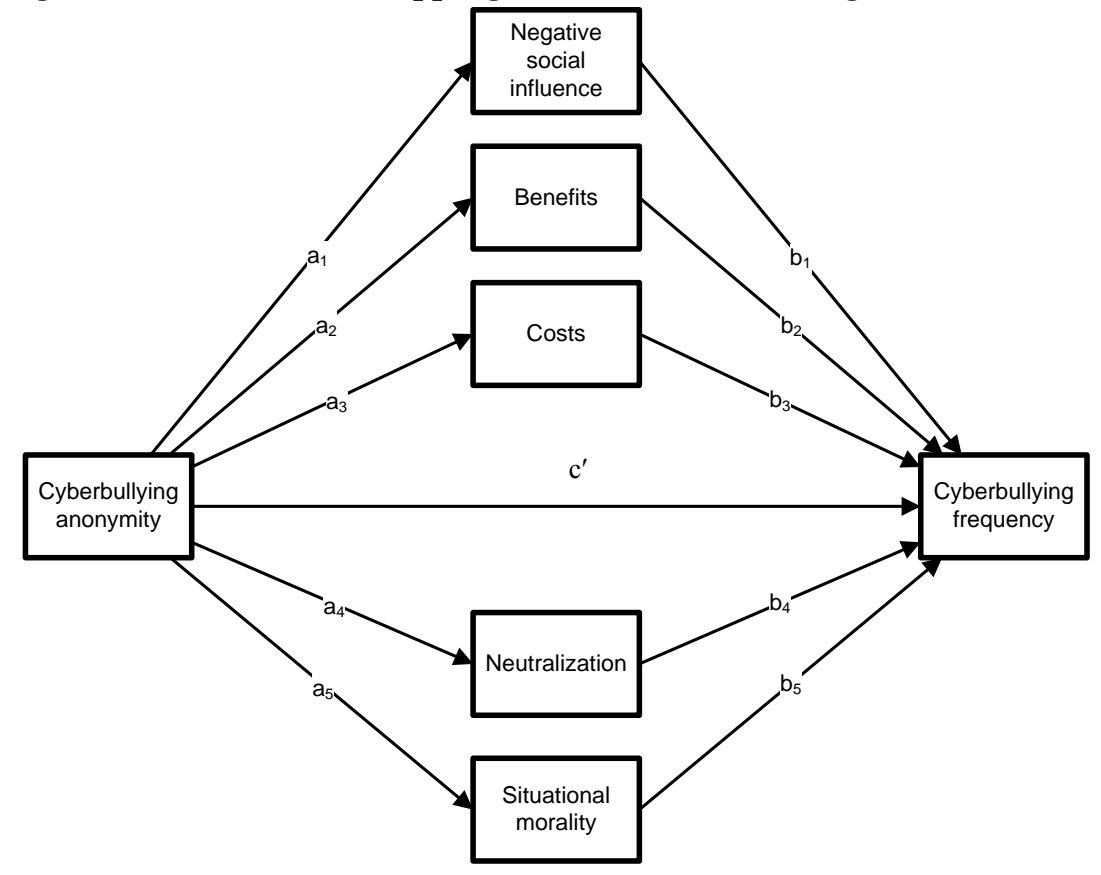


Sorting the values of $a b$ and $c^{\prime}$ in ascending order yields a percentile-based confidence interval $c i \%$. To do this, the ordinal positions of $a b$ and $c^{\prime}$ corresponding to the bounds of our interval are calculated using the formula $k(.5-c i / 200)$ for the lower bound and the formula $1+k(.5+c i / 200)$ for the upper bound (Hayes 2009). In this case, $\mathrm{k}$ is the number of resamples mentioned earlier. We assume a standard $95 \%$ confidence interval, so our ordinal ranges are 125 (lower bound) and 4876 (upper bound).

Observing the confidence interval $a b$, if we do not find zero between the upper and lower bounds, we can conclude with a confidence of ci\% that the indirect effect exists, that is, it is not zero (MacKinnon 2008). Examining the confidence interval for $c^{\prime}$ allows us to infer whether the mediation is full or partial. If $a b$ is non-zero and $c^{\prime}$ is zero, full mediation is indicated; on the other hand, if both $a b$ and $c^{\prime}$ are non-zero, then partial mediation can be inferred.

We followed the above procedures to bootstrap the effects of our mediating relationships. The results are shown in Table D.8. The results first show that indeed our model complies with SSSL in that the social learning constructs act as full mediators, with the exception of negative social influence because its relationship with anonymity was insignificant in the full model. This is a particularly compelling analysis because it provides further support for perceived anonymity creating a unique social media social structure context that drives the social learning processes, which in turn foster cyberbullying. 
Table D.8. Bootstrapped Confidence Interval Tests for Full and Partial Mediation Model (All Model Mediators of NSI)

\begin{tabular}{|c|c|c|c|c|c|c|c|c|}
\hline \multirow[t]{2}{*}{ Proposed relationship } & \multirow[b]{2}{*}{$\begin{array}{l}\text { Proposed } \\
\text { Mediator }\end{array}$} & \multicolumn{3}{|c|}{ Mediation Test $(a b)$} & \multicolumn{3}{|c|}{ Full/Partial Mediation Test $\left(c^{\prime}\right)$} & \multirow[b]{2}{*}{$\begin{array}{l}\text { Type of } \\
\text { mediation } \\
\text { relationship }\end{array}$} \\
\hline & & $\begin{array}{l}5 \% \text { lower } \\
\text { bound } \\
125\end{array}$ & $\begin{array}{l}95 \% \\
\text { upper } \\
\text { bound } \\
4876\end{array}$ & $\begin{array}{l}\text { Zero } \\
\text { included? }\end{array}$ & $\begin{array}{l}2.5 \% \\
\text { lower } \\
\text { bound }\end{array}$ & $\begin{array}{l}97.5 \% \\
\text { upper } \\
\text { bound }\end{array}$ & $\begin{array}{l}\text { Zero } \\
\text { included? }\end{array}$ & \\
\hline \multicolumn{9}{|c|}{ Testing social learning Constructs as Mediators in the Model } \\
\hline Anonymity $\left(\mathrm{a}_{1}\right) \rightarrow$ NSI $\left(\mathrm{b}_{1}\right) \rightarrow$ cyberbullying $\left(c^{\prime}\right)$ & NSI $\left(b_{1}\right)$ & -.020 & .098 & Yes & -.069 & .074 & Yes & $\mathrm{n} / \mathrm{a}^{*}$ \\
\hline $\begin{array}{l}\text { Anonymity }\left(\mathrm{a}_{2}\right) \rightarrow \text { Benefits }\left(\mathrm{b}_{2}\right) \rightarrow \text { cyberbullying } \\
\left(c^{\prime}\right)\end{array}$ & Benefits $\left(\mathrm{b}_{2}\right)$ & .002 & .053 & No & -.069 & .074 & Yes & Full \\
\hline Anonymity $\left(\mathrm{a}_{3}\right) \rightarrow$ Costs $\left(\mathrm{b}_{3}\right) \rightarrow$ cyberbullying $\left(c^{\prime}\right)$ & Costs $\left(b_{3}\right)$ & .020 & .082 & No & -.069 & .074 & Yes & Full \\
\hline $\begin{array}{l}\text { Anonymity }\left(\mathrm{a}_{4}\right) \rightarrow \text { Neutralization }\left(\mathrm{b}_{4}\right) \rightarrow \\
\text { cyberbullying }\left(c^{\prime}\right)\end{array}$ & Neutralization $\left(\mathrm{b}_{4}\right)$ & .022 & .102 & No & -.069 & .074 & Yes & Full \\
\hline $\begin{array}{l}\text { Anonymity }\left(\mathrm{a}_{5}\right) \rightarrow \text { Morality }\left(\mathrm{b}_{5}\right) \rightarrow \text { cyberbullying } \\
\left(c^{\prime}\right)\end{array}$ & Morality $\left(b_{5}\right)$ & .042 & .110 & No & -.069 & .074 & Yes & Full \\
\hline
\end{tabular}

*relationship between anonymity and NSI is insignificant; NSI = negative social influence 


\section{Detailed Sociodemographic Data}

The sociodemographic data of the 1,003 participants were as follows: age ( $\bar{x} 31.02$ years; SD 8.36); first year on the Internet ( $\bar{x}$ 1999; SD 4 years; min 1993, max 2012); work years ( $\bar{x} 12.00$ years; SD 8.27). The gender distribution was 514 males (51.2\%), 483 females (48.2\%), and 6 "other" gender (0.6\%). Employment was distributed as follows: 185 full-time student (18.4\%); 92 unemployed and not a student (9.2\%); 162 employed parttime (16.2\%); and 564 employed full-time (56.2\%). Table D.8 provides detailed data distributions on other demographic factors.

Table D.8. Demographic Data Distributions for Our Sample of Adult Cyberbullies (n=1003)

\begin{tabular}{|c|c|}
\hline $\begin{array}{l}\text { Distribution of tool most used for cyberbullying: } \\
\text { - } \quad \text { Facebook: } 530 \text { people }(52.8 \%) \\
\text { - } \text { Online discussion forum, including blogs, Reddit, Disqus, } \\
\text { Tumblr, etc.: } 193 \text { people }(19.2 \%) \\
\text { - } \quad \text { Twitter: } 100 \text { people }(10.0 \%) \\
\text { - YouTube: } 78 \text { people }(7.8 \%) \\
\text { - Instagram: } 43 \text { people }(4.3 \%) \\
\text { - Instant Messaging (IM), including Snapchat, WhatsApp, } \\
\text { - WeChat, etc.: } 37 \text { people ( } 3.7 \%) \\
\text { - } \text { Other social media: } 13 \text { people }(1.3 \%) \\
\text { - } \text { Ask.fm: } 1 \text { people }(0.5 \%) \\
\text { - Pinterest: } 1 \text { person }(0.1 \%) \\
\text { - Vine: } 1 \text { person }(0.1 \%)\end{array}$ & $\begin{array}{l}\text { Distribution of income: } \\
\text { - } \$ 0: 18 \text { people }(1.8 \%) \\
\text { - } \$ 1 \text { to } \$ 10,000: 89 \text { people ( } 8.9 \%) \\
\text { - } \$ 10,001 \text { to } \$ 30,000: 248 \text { people }(24.7 \%) \\
\text { - } \$ 30,001 \text { to } \$ 50,000: 301 \text { people }(30.0 \%) \\
\text { - } \$ 50,001 \text { to } \$ 70,000: 173 \text { people }(17.2 \%) \\
\text { - } \$ 70,001 \text { to } \$ 100,000: 99 \text { people }(9.9 \%) \\
\text { - } \$ 100,001 \text { to } \$ 150,000: 47 \text { people }(4.7 \%) \\
\text { - } \$ 150,001 \text { to } \$ 200,000: 16 \text { people }(1.6 \%) \\
\text { - } \$ 200,001 \text { to } \$ 300,000: 5 \text { people }(0.5 \%) \\
\text { - } \$ 300,001 \text { to } \$ 500,000: 1 \text { person }(0.1 \%) \\
\text { - } \$ 500,000 \text { to } \$ 1,000,000: 2 \text { people }(0.2 \%) \\
\text { - } \$ 1,000,001+: 4 \text { people }(0.4 \%)\end{array}$ \\
\hline $\begin{array}{l}\text { Distribution of hours on social media each day: } \\
\text { - } \quad 0 \text { (none): } 0 \text { people }(0 \%) \\
\text { - } 1 \text { to } 15 \text { minutes: } 14 \text { people }(1.4 \%) \\
\text { - } 16 \text { to } 30 \text { minutes: } 49 \text { people }(4.9 \%) \\
\text { - } 31 \text { minutes to } 1 \text { hour: } 170 \text { people }(16.9 \%) \\
\text { - } \quad>1 \text { hour }<=2 \text { hours: } 281 \text { people }(28.0 \%) \\
\text { - }>2 \text { hours }<=4 \text { hours: } 311 \text { people }(31.0 \%) \\
\text { - } \quad>4 \text { hours }<=7 \text { hours: } 134 \text { people }(13.4 \%) \\
\text { - } \quad>7 \text { hours }<=12 \text { hours: } 31 \text { people }(3.1 \%) \\
\text { - } \quad>12 \text { hours }<=18 \text { hours: } 9 \text { people }(0.9 \%) \\
\text { - } \quad>18 \text { hours: } 4 \text { people }(0.4 \%)\end{array}$ & $\begin{array}{l}\text { Distribution of educational level: } \\
\text { - } 5 \text { less than high school }(0.5 \%) \\
\text { - } 105 \text { high school or equivalent }(10.5 \%) \\
\text { - } 291 \text { some university but no degree }(29.0 \%) \\
\text { - } 130 \text { associate’s degree }(13.0 \%) \\
\text { - } 355 \text { bachelor's degree }(35.4 \%) \\
\text { - } 100 \text { master's degree }(10.0 \%) \\
\text { - } 17 \text { doctoral degree }(1.7 \%) .\end{array}$ \\
\hline
\end{tabular}




\section{REFERENCES}

Ajzen I (1991) The theory of planned behavior. Organizational Behavior and Human Decision Processes 50(2):179-211.

Akers RL (2011a) Social Learning and Social Structure: A General Theory of Crime and Deviance, (Northeastern University Press, Boston, MA).

Akers RL (2011b) Social structure and social learning in crime and deviance. RL Akers, ed. Social Learning and Social Structure: A General Theory of Crime and Deviance (Northeastern University Press, Boston, MA) 322-372.

Akers RL, La Greca AJ, Cochran J, Sellers C (1989) Social learning theory and alcohol behavior among the elderly. Sociological Quarterly 30(4):625-638.

Akers RL, Lee G (1999) Age, social learning, and social bonding in adolescent substance use. Deviant Behavior 19(1):1-25.

Alexy EM, Burgess AW, Baker T, Smoyak SA (2005) Perceptions of cyberstalking among college students. Brief Treatment and Crisis Intervention 5(3):279-289.

Ang RP, Goh DH (2010) Cyberbullying among adolescents: The role of affective and cognitive empathy, and gender. Child Psychiatry \& Human Development 41(4):387-397.

Ang RP, Huan VS, Florell D (2013) Understanding the relationship between proactive and reactive aggression, and cyberbullying across United States and Singapore adolescent samples. $J$. Interpersonal Violence 29(2):1-18.

Ang RP, Tan K-A, Mansor AT (2010) Normative beliefs about aggression as a mediator of narcissistic exploitativeness and cyberbullying. J. Interpersonal Violence 26(13):2619-2634.

Aricak T, Siyahhan S, Uzunhasanoglu A, Saribeyoglu S, Ciplak S, Yilmaz N, Memmedov C (2008) Cyberbullying among Turkish adolescents. CyberPsychology \& Behavior 11(3):253-261.

Bagozzi RP (1994) Structural equation models in marketing research: Basic principles. RP Bagozzi, ed. Principles of Marketing Research (Blackwell, Oxford, UK) 317-385.

Barlett CP, Gentile DA, Chew C (2014) Predicting cyberbullying from anonymity. Psych. Popular Media Culture 5(2):171-180.

Barlett CP, Prot S, Anderson CA, Gentile DA (2016) An empirical examination of the strength differential hypothesis in cyberbullying behavior. Psychology of Violence forthcoming(

Baron R, Kenny D (1986) The moderator-mediator variable distinction in social psychological research: Conceptual, strategic, and statistical considerations. Journal of Personality and Social Psychology 51(6):1173-1182.

Baroncelli A, Ciucci E (2014) Unique effects of different components of trait emotional intelligence in traditional bullying and cyberbullying. J. Adolescence 37(6):807-815.

Bauman S (2010) Cyberbullying in a rural intermediate school: An exploratory study. J. Early Adolescence 30(6):803-833.

Bauman S, Pero H (2011) Bullying and cyberbullying among deaf students and their hearing peers: An exploratory study. J. Deaf Studies and Deaf Education 16(2):236-253.

Bayraktar F, Machackova H, Dedkova L, Cerna A, Ševčíková A (2015) Cyberbullying: The discriminant factors among cyberbullies, cybervictims, and cyberbully-victims in a Czech adolescent sample. J. Interpersonal Violence 30(18):3192-3216.

Beran T, Li Q (2005) Cyber-harassment: A study of a new method for an old behavior. J. Educational Computing Research 32(3):265-277.

Beran T, Li Q (2008) The relationship between cyberbullying and school bullying. J. Student Wellbeing $1(2): 16-33$.

Bilić V (2014) The role of perceived social injustice and care received from the environment in predicting cyberbullying and cybervictimization. Medijska Istraživanja 20(1):101-125.

Bollen K, Lennox R (1991) Conventional wisdom on measurement: A structural equation perspective. Psychological Bulletin 110(2):305-314.

Boulton M, Lloyd J, Down J, Marx H (2012) Predicting undergraduates' self-reported engagement in 
traditional and cyberbullying from attitudes. Cyberpsychology, Behavior, and Social Networking 15(3):141-147.

Bulgurcu B, Cavusoglu H, Benbasat I (2010) Information security policy compliance: An empirical study of rationality-based beliefs and information security awareness. MIS Quarterly 34(3):523-548.

Calvete E, Orue I, Estévez A, Villardón L, Padilla P (2010) Cyberbullying in adolescents: Modalities and aggressors’ profile. Computers in Human Behavior 26(5):1128-1135.

Capece M, Lanza-Kaduce L (2013) Binge drinking among college students: a partial test of Akers' social structure-social learning theory. American Journal of Criminal Justice 38(4):503-519.

Cenfetelli RT, Bassellier G (2009) Interpretation of formative measurement in information systems research. MIS Quarterly 33(4):689-707.

Cromwell P, Thurman Q (2003) The devil made me do it: Use of neutralizations by shoplifters. Deviant Behavior 24(6):535-550.

DeHue F, Bolman C, Völlink T (2008) Cyberbullying: Youngsters' experiences and parental perception. CyberPsychology \& Behavior 11(2):217-223.

Diamantopoulos A, Siguaw JA (2006) Formative versus reflective indicators in organizational measure development: A comparison and empirical illustration. British J. Mgmt. 17(4):263-282.

Diamantopoulos A, Winklhofer HM (2001) Index construction with formative indicators: An alternative to scale development. Journal of Marketing Research 38(2):269-277.

Dilmac B (2009) Psychological needs as a predictor of cyber bullying: A preliminary report on college students. Educational Sciences: Theory and Practice 9(3):1307-1325.

Doane AN, Pearson MR, Kelley ML (2014) Predictors of cyberbullying perpetration among college students: An application of the theory of reasoned action. Computers in Human Behavior 36(July):154-162.

Dooley JJ, Pyżalski J, Cross D (2009) Cyberbullying versus face-to-face bullying. J. Psych. 217(4):182188.

Durkin KF, Wolfe TW, Clark GA (2005) College students and binge drinking: An evaluation of social learning theory. Sociological Spectrum 25(3):255-272.

Eliason SL, Dodder RA (1999) Techniques of neutralization used by deer poachers in the western United States: A research note. Deviant Behavior 20(3):233-252.

Erdur-Baker Ö (2010) Cyberbullying and its correlation to traditional bullying, gender and frequent and risky usage of internet-mediated communication tools. New Media \& Society 12(1):109-125.

Fornell C, Larcker DF (1981) Evaluating structural equation models with unobservable variables and measurement error. Journal of Marketing Research 18(1):39-50.

Gefen D, Straub DW (2005) A practical guide to factorial validity using PLS-Graph: Tutorial and annotated example. Communications of the Association for Information Systems 16(5):91-109.

Gibb ZG, Devereux PG (2014) Who does that anyway? Predictors and personality correlates of cyberbullying in college. Computers in Human Behavior 38(September):8-16.

Görzig A, Frumkin LA (2013) Cyberbullying experiences on-the-go: When social media can become distressing. Cyberpsychology 7(1):1-17.

Gradinger P, Strohmeier D, Spiel C (2009) Traditional bullying and cyberbullying: Identification of risk groups for adjustment problems. J. Psychology 217(4):205-213.

Hayes AF (2009) Beyond Baron and Kenny: Statistical mediation analysis in the new millennium. Communication Monographs 76(4):408-420.

Heirman W, Walrave M (2012) Predicting adolescent perpetration in cyberbullying: An application of the theory of planned behavior. Psicothema 24(4):614-620.

Hemphill SA, Heerde JA (2014) Adolescent predictors of young adult cyberbullying perpetration and victimization among Australian youth. J. Adolescent Health 55(4):580-587.

Herath T, Rao H (2009) Protection motivation and deterrence: A framework for security policy compliance in organisations. European Journal of Information Systems 18(2):106-125.

Hinduja S (2007) Neutralization theory and online software piracy: An empirical analysis. Ethics and Information Technology 9(3):187-204. 
Hinduja S, Patchin JW (2008) Cyberbullying: An exploratory analysis of factors related to offending and victimization. Deviant Behavior 29(2):129-156.

Hinduja S, Patchin JW (2013) Social influences on cyberbullying behaviors among middle and high school students. J. Youth and Adolescence 42(5):711-722.

Hoff DL, Mitchell SN (2009) Cyberbullying: Causes, effects, and remedies. J. Educational Admin. 47(5):652-665.

Hoffmann JP (2003) A contextual analysis of differential association, social control, and strain theories of delinquency. Social Forces 81(3):753-785.

Holland-Davis L (2006) Putting behavior in context: A test of the social structure-social learning model. In: Sociology, University of Florida.

Holt TJ, Burruss GW, Bossler AM (2010) Social learning and cyber-deviance: Examining the importance of a full social learning model in the virtual world. J. Crime and Justice 33(2):31-61.

Hu Q, Xu Z, Dinev T, Ling H (2011) Does deterrence work in reducing information security policy abuse by employees? Communications of the ACM 54(6):54-60.

Jang H, Song J, Kim R (2014) Does the offline bully-victimization influence cyberbullying behavior among youths? Application of General Strain Theory. Computers in Human Behavior 31(85-93.

Juvonen J, Gross EF (2008) Extending the school grounds?-Bullying experiences in cyberspace. $J$. School Health 78(9):496-505.

Kim E, Akers RL, Yun M (2013) A cross-cultural test of social structure and social learning: Alcohol use among South Korean adolescents. Deviant behavior 34(11):895-915.

Kokkinos CM, Antoniadou N, Dalara E, Koufogazou A, Papatziki A (2013) Cyber-bullying, personality and coping among pre-adolescents. Intl. J.Cyber Behavior, Psychology and Learning 3(4):55-69.

Kowalski RM, Limber SP (2007) Electronic bullying among middle school students. J. Adolescent Health 41(6):S22-S30.

Kowalski RM, Morgan CA, Limber SP (2012) Traditional bullying as a potential warning sign of cyberbullying. School Psychology International 33(5):505-519.

Lanza-Kaduce L, Capece M, Alden H (2006) Liquor is quicker: Gender and social learning among college students. Criminal Justice Policy Review 17(2):127-143.

Lee G, Akers RL, Borg MJ (2004) Social learning and structural factors in adolescent substance use. W. Criminology Rev. 5(1):17-34.

Li Q (2007) Bullying in the new playground: Research into cyberbullying and cyber victimisation. Australasian J. Educational Tech. 23(4):435-454.

Li Q, Fung T (2012) Predicting student behaviors. Q Li, D Cross, PK Smith, eds. Cyberbullying in the Global Playground: Research from International Perspectives (Wiley-Blackwell, Hoboken, NJ) 99-114.

Low S, Espelage D (2013) Differentiating cyber bullying perpetration from non-physical bullying: Commonalities across race, individual, and family predictors. Psychology of Violence 3(1):39-52.

Lowry PB, Gaskin J (2014) Partial least squares (PLS) structural equation modeling (SEM) for building and testing behavioral causal theory: When to choose it and how to use it. IEEE Transactions on Professional Communication 57(2):123-146.

Lowry PB, Romano NC, Jenkins JL, Guthrie RW (2009) The CMC interactivity model: How interactivity enhances communication quality and process satisfaction in lean-media groups. Journal of Management Information Systems 26(1):155-196.

Lyndon A, Bonds-Raacke J, Cratty AD (2011) College students' Facebook stalking of ex-partners. Cyberpsychology, Behavior, and Social Networking 14(12):711-716.

MacKinnon DP (2008) Introduction to Statistical Mediation Analysis, (Erlbaum, New York, NY).

Menesini E, Nocentini A, Camodeca M (2013) Morality, values, traditional bullying, and cyberbullying in adolescence. British J. Developmental Psychology 31(1):1-14.

Menesini E, Nocentini A, Palladino BE, Frisén A, Berne S, Ortega-Ruiz R, Calmaestra J, Scheithauer H, Schultze-Krumbholz A, Luik P (2012) Cyberbullying definition among adolescents: A comparison across six European countries. Cyberpsychology, Behavior, and Social Networking 
15(9):455-463.

Minor WW (1981) Techniques of neutralization: A reconceptualization and empirical examination. $J$. Research in Crime and Delinquency 18(2):295-318.

Mishna F, Khoury-Kassabri M, Gadalla T, Daciuk J (2012) Risk factors for involvement in cyber bullying: Victims, bullies and bully-victims. Children and Youth Services Review 34(1):63-70.

Morris RG, Higgins GE (2010) Criminological theory in the digital age: The case of social learning theory and digital piracy. Journal of Criminal Justice 38(4):470-480.

Müller CR, Pfetsch J, Ittel A (2014) Ethical media competence as a protective factor against cyberbullying and cybervictimization among German school students. Cyberpsychology, Behavior, and Social Networking 17(10):644-651.

Navarro JN, Jasinski JL (2012) Going cyber: Using routine activities theory to predict cyberbullying experiences. Sociological Spectrum 32(1):81-94.

Nicol A, Fleming MJ (2010) "i h8 u": The influence of normative beliefs and hostile response selection in predicting adolescents' mobile phone aggression—A pilot study. J.School Violence 9(2):212-231.

O'Keeffe GS, Clarke-Pearson K, Council on Communications Media (2011) The impact of social media on children, adolescents, and families. Pediatrics 127(4):800-804.

Orcutt JD, Schwabe AM (2012) Gender, race/ethnicity, and deviant drinking: A longitudinal application of social structure and social learning theory. Sociological Spectrum 32(1):20-36.

Patchin JW, Hinduja S (2010) Traditional and nontraditional bullying among youth: A test of general strain theory. Youth \& Society 43(2):727-751.

Pavlou P, Liang H, Xue Y (2007) Understanding and mitigating uncertainty in online exchange relationships: A principal-agent perspective. MIS Quarterly 31(1):105-136.

Petter S, Straub DW, Rai A (2007) Specifying formative constructs in information systems research. MIS Quarterly 31(4):623-656.

Pornari CD, Wood J (2010) Peer and cyber aggression in secondary school students: The role of moral disengagement, hostile attribution bias, and outcome expectancies. Aggressive Behavior 36(2):8194.

Puhakainen P, Ahonen R (2006) Design theory for information security awareness. In: Department of Information Processing Science, University of Oulu, Oulu, Finland.

Raskauskas J, Stoltz AD (2007) Involvement in traditional and electronic bullying among adolescents. Developmental Psychology 43(3):564-575.

Renati R, Berrone C, Zanetti MA (2012) Morally disengaged and unempathic: Do cyberbullies fit these definitions? An exploratory study. CyberPsychology, Behavior \& Social Networking 15(8):391398.

Riebel J, Jaeger RS, Fischer UC (2009) Cyberbullying in Germany—An exploration of prevalence, overlapping with real life bullying and coping strategies. Psychology Science Quarterly 51(3):298-314.

Schultze-Krumbholz A, Scheithauer H (2009) Social-behavioral correlates of cyberbullying in a German student sample. J. Psychology 217(4):224-226.

Siegal LJ (2011) Criminology: The Core, 4th Edition ed.(Wadsworth, Cengage Learning, Belmont, CA).

Siponen M, Vance A (2010) Neutralization: New insights into the problem of employee information systems security policy violations. MIS Quarterly 34(3):487-502.

Smith PK, Mahdavi J, Carvalho M, Fisher S, Russell S, Tippett N (2008) Cyberbullying: Its nature and impact in secondary school pupils. J. Child Psychology and Psychiatry 49(4):376-385.

Sobel ME (1982) Asymptotic confidence intervals for indirect effects in structural equation models. Sociological Methodology 13(290-312.

Sontag LM, Clemans KH, Graber JA, Lyndon ST (2011) Traditional and cyber aggressors and victims: A comparison of psychosocial characteristics. J. Youth and Adolescence 40(4):392-404.

Staples DS, Hulland JS, Higgins CA (1999) A self-efficacy theory explanation for the management of remote workers in virtual organizations. Organization Science 10(6):758-776.

Steffgen G, König A, Pfetsch J, Melzer A (2011) Are cyberbullies less empathic? Adolescents' 
cyberbullying behavior and empathic responsiveness. Cyberpsychology, Behavior, and Social Networking 14(11):643-648.

Straub DW, Boudreau MC, Gefen D (2004) Validation guidelines for IS positivist research. Communications of the Association for Information Systems 14(1):380-426.

Sykes GM, Matza D (1957) Techniques of neutralization: A theory of delinquency. American Sociological Review 22(6):664-670.

Topçu C, Erdur-Baker Ö, Capa-Aydin Y (2008) Examination of cyberbullying experiences among Turkish students from different school types. CyberPsychology \& Behavior 11(6):643-648.

Treviño LK, Weaver GR, Reynolds SJ (2006) Behavioral ethics in organizations: A review. Journal of Management 32(6):951-990.

Udris R (2014) Cyberbullying among high school students in Japan: Development and validation of the online disinhibition scale. Computers in Human Behavior 41(December):253-261.

Vance A, Lowry PB, Eggett DL (2015) A new approach to the problem of access policy violations: Increasing perceptions of accountability through the user interface. MIS Quarterly 39(2):345366.

Varjas K, Talley J, Meyers J, Parris L, Cutts H (2010) High school students' perceptions of motivations for cyberbullying: An exploratory study. Western J. Emergency Medicine 11(3):269-273.

Vazsonyi AT, Machackova H, Sevcikova A, Smahel D, Cerna A (2012) Cyberbullying in context: Direct and indirect effects by low self-control across 25 European countries. Euro. J. Developmental Psych. 9(2):210-227.

Verrill SW (2005) Social structure and social learning in delinquency: A test of Akers' social structuresocial learning model. In: Criminology, University of South Florida.

Walker CM (2012) Twenty-first century cyberbullying defined: An analysis of intent, repetition and emotional response. In: Communications Media, Indiana University of Pennsylvania.

Walrave M, Heirman W (2011) Cyberbullying: Predicting victimisation and perpetration. Children \& Society 25(1):59-72.

Warr M (1993) Age, peers, and delinquency. Criminology 31(1):17-40.

Whaley RB, Smith JM, Hayes-Smith R (2011) Teenage drug and alcohol use: Comparing individual and contextual effects. Deviant Behavior 32(9):818-845.

Williams KR, Guerra NG (2007) Prevalence and predictors of internet bullying. J. Adolescent Health 41(6):S14-S21.

Wright MF (2014) Predictors of anonymous cyber aggression: The role of adolescents' beliefs about anonymity, aggression, and the permanency of digital content. Cyberpsychology, Behavior, and Social Networking 17(7):431-438.

Xiao BS, Wong YM (2013) Cyber-bullying among university students: An empirical investigation from the social cognitive perspective. International Journal of Business and Information 8(1):34-69.

Yang SC (2012) Paths to bullying in online gaming: The effects of gender, preference for playing violent games, hostility, and aggressive behavior on bullying. J. Educational Computing Research 47(3):235-249.

Ybarra ML (2004) Linkages between depressive symptomatology and Internet harassment among young regular Internet users. CyberPsychology \& Behavior 7(2):247-257. 
${ }^{\mathrm{i}}$ The difference is that items within formative constructs are theoretically distinct and thus are not replaceable with other items in the same construct; items in reflective constructs are theoretically the same and thus are replaceable with each other (Diamantopoulos and Winklhofer 2001). This distinction has recently become a serious issue in systems-related research where it has been discovered that many previous studies have been mis-specified because they did not distinguish between reflective and formative constructs (Petter et al. 2007). Such mis-specification can lead to problems in empirical results and theoretical interpretations, including the potential increase in both Type I and Type II errors (Petter et al. 2007).

ii The basic standard followed here is that the square root of the AVE for any given construct (latent variable) should be higher than any of the correlations involving the construct (Fornell and Larcker 1981; Staples et al. 1999). The numbers are shown in the diagonal for constructs (bolded and underlined).

iii We also gathered organizational commitment in case high correlations existed so we could use it to perform the marker-variable technique, but this was unnecessary given the nature of the model's correlations. Namely, the neutralization constructs had moderately high intercorrelations, which was theoretically expected. No patterns existed that hinted at commonmethod bias.

iv Validating items within formative measures is particularly challenging because these items can move in different directions apart from each other. Whereas reflective indicators must demonstrate considerably high correlations among each other (i.e., exhibit high conceptual overlap) to be valid internally, the indicators of a formative construct need not meet this criterion, and instead need to represent distinct facets of the overall construct being modeled (Bollen and Lennox 1991; Diamantopoulos and Winklhofer 2001; Petter et al. 2007). Reflective items are interchangeable but formative items are not interchangeable; hence, reliability measurements are not appropriate for formative constructs (Diamantopoulos and Winklhofer 2001). Specifically, internal consistency examinations of formative constructs with Cronbach's $\alpha$ and average variance extracted (AVE) calculations are not methodologically appropriate (Bagozzi 1994; Cenfetelli and Bassellier 2009; Petter et al. 2007).Researchers have traditional used theoretical reasoning alone to support the validity of formative constructs (Diamantopoulos and Winklhofer 2001). Over time, methodological approaches have emerged to improve validation of formative constructs, such as using the modified multitrait-multimethod (MTMM) approach and assessing multicollinearity (Petter et al. 2007; Straub et al. 2004).

${ }^{\mathrm{v}}$ It would be more ideal to do this using a MIMMIC model where all of the formative items of a second-order construct were correlated to the average of a separately created reflective construct representing overall second-order construct. However, we had no such reflective meta-constructs available from the literature. 